\title{
DESIGNING A NATIONAL RESTAURANT INSPECTION DISCLOSURE SYSTEM FOR NEW ZEALAND
}

by

KATIE FILION

B.Sc., University of Guelph, 2008

\begin{abstract}
A THESIS
submitted in partial fulfillment of the requirements for the degree
\end{abstract}

\section{MASTER OF SCIENCE}

Department of Diagnostic Medicine and Pathobiology

College of Veterinary Medicine

\author{
KANSAS STATE UNIVERSITY \\ Manhattan, Kansas
}

2010

Approved by:

Major Professor

Dr. Douglas Powell 


\begin{abstract}
The World Health Organization estimates that up to $30 \%$ of individuals in developed countries become ill from food or water each year, with up to $70 \%$ of these illnesses estimated to be linked to foodservice. Restaurant inspections aim to prevent restaurant-associated foodborne outbreaks while enhancing consumer confidence in the safety of food prepared in these establishments. Inspection disclosure systems have been developed as a tool for consumers and incentive for foodservice operators. Disclsosure systems are common in developed countries; however, they are inconsistent. Previous research has not determined the best format to disclose inspection results to the public while providing incentives for operators. This research aimed to develop a consistent, compelling and trusted disclosure system for New Zealand. The research evaluated existing disclosure systems operating internationally and nationally. The national review interviewed with Environmental Health Officers $($ EHOs $)(n=8)$, operators $(n=109)$ and consumers $(\mathrm{n}=244)$, and findings were used for card designs. Cards were evaluated internally $(n=43)$, then by 11 focus groups $(n=68)$. Two cards, letter and gauge, were introduced to food premises $(n=371)$ in six districts for three months for evaluation. Operators $(n=269)$ and consumers $(n=991)$ were interviewed to determine which design best communicated inspection results. The majority of operators indicated they had not received consumer feedback about the card, and half felt the card was something consumers would use. Less than half of consumers indicated they noticed cards prior to entering a premises; from these data it appeared the letter attracted more initial attention (78\% of respondents) than the gauge (45\%). Consumers indicated card placement was an important factor in noticing cards. Nearly all interviewed consumers indicated they expected cards at restaurants, take-aways and fish n' chips shops. When asked which card they preferred, $58 \%(n=38)$ of operators with the gauge preferred the letter; and $79 \%$ $(n=47)$ of operators with the letter preferred the letter. Consumer preference was for the letter, with $88 \%(n=133)$ of those in gauge districts preferring the letter, and $72 \%(n=161)$ of those in letter districts preferring the letter. Based on these data the letter card was recommended for a national inspection disclosure system for New Zealand.
\end{abstract}




\section{Table of Contents}

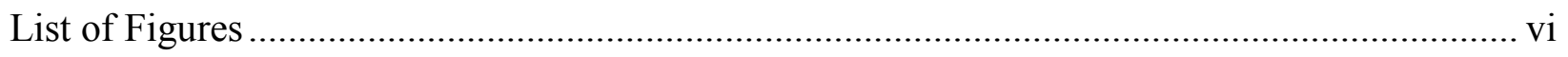

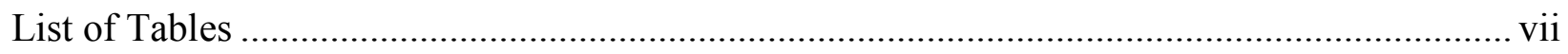

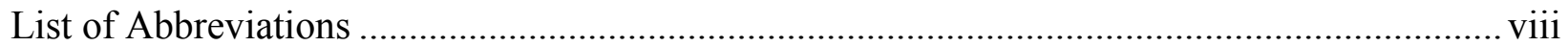

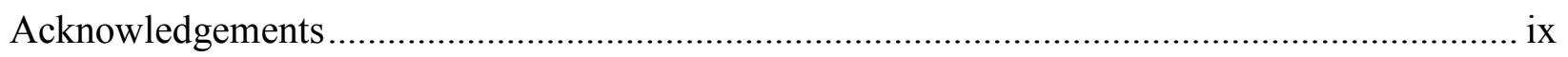

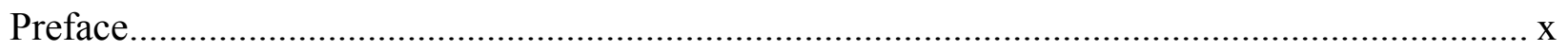

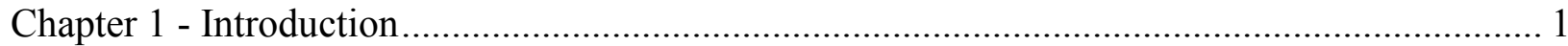

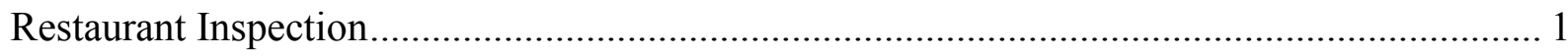

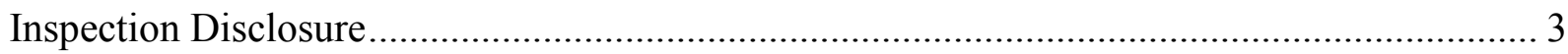

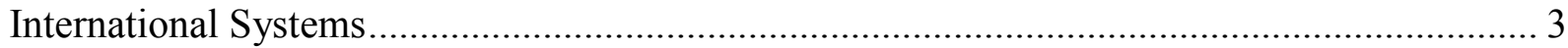

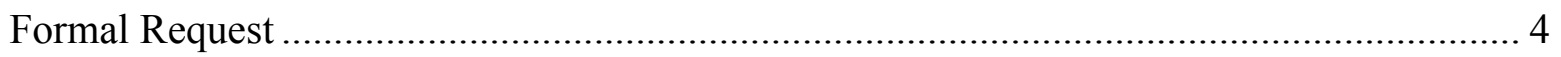

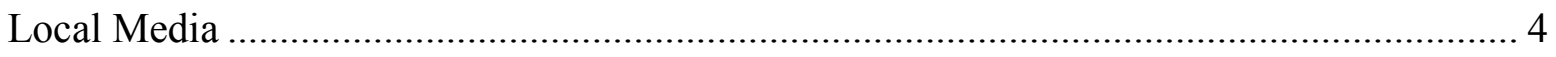

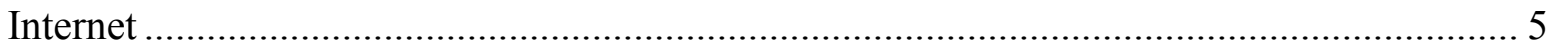

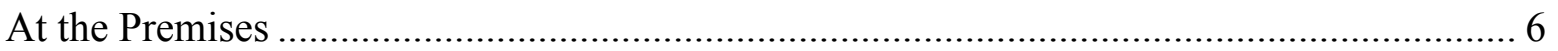

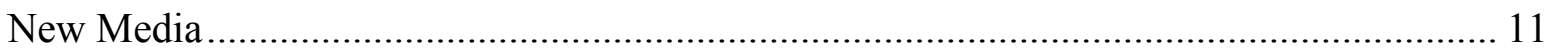

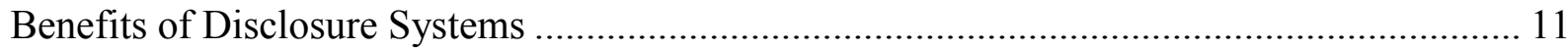

Problems with Inspection Disclosure …………………................................................ 13

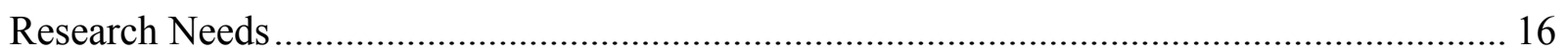

Chapter 2 - Existing Disclosure Systems in New Zealand .......................................................... 19

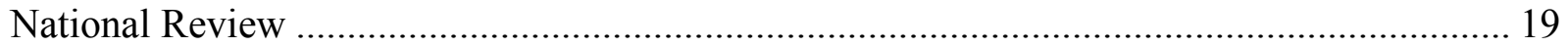

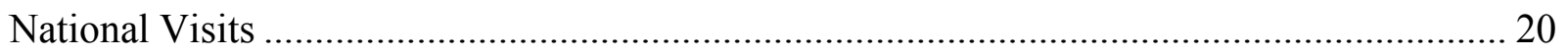

Interviews with Environmental Health Officers …………………………………...... 23

Interviews with Foodservice Operators/ Food handlers ……………………………....... 25

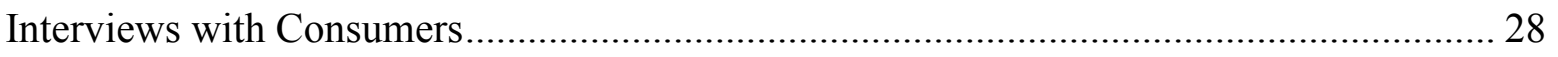

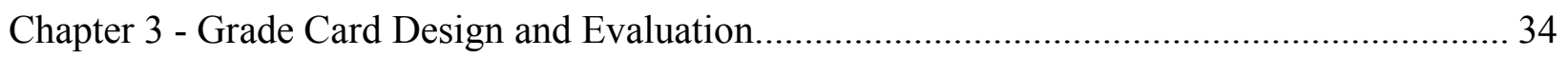

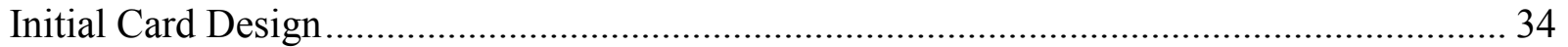

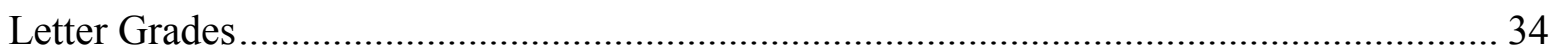

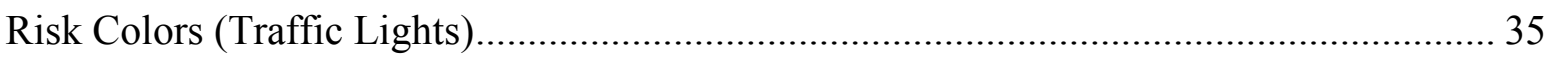

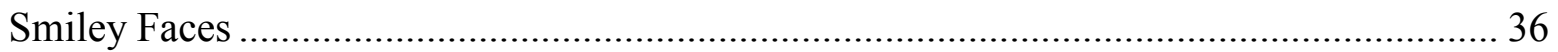

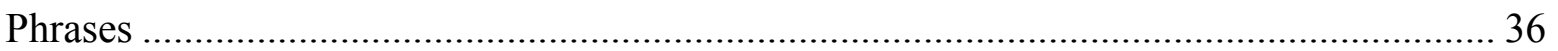




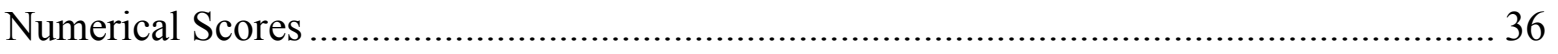

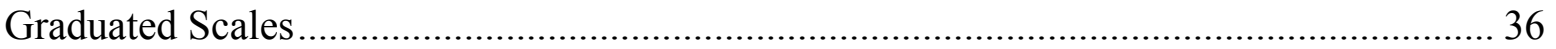

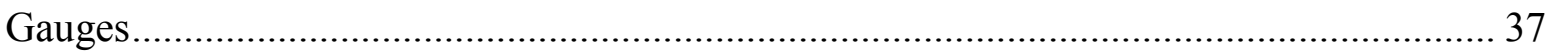

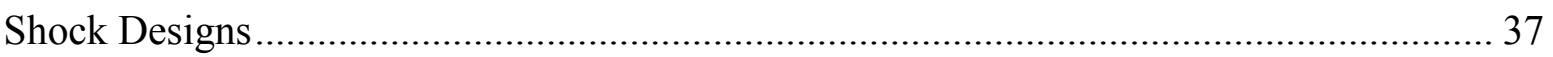

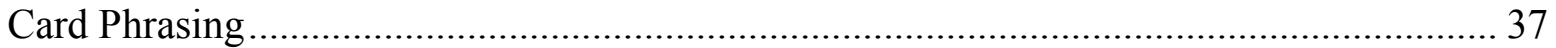

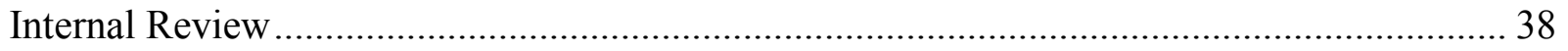

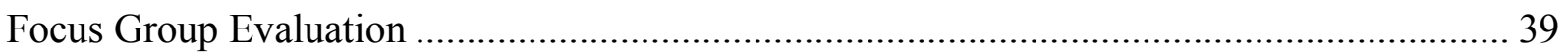

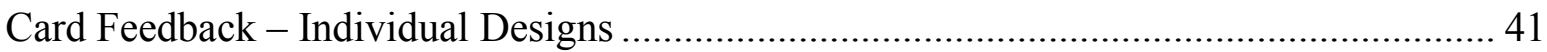

Card Feedback - Overall Design ..................................................................................... 44

Card Feedback - Card Placement ……………………….............................................. 45

Card Feedback - Complimentary Tools and Contact Information ....................................... 46

Card Feedback - Knowledge of Foodservice Grading ...................................................... 46

Card Feedback - Reaction to the Grading Project............................................................. 47

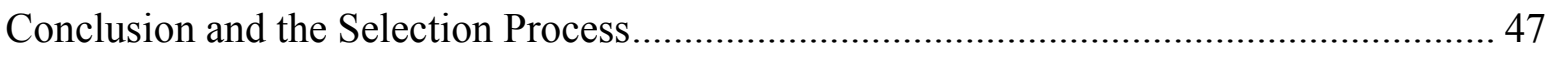

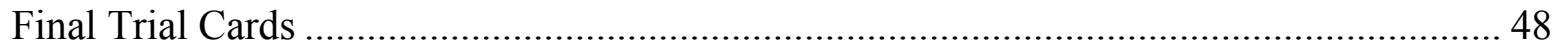

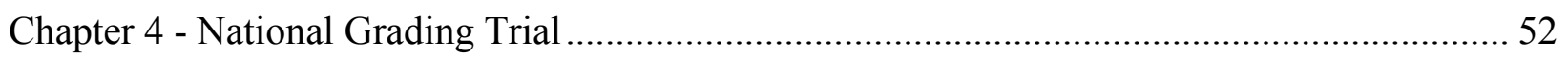

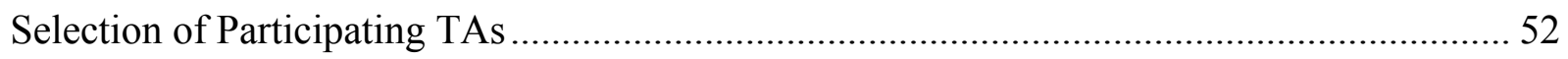

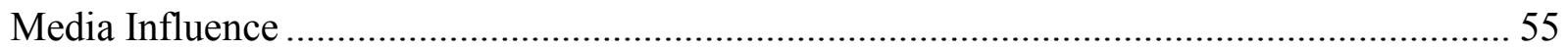

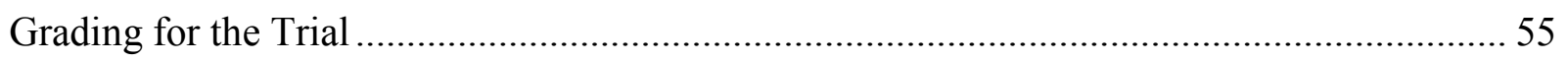

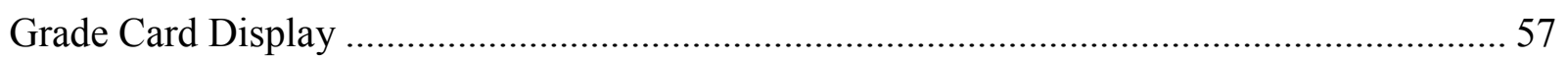

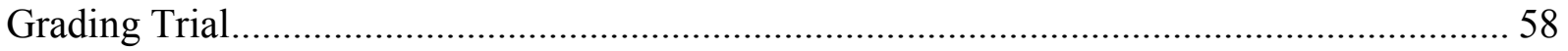

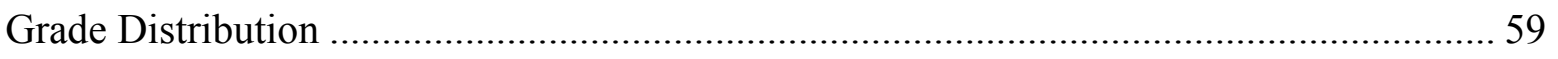

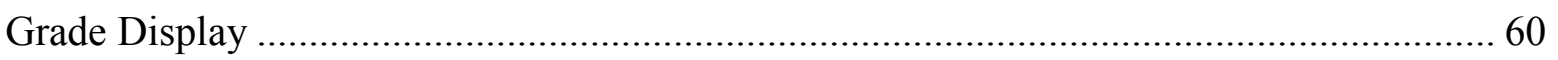

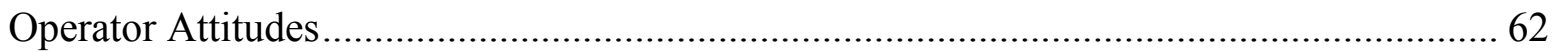

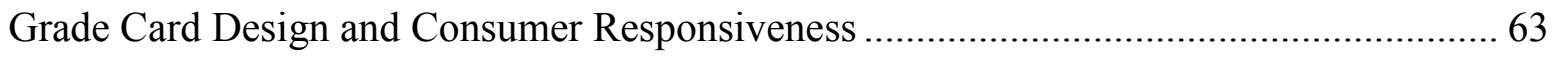

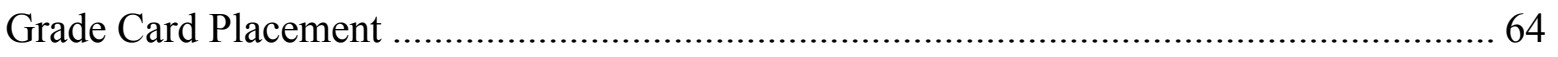

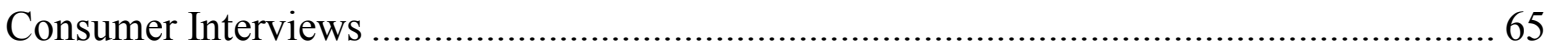

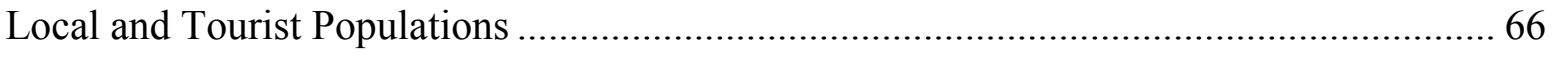

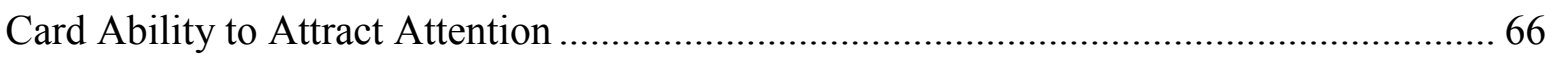

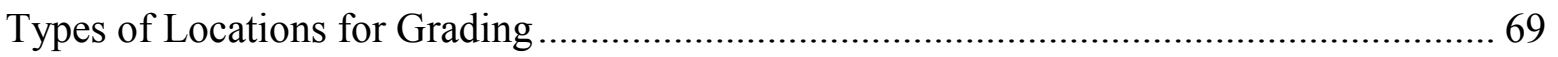

Letter Grade vs. Gauge Communication............................................................................ 70 


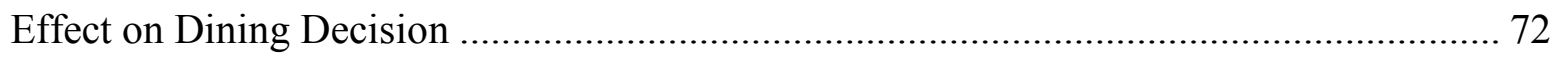

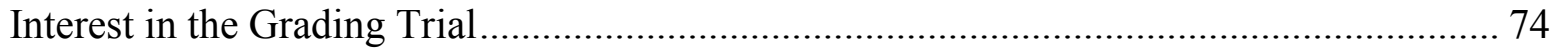

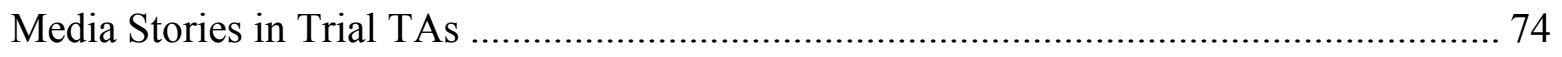

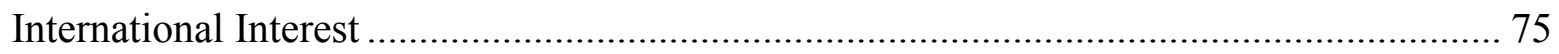

Chapter 5 - Final Focus Groups and Card Redesign....................................................................... 77

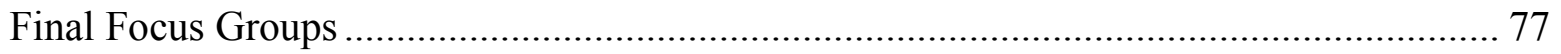

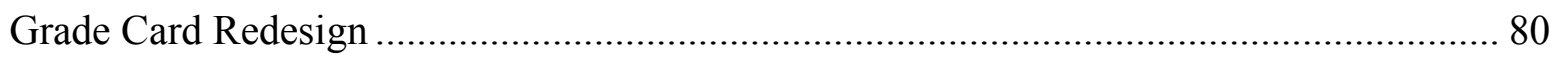

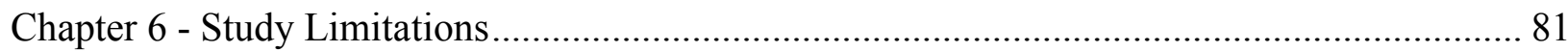

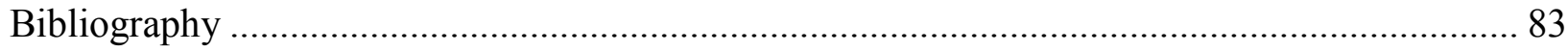

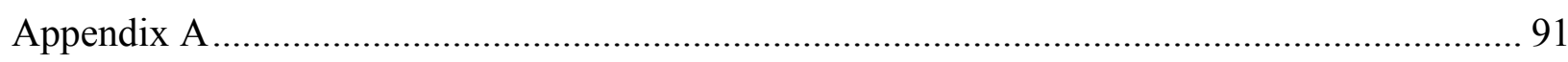

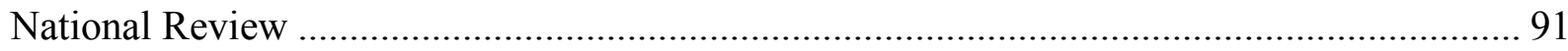

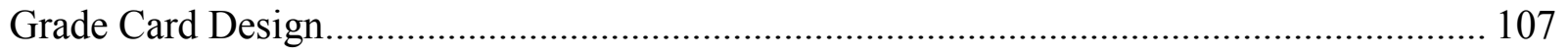

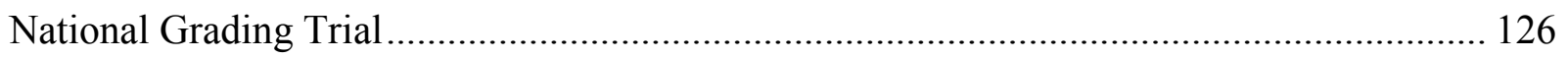




\section{List of Figures}

Figure 1.1 Examples of international inspection disclosure systems 10

Figure 2.1 Summary of inspection disclosure systems operating in New Zealand at the time of the national review and TAs selected for visits during the review. 21

Figure 2.2 Summary of foodservice operator/food handler interviews regarding local inspection disclosure systems. 26

Figure 2.3 Summary of consumer interviews regarding local inspection disclosure systems..... 29

Figure 3.1 Final two cards (right), letter grade and gauge card, following redesign based on focus group feedback.

Figure 4.1 Six trial TAs and respective location, population and premises involved in the grading trial.

Figure 4.2 The six grade cards provided to foodservice premises during the national grading trial. 56

Figure 4.3 Grade distribution by TA at the end of the national grading trial. 59

Figure 4.4 Percentage of premises achieving an Excellent/A or Good/B Card vs. percentage of premises displaying assigned card by TA.

Figure 4.5 Operator responses to grade card design, and operator indication of consumer response to the card at their premises.

Figure 4.6 Gauge and letter grade card operator reasoning for placing grade card in the chosen location. 65

Figure 4.7 Percentage of consumers interviewed from New Zealand and overseas. 66

Figure 4.8 Elements of the grade card that caught consumer attention by consumers who noticed the card prior to participating in interviews.

Figure 4.9 Consumer responses for card inability to attract initial attention by consumers who did not notice card prior to participating in interviews. 68

Figure 4.10 Foodservice locations consumers expect to find grade cards at. 70

Figure 4.11 Comparing gauge and letter grade card ability to communicate food safety information. 71

Figure 4.12 Consumer responses to grade card effect on dining decision................................. 72

Figure 4.13 NSW Food Authority's Scores on the Doors grade card. 75 


\section{List of Tables}

Table 2.1 Arrangement and location of focus group interviews with EHOs in New Zealand TAs

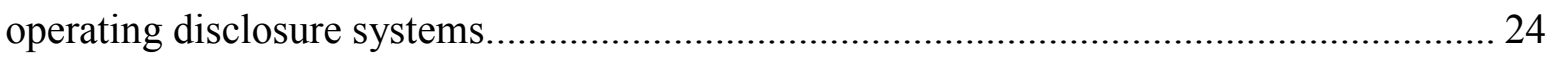

Table 3.1 Arrangement and location of focus groups evaluating grade card designs. ................. 40 


\section{List of Abbreviations}

CBD - Central Business District

EHO - Environmental Health Officer

HACCP - Hazard Analysis and Critical Control Points

KSU - Kansas State University

L.A. - Los Angeles

NSW - New South Wales

NZFSA - New Zealand Food Safety Authority

PHU - Public Health Unit

TA - Territorial Authority

UK - United Kingdom 


\section{Acknowledgements}

This thesis not only represents the outcome of my research at Kansas State University (KSU), but a year's study in New Zealand with the Food Safety Authority (NZFSA). This opportunity would not have been possible without the determination of members of both KSU and NZFSA, and for that I am heartily thankful.

To my supervisor, Dr. Doug Powell, I offer my sincerest gratitude for not only his determination in creating the opportunity for a graduate student to study abroad in New Zealand, but his continued patience and support while working on this thesis. I consider myself extremely fortunate to have developed as a student under his guidance.

To the members of NZFSA, particularly Geoff Allen and Sally Johnston, I consider myself fortunate to have studied under their guidence. Not only did they make my transition to life in New Zealand effortless, but working along side them provided me with an amazing opportunity I will never forget.

I am grateful to Dr. Katherine Stanske KuKanich and Dr. Lisa Freeman for their knowledge and attention to detail, without whom the editing of this thesis would not have been successful.

Thank you to Dr. Ben Chapman, whose continued guidance has supported me through times of uncertainty in both my undergraduate and graduate studies.

At last, I wish to thank all of the wonderful people I met in New Zealand during my year of study. Their friendships provided me with amazing memories I will not soon forget. 


\section{Preface}

In 2009-2010, a partnership between Kansas State University and the New Zealand Food Safety Authority (NZFSA) provided the opportunity for a graduate student to conduct research for the development of a national restaurant inspection disclosure system (or grading scheme) for New Zealand. The research, part of a larger NZFSA project, termed the Domestic Food Review, aimed to provide a consistent, compelling and trusted inspection disclosure system for food premises throughout New Zealand. The development of a national inspection disclosure system involved creating consistent inspection criteria, calibrating the inspection process, as well as designing and introducing the new inspection disclosure system, while phasing out existing systems. The research provided information on disclosure system design and implementation. 


\section{Chapter 1 - Introduction}

The World Health Organization estimates that up to $30 \%$ of individuals in developed countries become ill from food or water each year (World Health Organization, 2007). Up to $70 \%$ of these illnesses are estimated to be linked to food prepared at foodservice establishments (Olsen et al., 2000; Lee \& Middleton 2003; Center for Science in the Public Interest 2008; Jacob \& Powell, 2009). Media coverage of food safety issues is extensive and may fuel the view that hygiene (or safety) standards are low among restaurants (Bruhn, 1997; Worsfold \& Worsfold, 2008). Consumer confidence in the safety of food prepared in restaurants is fragile, varying significantly from year-to-year (Food Marketing Institute, 2008), with many consumers attributing foodborne illness to foodservice (Fein et al., 1995). One of the key influences of restaurant choice is consumer perception of the hygiene of a restaurant. Restaurant hygiene information is something consumers desire, and when available, may use to make dining decisions (Worsfold \& Worsfold, 2007).

\section{Restaurant Inspection}

Based on federal food codes, established food safety standards for food service are enforced by federal, state and local government agencies (Almanza et al., 2002) through routine examinations. These examinations typically apply to foodservice operations, including restaurants, cafes, fast food or take-away operations, and may include temporary event stands, grocery stores or butchers (depending on the jurisdiction). These examinations, referred to in this thesis as restaurant inspections, but also called health, hygiene, food safety or foodservice inspections, are principally designed to prevent restaurant-associated foodborne disease outbreaks (Jones et al., 2004; Reske et al., 2007) while promoting discussion among those within the food industry. Inspections carried out by environmental health officers (EHOs) may significantly impact consumer confidence in the safety of food produced in restaurants, influence dining decisions and provide incentives for establishments to promote a safe food environment (Fielding et al., 2001; Jin \& Leslie, 2003; Simon et al., 2005; Worsfold \& Worsfold, 2007) when publicly available. 
The fundamentals of restaurant inspection are well-established throughout developed countries. Municipal restaurant inspections are food safety risk management programs, an action to demonstrate to consumers that food providers are cognizant of consumer concerns about food safety and that those within the farm-to-fork food safety system - in this case, food service operations - are working to reduce levels of risk (Powell, 2002). Methods of scoring inspection results vary between jurisdictions. In the U.S., the Food and Drug Administration (FDA) Food Code ${ }^{1}$ provides a guide from which regional health departments develop foodservice sanitation standards, and the Hazard Analysis Critical Control Point ${ }^{2}$ (HACCP)-based inspection has been implemented in many jurisdictions that categorize restaurants based on risk (Seiver \& Hatfield, 2000). Although criteria for restaurant inspections are fairly well established, inconsistencies between jurisdictions exist when defining a critical violation. Often described as a violation more likely to contribute to food contamination, illness or health hazards, the actual items that constitute a critical violation during the inspection process may vary. In some jurisdictions the presence of a critical violation elicits closure followed by reinspection, while in others it simply results in a lower inspection score. As a result, many systems exist to quantify results during inspection. Staring with a value of 100 and subtracting violations (with critical violations being a larger deduction) is one method: a score of 100 is awarded to establishments that comply with all food safety standards. Conversely, beginning with zero and tallying violations (with critical violations being worth a higher value), a larger numerical value indicates a riskier food establishment. Other jurisdictions simply tally violations and may or may not indicate whether these are critical or non-critical. Variations not only exist between jurisdictions or municipalities but also between EHOs; although EHO standardization is designed to synchronize violation interpretations, it will vary from person-to-person. The many variables of the

${ }^{1}$ http://www.fda.gov/Food/FoodSafety/RetailFoodProtection/FoodCode/FoodCode2009/ Accessed November 27, 2010.

${ }^{2} \mathrm{HACCP}$ is a systematic preventative approach to food safety and pharmaceutical safety. It addresses physical, chemical and biological hazards as a means of prevention rather than a finished product inspection. 
inspection process will affect inspection disclosure schemes but are outside the scope of this discussion.

\section{Inspection Disclosure}

Restaurant inspection disclosure systems are tools designed to communicate the information acquired through restaurant inspections to consumers and others, while providing an incentive for restaurant operators to comply with food regulations. Seiver \& Hatfield (2000) suggest that the public disclosure of restaurant inspection results communicates the importance of risks and violations found during an inspection. With several of the key elements of a foodservice operation being hidden from consumers (such as food storage conditions or where food is purchased), consumers will look to observable information cues during establishment selection (Hensen et al., 2006).

Restaurant inspection disclosure systems can provide such informational cues. Inspection disclosure systems take a variety of forms, including:

- formal request - consumers must formally request inspection information for a premises at the local health department;

- local media - local newspapers or radio stations package acquired inspection information, and stories often focus on rewarding high achieving premises, or shaming those who have done poorly on recent inspection;

- Internet - searchable databases and name-and-shame websites have been developed to allow consumers access to recent inspection information; and,

- at the premises - cards or full inspection reports may be posted at the premises to communicate the most recent inspection results to consumers.

\section{International Systems}

Restaurant inspection disclosure systems are common in developed countries; however, these systems are inconsistent, varying between countries, states or cities. A review of international inspection disclosure systems is provided below. Sample grade cards can be found in the Appendix. 


\section{Formal Request}

In some U.S. jurisdictions, a consumer must formally request to view the most recent inspection from the local health department and may wait months before receiving the results (Center for Science in the Public Interest, 2008). In other jurisdictions, inspection results (or reports) are available upon request at the restaurant. These methods are neither convenient nor reasonable for most consumers, as inspection reports are often difficult to understand (Center for Science in the Public Interest, 2008) and may take weeks to become available when consumers may want to make a dining decision that evening. Additionally, disclosure systems in which the consumer must request inspection information provide minimal incentive for foodservice establishments to adhere to minimum standards of food safety.

\section{Local Media}

The local media is a source of inspection information in many jurisdictions. Newspapers, television and radio stations package information from local health units regarding dirty restaurants, closures and convictions (Hensen et al., 2006), as well as acknowledge those establishments meeting or exceeding food safety standards. Media can influence consumer dining decisions (Gregory \& Kim, 2005). For many years, media images of dirty kitchens, inexperienced or poorly trained staff, or rodent infestations have fueled consumer concern for the safety of food prepared in restaurants (Worsfold, 2006b). Gregory \& Kim (2005) and Hensen et al. (2006) separately surveyed consumers in an attempt to determine the role of information sources on dining decisions. While Gregory \& Kim (2005) concluded that friends or relatives were the most significant source of information consumers use to make dining decisions, they acknowledged store signage, newspapers and magazines as being more important than other information sources. Hensen et al. (2006) indicated that when consumers were asked on a 5-point Likert scale, with 5 being 'very important' and 1 being 'very unimportant,' newspapers, television and radio were considered important sources of food safety information; however, the authors concluded that the inspection certificate posted at the premises was scored as more important than these media forms. The authors suggest that "while the media may be predominant sources of information on restaurant closure and conviction for high-profile cases, on a day-to-day basis when choosing where to eat, inspection 
certificates at-the-premises are a more prominent source of information' (Hensen et al., 2006).

\section{Internet}

Online databases vary in content and may be used to compliment disclosure at the premises. Online restaurant inspection databases may be maintained by local health departments, news stations or consumer blogs. Since the first posting of inspection results online in Los Angeles (L.A.) County in 1998 (Fielding et al., 2001), many inspection authorities have adopted this medium to present a database of results searchable by establishment name or code, neighborhood, location or results from the latest inspection (DPR Online Services, 2008; New York City, 2008; Office of Environmental Health Services, 2008). Some of these databases provide only the number of critical violations, or both critical and non-critical violations, while others elaborate with details of the cited infractions. Some jurisdictions, such as the U.S. state of Alaska, provide online copies of all food establishment inspection reports completed by EHOs (Division of Environmental Health, 2008). In the U.S. state of Idaho, inspection authorities allow consumers to receive e-mail updates when new inspection results are posted (Central District Health Department, 2007).

In the United Kingdom (U.K.), food establishments may voluntarily post inspection scores or symbols at the premises, but they are not required to do so. However, all inspection reports are available through local inspection authority websites (Worsfold \& Worsfold, 2008). Websites appear to be a popular method of restaurant inspection disclosure, with many municipalities adopting this medium. Several areas in Scotland began posting inspection results in November 2006 after a survey found $82 \%$ of consumers wanted to see inspection information at local eating establishments and $94 \%$ thought it should be accessible online (Worsfold \& Worsfold, 2007). Consumers and businesses reported that the posted results were valuable, according to research by the Food Standards Agency of Scotland several months later (Worsfold \& Worsfold, 2007). However, a review of the DineSafe disclosure scheme in Toronto, Canada, revealed only $10 \%$ of the public was aware of the online component compared with $75 \%$ being aware of inspection notices posted at the premises (Toronto Staff Report, 2002). Additionally, although initially popular, online disclosure websites may receive decreased visits after 
the initial novelty of the system wears off. In the city of Waterloo, Canada, the inspection disclosure website recorded more than one million visits in the first year of introduction, but since has decreased to approximately 300,000 visits per year (Barrick, 2009).

Rather than a database of results, online name-and-shame notices are published by the Food Safety Authority of Ireland. Foodservice establishments that fail to improve conditions of practices deemed 'likely to pose a risk to public health' are issued an improvement order that is posted on the Authority's website until the situations are corrected. Following correction, the improvement order remains visible to the public for another 3 months. A closure order is issued if 'there is likely to be a grave and immediate danger to public health' or an improvement order is not complied with in a timely fashion. These orders are likewise posted to the website until situations are remedied, and for 3 months afterward (Food Safety Authority of Ireland, 2008). Recently the state of New South Wales (NSW) in Australia has adopted a similar system to disclose inspection results online where consumers can search a register for penalty and prosecution notices (NZW Food Authority, 2010).

\section{At the Premises}

Disclosure at the premises may be done through the use of a communication card or physical display of the establishment's inspection report. Communication cards, also called grade cards, attempt to summarize the inspection result of a particular premises into a simpler format for consumers to understand. Popular card designs include letter grades, numerical scores, color-coding, statements, symbols or award schemes.

\section{Letter Grades}

The California County of San Diego was one of the first regions in the U.S. to create a disclosure system to convey inspection results to the public, introducing letter grades to rate establishments in 1947 (Foley, 2009). L.A. County followed suit, and since 1996 has required food establishments to display the results of their most recent restaurant inspection in the form of an A, B or C letter grade - except in the case of restaurants scoring below a ' $\mathrm{C}$ ' for which the actual numerical value is provided (Teledas Co., 2004). Multiple major U.S. cities have adopted similar systems, as have several states, however, in the U.S. and many other developed countries with grading, there is no 
national system. In Auckland, New Zealand, a food hygiene grade from A to E is assigned to inspected establishments. In this system, ' $\mathrm{C}$ ' is excluded as it may be mistakenly thought of as a 'passing' grade, and a 'Gold A' has been added, which recognizes establishments that demonstrate safe practices above full compliance with food hygiene laws. The hygiene grade, $8 \times 10$ inches in size, must be displayed 'in a prominent position on the premises that is visible to the public' (Auckland City Council, 2007).

\section{Numerical Scores}

The HACCP-based approach to restaurant inspection that categorizes establishments into high-, medium- and low-risk facilities is common throughout the U.S. (Seiver \& Hatfield, 2000). A common checklist for restaurant inspection used in the U.S. is the FDA-approved Foodservice Establishment Inspection Report; however, many jurisdictions are replacing this with a HACCP- based inspection form. The FDAapproved 44- point list of violations assigns a weight based on the estimated risk to human health of each violation. The highest possible score is 100 , which is reduced when

violations are cited. Although the inspection checklist may be consistent, what constitutes establishment closure is not. In Danbury, Connecticut, an establishment must score 80 and not receive any 4-point violations to receive a pass; in Nashville, Tennessee, a score of 70 is required to pass inspection (Danbury Public Health, 2010; Nashville Metro Public Health, 2010). In Mobile, Alabama, a score below 85 elicits closure and reinspection (Mobile County Health Department, 2008). The numerical score and copy of the inspection report are required to be posted at the establishment. Inspection authorities that do not deduct violations from 100 will often later convert the inspection score to a value out of 100. Conversely to deducting points for violations, in New York City, health officials assign a numerical score during inspections that tallies violations. Scores greater than 28 denote the restaurant as a public health hazard and must be re-inspected to ensure corrections are made (New York City, 2008). New York City has recently adopted a plan to disclose inspection results to the public using a letter grade system similar to that of L.A. rather than posting a numerical score card at the premises (Collins, 2009).

\section{Colored Cards}


Officials in the city of Toronto, Canada, require food establishments to display their most recent inspection results in the main entrance of premises in the form of a green, yellow or red card, indicating a pass, conditional pass or closed notice respectively (City of Toronto, 2008). During the development of the Toronto disclosure system, a review of current literature indicated that color could be used to draw attention and suggest caution (Powell, 2002). A similar system used in Columbus, Ohio, includes the green-, yellow- and red-colored cards, with the addition of a white notice that is issued when an establishment is on probation and requires a follow-up inspection. The red card in this case is used when an establishment on probation failed re-inspection (Columbus Public Health, 2006). Lexington-Fayette County in Kentucky uses a combination of numerical and color disclosure schemes: scores of 85 or above as well as no 4- or 5-point violations will be posted in green; scores of 84 and under, or those with 4- or 5-point violations will be posted in red; and scores below 70 will be issued 'Notice of Intent to Suspend Permit' (Lexington-Fayette County, 2008).

\section{Statement Cards}

The Niagara Region of Ontario, Canada, conducts inspections similar to those in the city of Toronto; however, its disclosure system describes inspected establishments as simply 'in compliance' or 'not in compliance.' This region also maintains an online database to convey the most recent inspection results to consumers, with details of critical and non-critical violations (Regional Municipality of Niagara, 2007). A study in Hamilton, Ontario (Hensen et al., 2006) - a municipality that initially used only 'pass' and 'fail' notices but was considering utilizing the 'conditional pass' notice - found that the additional 'conditional pass' option had a 'significant and negative impact' on survey respondents' self-reported likelihood to patronize a restaurant. Other examples of information statements include the following: 'approved' or 'not approved;' 'satisfactory,' 'conditionally satisfactory' or 'unsatisfactory;' and 'exceeds minimum standards,' 'meets minimum standards' or 'does not meet minimum standards.'

\section{Symbols}

Since 2001, the Danish Veterinary and Food Administration has used smiley faces as a means to disclose restaurant inspection results to the public. The full details of 
Danish inspection reports are published on a website, with a 'smiley' face depicting five different scenarios that range from a sad, 'sour smiley' - assigned to establishments that were issued a fine, reported to the police or had approval withdrawn - to an ecstatic, 'happy smiley' - for restaurants that received no negative remarks (Danish Veterinary and Food Administration, 2008). The newly added Elite-Smiley may also be awarded when establishments receive the happy smiley in four consecutive inspections. These reports and respective smiles must be posted at the restaurant premises and visible to consumers outside the establishment who are making a choice to dine there (Danish Veterinary and Food Administration, 2008). Inspection results in the northern region of the U.S. state of Iowa are conveyed using the 5-Star Program in which colored stars assigned to establishments correspond with positive food-handling behaviors observed during inspection. A yellow star is awarded when proper holding temperatures are respected, a blue for proper cooking, a red for clean equipment, a brown for good employee hygiene, and a green star when the establishment's food ingredients are received from safe sources. For each inspection, the restaurant's awarded stars are displayed online alongside the number of critical and total violations cited (Cerro Gordo County, 2008). Farmington Valley and Norwalk Counties in the U.S. state of Connecticut use waiter or lighthouse symbols, respectively, to disclose inspection information: a score of 90-100 receives 3 waiters or lighthouses, 80-89 receives 2, and below 80 receives 1 (Farmington Valley Health Department, 2009; Norwalk Health Department, 2009).

\section{Award Schemes}

In addition to inspection disclosure systems, several municipalities have elected to provide awards for establishments that exceed food safety standards. The aforementioned Gold A granted in Auckland, New Zealand, or the Elite-Smiley in Denmark, are examples of award schemes and are often in addition to existing disclosure systems at the establishment. During evaluation of the Eat Safe award scheme in the U.K., Worsfold (2005) found $79 \%$ of those surveyed said they would be influenced by the presence of a hygiene award. However, it was noted in previous evaluations that there is little public awareness of a similar award scheme in Scotland (Worsfold, 2005). 
Letter Grades: New York City, U.S.
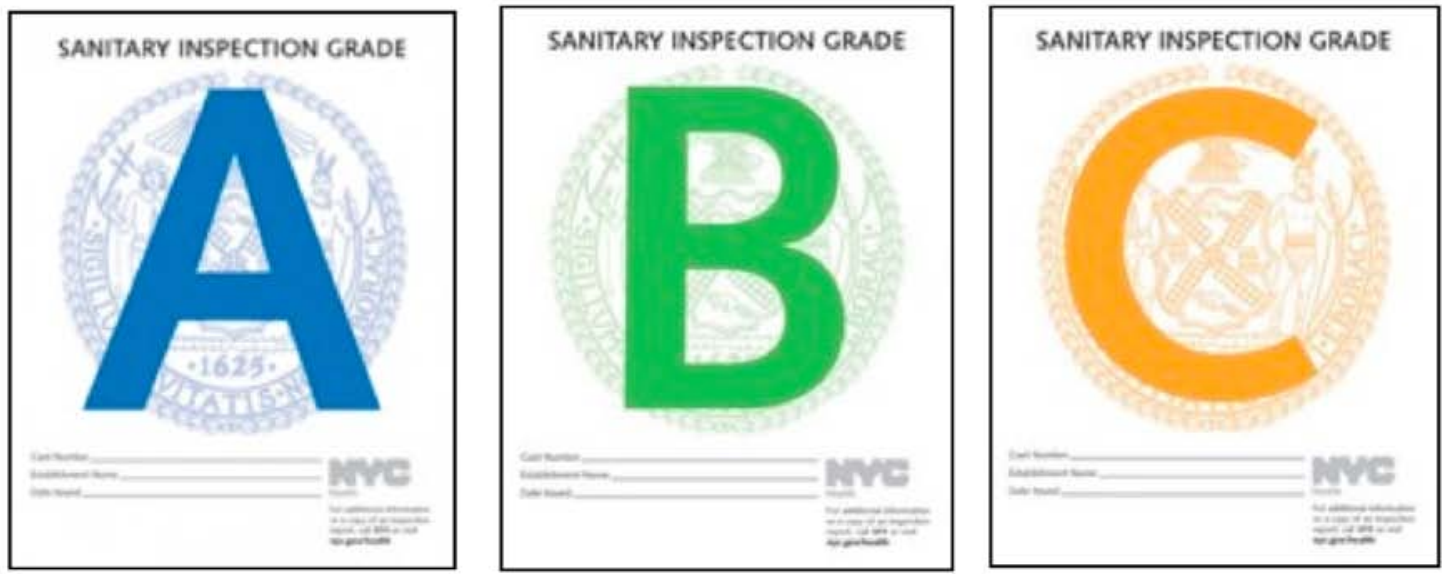

Colored Cards: Toronto, Canada
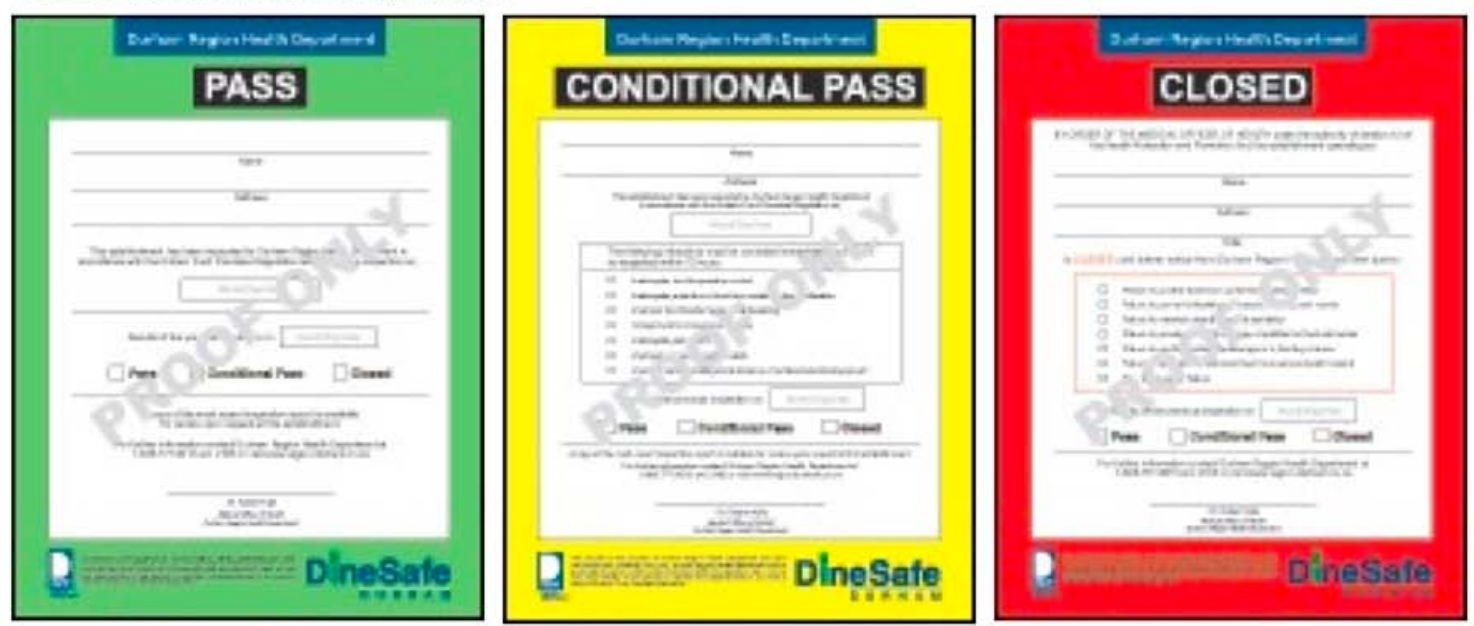

Symbols: Denmark

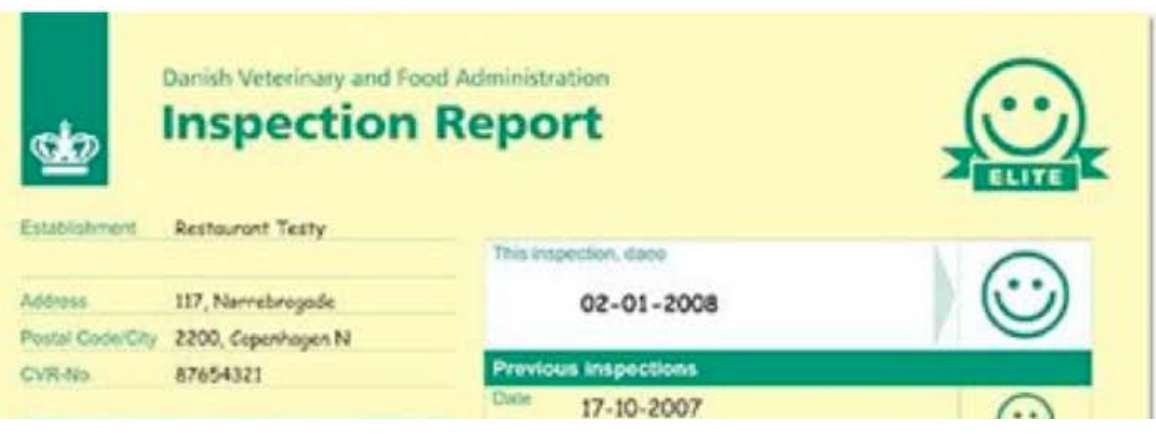

Figure 1.1 Examples of international inspection disclosure systems 


\section{New Media}

The U.S. Centers for Disease Control and Prevention (CDC 2008) has called upon food safety communicators to design new methods and messages aimed at increasing safe food handling practices from farm-to-fork. One such form of new media, blogs, can provide rapid, relevant, evidence-based food safety information framed in the context of current events that affect people's lives (Powell et al., 2009). One-in-three Internet users (an estimated 57 million people) report they read blogs (Lenhart and Fox 2006), and there are numerous blogs devoted to restaurant reviews. Popular food blogs not only review a restaurant's atmosphere, service, cuisine and pricing, but they often include the business' most recent food safety inspection result.

In addition to blogs, applications have been created for cell phones to provide users with restaurant inspection results in real time, allowing users to check restaurant grades quickly and make dining decisions based on safety while away from home. An example of these applications, Food Hygiene for iPhone, ${ }^{3}$ uses information published on the U.K. Scores on the Doors website ${ }^{4}$ to enable users to access hygiene grades on the go, while providing directions and restaurant contact information.

\section{Benefits of Disclosure Systems}

Consumers both desire and deserve accessible and understandable information on the conditions and practices of foodservice establishments. Consumer interest in the website that discloses inspection results for the U.K. city of Liverpool generated 100,000 hits within 2 days of posting the first inspection results (Chartered Institute of Environmental Health, 2007). Information provided using such media could be reassuring to diners, demonstrating that restaurants are being monitored for food safety standards. According to the Director of Public Health for L.A. County, Dr. Jonathan Fielding, the grading system used in L.A. bolsters consumer confidence in the county's restaurant inspection system (Center for Science in the Public Interest, 2008). Consumers in the city of Hamilton, Canada, were asked how important the presence of an inspection notice in a

\footnotetext{
${ }^{3}$ iPhone is an Internet and multimedia enabled smartphone using software iTunes, designed and marketed by Apple, Inc., Cupertino, California.

${ }^{4}$ www.scoresonthedoors.org.uk Accessed: November 28, 2010.
} 
restaurant's window was when choosing where to dine, and respondents assigned it an average importance of 4.44 on a 5-point scale (Hensen et al., 2006). As many as 95\% of residents surveyed in Toronto, Canada, indicated they made dining decisions based on the colored inspection cards posted at establishments (Toronto Staff Report, 2002).

By influencing restaurant choice, inspection result postings can provide incentives for those within the foodservice industry to focus on food safety endeavors. Restaurateurs and patrons react emotionally to posted scores (Wiant, 1999). Public reporting of poor inspection results may lead to negative consumer attitudes toward an establishment, and consequently influence foodservice workers and managers to comply with regulations in order to improve food safety scores (Almanza et al., 2002). According to the Danish Veterinary and Food Administration (2008), over half (59\%) of consumers have changed their dinner plans after reviewing the smiley face posted at a restaurant. The Ministry asserts that the smiley face scheme is one of the best-known consumer schemes in Denmark, and a recent survey found that $97 \%$ of consumers felt the scheme was a 'good' or 'very good' idea, as did $88 \%$ of foodservice businesses. Additionally, 8/10 managers or owners reportedly discussed practices with their staff that would lead them to attain the coveted 'happy smiley' (Danish Veterinary and Food Administration, 2008).

Hospitalization rates linked to suspect foodborne illnesses were seen to decrease by approximately $20 \%$ in the year a mandatory letter grade disclosure system was implemented in L.A. County (Jin \& Leslie, 2003; Simon et al., 2005). However, limitations in surveillance data make it impossible to determine in which settings the majority of foodborne illnesses occur (Powell, 2002; Jacob \& Powell, 2009), let alone the relationship between inspection disclosure systems and a reduction in illness rates. Linking a foodborne disease outbreak to a restaurant alone can be challenging, and then making the connection between confirmed outbreaks and inspection grades is a daunting task. Restaurant grade cards in L.A. did promote food safety awareness in public and provide incentive for restaurants in the county to comply with food safety regulations and increase inspection scores (Fielding et al., 2001; Jin \& Leslie, 2003). A similar system in Las Vegas, Nevada, also found that establishments were more likely to demonstrate an increased diligence in food safety practices to maintain compliance (Hahn, 2000). A review of the color-coded disclosure system in Toronto, Ontario, concluded that it 
successfully 'increased compliance and continuous improvement in food safety among Toronto restaurants (Basrur, 2003). Food safety violations were also reported to decrease for the city's restaurants (Toronto Staff Report, 2002).

Tools that compliment inspection disclosure schemes, such as food safety information on a respected website, can and will be used by a proportion of consumers, although they should not be used to substitute for disclosure at the premises (Spear, 2006). The Toronto, Canada, study indicated that consumers were more aware of disclosure at the premises in the form of colored cards than the website (Toronto Staff Report, 2002). According to Worsfold \& Worsfold (2008), online disclosure systems provide the computer-literate consumer quick and relatively easy access to inspection information. The numerous inspection disclosure applications available for mobile phones may increase the accessibility of this information for consumers.

\section{Problems with Inspection Disclosure}

The process of restaurant inspection itself is fraught with issues, with many variations between jurisdictions (Chapman et al., 2010), within the U.S. and abroad:

- frequency of inspection;

- inspections may be scheduled or unannounced;

- time of day an inspection occurs may affect an establishment's performance (busier times may result in increased food safety infractions);

- criteria for inspections are inconsistent - most notably the definition of "critical violation;'

- several food safety issues that are difficult to assess in the brief time frame of an inspection (e.g. acquiring food from a safe source); and,

- variation between EHOs due to subjective interpretation (despite standardized training requirements in many jurisdictions).

The purpose of restaurant inspection is ultimately to reduce the incidence of foodborne illness, yet research has indicated that inspection scores are not predictive of foodborne illness outbreaks. In a review of 167,574 inspections in the U.S. state of Tennessee between January 1993 and April 2000, Jones et al. (2004) found that mean inspection scores of establishments experiencing foodborne illness outbreaks did not 
differ from establishments without reported illnesses. Cruz et al. (2001) reviewed inspection scores for 51 food establishments associated with confirmed foodborne illness outbreaks in Miami-Dade County, Florida in 1995 and compared these reports to randomly selected establishments without outbreaks. The study suggested that inspections in Miami-Dade County did not reliably identify restaurants with increased risk of foodborne illness (Cruz et al., 2001). Irwin et al. (1989) reported a correlation between restaurant inspection scores and foodborne illness in Seattle-King County, Washington; however, this study was retrospective, not measuring incidence and was based on single inspections rather than cumulative information (Powell, 2002). Research has aimed to provide evidence that inspection scores predict foodborne disease outbreaks. Allwood et al. (1999) compared mean inspection scores for 320 food premises in the state of Minnesota between 1987 and 1988 and concluded that scores were positively associated with frequency of health inspections, indicating this supported the author's assumption that health inspections play a vital role in protecting the public from foodborne illness. However, in a survey of 141 Canadian jurisdictions, Riben et al. (1994) concluded that inspection frequency was not correlated with disease or violation frequency.

It is uncertain whether inspection scores are predictive of foodborne illness outbreaks. Creating a study that accurately measures the relationship between restaurant inspection scores and foodborne illness outbreaks is difficult. To accurately connect inspection scores to foodborne disease outbreaks several issues must be addressed:

- inconsistencies in the inspection process - creating consistent inspection criteria, ensuring EHOs are trained and calibrated to make the same interpretations;

- public reporting of disease outbreaks -- ensuring individuals with illness symptoms seek medical attention, receive proper testing, and receive a positive test result;

- molecular fingerprinting of disease pathogens - enabling the ability to make a connection between a pathogen and a food (then foodservice establishment). 
Only once these issues are adressed may it be possible to draw connections between health inspection scores and foodborne disease outbreaks. However, regardless of whether a decrease in foodborne illness rates is associated with disclosing inspection results, these communication tools can promote discussions between those in the food industry and instill consumer confidence in food prepared in foodservice.

As Jones et al. (2004) state, "reported foodborne outbreaks are rare in relation to the number of restaurants and the small percentage of suspected foodborne illnesses linked to epidemiologically confirmed, restaurant-associated outbreaks, make such analyses difficult." With numerous variables and inconsistencies in the restaurant inspection process itself, EHOs and those within the food-service industry debate whether consumers are able to understand the meaning of posted inspection information (Almanza et al., 2002). Multiple studies suggest consumers may have little understanding of the meaning of posted letter grades or inspection scores, although their interpretations play a role in their choice to patronize a restaurant (Dundes \& Rajapaksa, 2001; Hensen et al., 2006).

Accurately quantifying all of the aspects of inspection to create a risk communication tool that can convey a message about the safety of a food establishment is a daunting task. Jones \& Grimm (2008) found that, in a region where restaurants were required to make inspection results publicly visible on their premises and allow information to be disclosed on the Internet, survey participants indicated the availability of this information had an effect on where they chose to eat. However, the researchers also found that consumers have a number of misconceptions and unrealistic expectations of the restaurant inspection system (Jones \& Grimm, 2008). Worsfold (2006b) suggested that restaurant patrons are not well informed about the role of local authorities in protecting food safety and how the food safety laws are enforced. For example, consumers may be confused about the frequency of inspections and, therefore, how often violations occur at an establishment (Hensen et al., 2006). Restaurant inspections report on the conditions of an establishment at a single point in time and may not reflect the overall (good or bad) culture of food safety at the restaurant (Chapman, 2008). Although an inspection is only designed to evaluate an establishment at one moment in time, patrons interpret scores as an overall indicator of quality (Wiant, 1999). 
Details of inspection reports may also be difficult to understand. Consumers may have difficulty assessing the severity of violations cited in terms of their risk to food safety (Worsfold, 2006b). Additionally, inspection and disclosure systems can vary between jurisdictions, which may lead to confusion among consumers who dine in multiple jurisdictions. An examination by the San Diego Union-Tribune of inspection data in San Diego County, California, found that restaurants receiving an A grade - the top rating for that jurisdiction - may have also been cited for up to two major violations, those that are thought to 'pose an imminent health hazard.' The newspaper noted that most jurisdictions throughout the U.S. are reluctant to award establishments with only one major violation in their report a top grade (Williams \& Armendariz, 2007). These variations in what constitutes a score between jurisdictions can be confusing for consumers, but even with a unified system, problems may arise. Hatfield \& Siever (2001) found that with numerical grading schemes, consumers still think in terms of pass/fail. This may be true in the case of letter grades, colored cards or any other disclosure methods.

Pressure from the restaurant industry may hinder inspection disclosure scheme implementation (Wiant, 1999). Worsfold (2006a) found some objection among hospitality and foodservice management to the Scores on the Doors program in the U.K. Some managers were averse to implementing public disclosure systems for fear of confusing consumers, as mentioned above, or for the difficulty and cost of implementing such a program (Worsfold, 2006a). Additionally, concerns have been raised in simplifying the complexities of the restaurant inspection report into a single score, grade or symbol (Worsfold, 2006a). With all of these limitations, consumers are entitled to public health information, and it is the responsibility of public health regulators to develop a method to communicate this information in a clear, compelling and consistent manner.

\section{Research Needs}

Previous research has focused on assessing the effectiveness of inspection disclosure systems but has not determined which system or message-delivery medium is most desired by consumers. Research should focus on both the medium and the message. Is there a preferred method for consumers and foodservice operators to convey the results 
of restaurant inspection, and how can the message be made more meaningful? Do consumers prefer disclosure at the premises in the form of cards? If so, which format letter grades, numerical scores, symbols, colored cards or phrases - is preferable? Various scores and grades have been used to communicate restaurant inspection results to public audiences, but which of these is most effective is not known. Even within a particular score category, such as letter grades, there are unknowns. For example, how effective is a 3-tier scheme of A, B and C compared with a similar 4-tier letter scheme? Are consumers misled with those middle terms such as ' $C$ ' as some jurisdictions predict? Are multi-tier schemes the best way to communicate inspection results to the public, or do consumers solely think in terms of pass/fail as some research has shown (Hatfield \& Siever, 2001)?

Additionally, it is unknown to what degree inspection information should be disclosed to consumers. Examples of score schemes vary from a simple notification of 'pass,' 'conditional pass' or 'fail' (City of Toronto, 2008), to detailed pictograms colorcoordinated to expose various elements of the inspection process (Cerro Gordo County, 2008). It is unknown whether a combination of mediums is most effective - e.g. score cards displayed on premises with basic information, and further details of infractions available online - or whether one medium alone is most desired by consumers. Does the increased accessibility of inspection information on mobile phones affect consumer dining decisions? Research should focus on determining the most compelling method for communicating results to the public.

Although some research has indicated consumers rate food safety as more important than any other factor (Worsfold, 2006b), and it is self-reported that consumers would not dine at an establishment with a poor inspection rating (Leach, 2003; Worsfold, 2006b), whether this would, in reality, affect a diner's decision is unknown. The 'loyalty' factor - consumers who dine at an establishment in support of a cause/friend/relative/ colleague - also may affect one's decision to dine at an establishment, regardless of the above- mentioned qualities. Research could determine whether pairing restaurant food safety scores with that of quality, cuisine and atmosphere is attractive to consumers. Finally, what methodological approach is best to acquire information about consumer preference of disclosure systems? 
The objectives of this thesis were to provide a consistent, compelling and trusted national inspection disclosure system for food premises in New Zealand. This involved:

- evaluating existing inspection disclosure systems operating regionally throughout New Zealand;

- designing and evaluating a grade card for at-the-premises disclosure;

- making a final recommendation to NZFSA regarding grade card design for implementation in a national scheme. 


\section{Chapter 2 - Existing Disclosure Systems in New Zealand}

A key task in developing a national inspection disclosure system for New Zealand would involve phasing out existing systems. A review of existing inspection disclosure systems in New Zealand was completed to provide information for future phasing out and to provide feedback on regional system preferences which could be incorporated or improved upon in a national system.

It should be noted that 'takeaway' refers to a foodservice business offering pickup food, such as fast-food restaurants; 'fish n' chips' premises refer to foodservice businesses serving dine-in or take-out fish and fries (and often other assorted fried foods); 'sausage sizzle' refers to barbeque stands (often operated by volunteers raising money) serving hot sausages and hot dogs; and 'dairy' refers to convenience stores, and for the purpose of this research refers to dairies serving hot food.

\section{National Review}

The review involved contacting the 74 Territorial Authorities (TAs or local governments) in New Zealand and determining whether an inspection disclosure system currently existed in their area, and if so, what this system entailed. The national review revealed the following:

- 24 of the 74 TAs disclose inspection information to consumers

○ 23 of the 24 existing disclosure systems use disclosure at the premises

- 21 of these systems are in the form of letter grades, with the majority operating in the North Island. Examples of current grade combinations include: A+, A, B+, B, C (Whangarei District), A, B, C, D, Exempt (North Shore City), Gold A, A, B, D, E (Auckland City), A, B, Ungraded (Horowhenua District), and A, B, C, D (Dunedin).

o Three are awards systems. Examples include: 'Excellent' cards (Wellington City), and 'Excellent' and 'Very Good' cards (Porirua City).

- One TA uses online disclosure to publish closed premises (Rotorua). 
- 21 of the 24 grading schemes are located in the North Island, and three in the South Island of New Zealand

\section{National Visits}

Following this review, the researcher visited a selection of TAs with disclosure systems to discuss with EHOs, food premises operators and consumers any preferences regarding the disclosure system in their district. For this thesis, food premises operators refers to the owner or manager of a foodservice premises; food handler refers to a foodservice employee other than the operator; and consumer refers to a patron of a foodservice premises. Of the 24 TAs with disclosure systems, eight were visited. A summary of disclosure system distribution in New Zealand at the time of the national review (July 2009), and selected TAs for visits is summarized in Figure 2.1. 


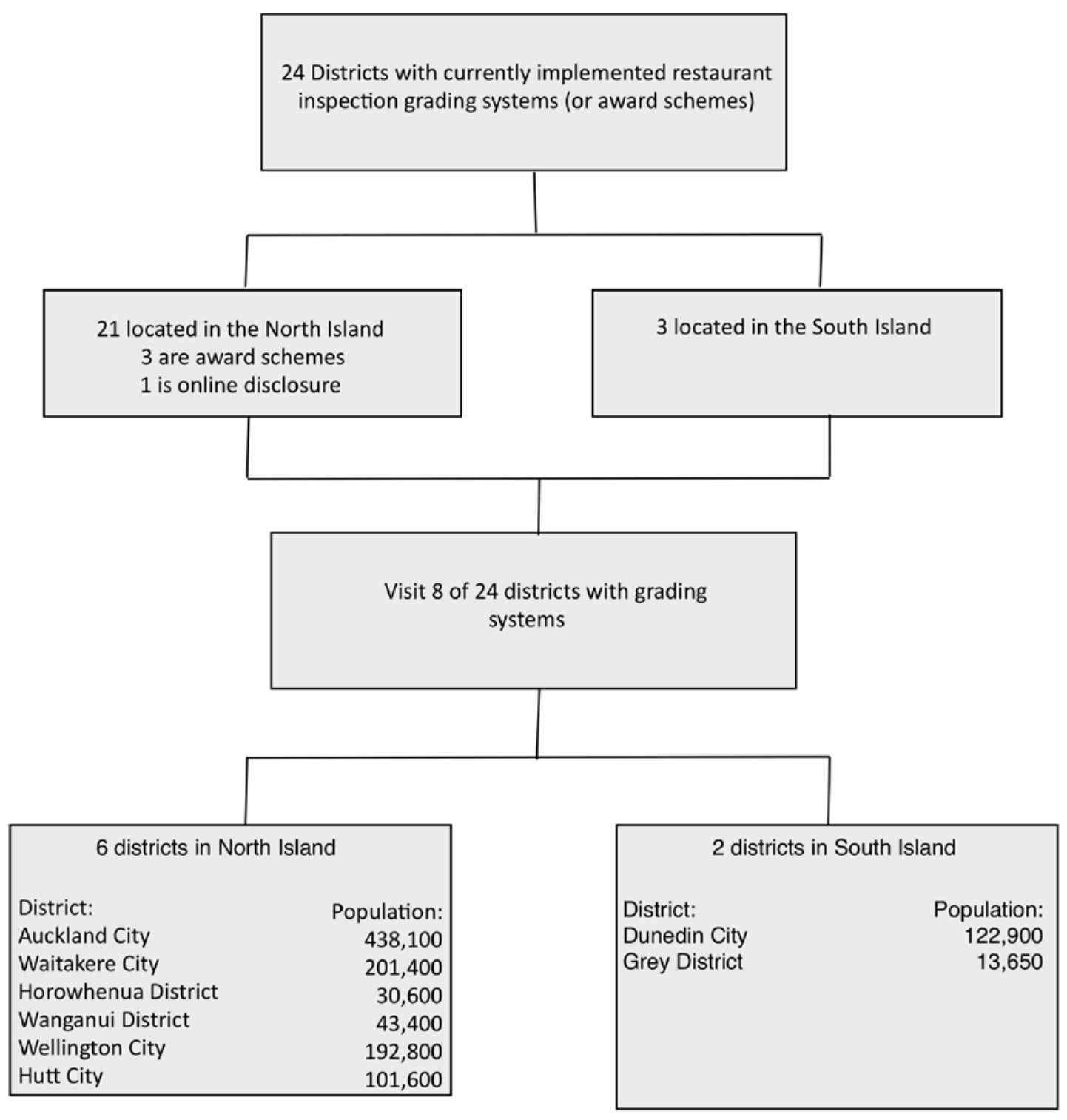

Figure 2.1 Summary of inspection disclosure systems operating in New Zealand at the time of the national review and TAs selected for visits during the review.

TAs selected for visits were chosen for one or more of the following reasons:

- Popularity of the disclosure system - The disclosure system has been recognized and referenced nationally, often through local media or television programs (Auckland City, Waitakere City, Dunedin City) 
- Population size - Disclosure systems are located in regions of all population sizes. A selection of TAs were visited due to their smaller population size (Horowhenua District, Wanganui District, Grey District)

- Convenience: The researcher was located in Wellington City, therefore TAs located in close proximity to Wellington were selected for travel convenience (Wellington City, Hutt City Council)

A description of the disclosure systems operating in the eight-selected TAs at the time of visits can be found in Appendix (Table A.1). Of the eight-visited TAs, four operated on mandatory display systems and four operated on voluntary display. Most mandatory display systems required premises prominently display the assigned grade card unobscured, and often cards were displayed near the premises' certificate of registration (or in some cases the grade was a watermark on the certificate of registration). One TA, Waitakere City, had a bylaw requiring grade cards be displayed at the principal entrance, providing measurements of how far the card could be from the entrance. The TA introduced this bylaw after several premises misinterpreted the "prominently displayed and unobscured" requirements. Voluntary display systems were often introduced when a bylaw had not yet been passed or had not been issued for the TA.

Although 23 of the 24 existing systems disclose inspection information at the premises in the form of a card, regulations regarding card placement vary between TAs. Hutt City for example, allowed premises to voluntarily display their 'Excellent' or 'Very Good' cards, while Auckland City Council required grade cards "shall be conspicuously displayed at the principal entrance in full view and unobscured" (Auckland City Council, 2010). Other TAs simply required operators to display their grade card, with card placement anywhere in the premises, typically in the kitchen, near the register, or at the premises entrance. Additionally, grading criteria, like the disclosure systems themselves, varied between districts. What qualifies as an A in Auckland City did not necessarily equate to an Excellent in Wellington City.

National visits were designed to determine whether any components of existing disclosure systems could be used in development of the national scheme, and whether any components of regional systems were not working well, and therefore should not be 
included or should be modified in the national scheme. To determine the positive and negative aspects of regional disclosure systems, the researcher interviewed EHOs, food business operators or food handlers, and consumers in the eight-selected TAs. Data collection methods varied between groups; semi-standardized focus group interviews or individual semi-standardized face-to-face interview were used to collect data from EHOs; semi-standardized face-to-face interviews were used to collect data from operators and foodservice personnel; and intercept interviews were used for collecting consumer data. Semi-standardized interviews involve asking a number of predetermined questions and special topics, typically asked in a consistent order; however the interviewers had freedom to digress beyond prepared questions (Berg, 2009). Intercept interviews involved approaching participants exiting a specific location, in this case foodservice premises, and asking them to participate in a brief survey or interview. EHOs from TAs with grading systems were of senior levels (often termed Senior or Principal EHO). Foodservice operators were selected with the aid of EHOs in the TA, often based on food premises location, and operators of various inspection grade levels were interviewed. Consumers were selected at random when exiting target foodservice locations - these locations were selected based on a central or populated location within the TA.

\section{Interviews with Environmental Health Officers}

Interviews with EHOs were pre-scheduled by the researcher or an NZFSA regional contact. EHO interviews aimed to be in the format of focus groups; however at times this was not possible due to the location of the selected TA (Grey District, Dunedin City). Eight EHOs were interviewed. A focus group is an interview style designed for small groups of unrelated individuals, aiming to promote discussion on a particular topic (Berg, 2009). The focus group format was selected to promote discussion between members of different TAs regarding disclosure system operations, as well as to save researcher and participant time. When focus groups were not possible, semi-standardized interviews were conducted. Focus group arrangement and location is provided in Table 2.1 . 
Table 2.1 Arrangement and location of focus group interviews with EHOs in New Zealand TAs operating disclosure systems.

\begin{tabular}{|l|l|l|}
\hline Group & Location & TA Representatives Present \\
\hline 1 & $\begin{array}{l}\text { Auckland City } \\
\text { Council }\end{array}$ & $\begin{array}{l}\text { Auckland City Council } \\
\text { Waitakere City Council } \\
\text { NZFSA Local Government Program Coordinator }\end{array}$ \\
\hline 2 & $\begin{array}{l}\text { NZFSA Head Office, } \\
\text { Wellington }\end{array}$ & $\begin{array}{l}\text { Wellington City Council } \\
\text { Hutt City Council }\end{array}$ \\
\hline 3 & Palmerston North & Wanganui District Council \\
City Council & Horowhenua District Council \\
\hline 4 & Dunedin City Council & Dunedin City Council \\
\hline 5 & Local Café & Grey District Council \\
\hline
\end{tabular}

Prior to commencing the interviews, the researcher briefed EHOs on the project and goals of the interview. The interview was typically scheduled for one hour and audiorecorded using a digital camera pending participant permission. A sample of interview questions can be found in the Appendix (Questions for EHOs in districts operating a disclosure system). EHO interviews provided information on how disclosure systems were currently operated in different TAs, as well as feedback on these systems. Interviews indicated that feedback received to the council on current grading systems was generally positive from both consumers and operators; however, they noted that resistance was encountered during the implementation period. Three of the eight EHOs interviewed mentioned occasions where operators complained about the grade another operator had received, and indicated this dialogue typically occurred during the inspection process. All of the interviewed EHOs indicated the importance and difficulty in creating consistent grade assignment between individual EHOs, and emphasized the need for consistency in a national system. Anecdotal evidence from interviews suggests greater consumer and operator feedback in districts where media coverage of the disclosure system was present (e.g. newspaper publishing of inspection grades, television programs), and in districts where card display was mandatory rather than voluntary. All eight EHOs interviewed preferred mandatory display for disclosure systems, suggesting 
or indicating from personal experience that lower grades would not be displayed in a voluntary system. Four of the eight EHOs supported initiatives by their TA to provide operators with monetary incentives to achieve higher grades - higher graded premises pay lower inspection fees than lower graded premises. All of the EHOs interviewed supported a national disclosure system and agreed disclosure systems can be a tool for consumers; however, they often mentioned that it should be made clear inspection is only a snapshot in time. EHOs' largest concern, in both regional and national disclosure systems, was in regards to consistency. Three EHOs mentioned the difficulty in producing consistent grades within their TA and questioned how this could be achieved with a national system. A summary of EHO interview questions and typical responses is provided in the Appendix (Table A.2).

\section{Interviews with Foodservice Operators/ Food handlers}

Semi-standardized intercept interviews were conducted with foodservice operators or food handlers in the Central Business District (CBD) of the eight selected TAs. A convenience sample was used to select premises from all grade levels within the $\mathrm{CBD}$, with the researcher walking throughout the CBD and selecting a premises for interviews. In all of the participating TAs except Wellington and Hutt City the researcher had not been in the district prior to conducting the national review. With the researcher being based in the Wellington region, it was possible the researcher may have dined at premises in these TAs previously; however, premises in these TAs were still selected at random. In districts where grade display was not mandatory, often the council would provide the researcher with premises lists, indicating which premises achieved which grade as a guide for interviews. Convenience sampling was still used in these districts, premises lists simply provided the researcher with post-interview grade knowledge that may not have been noticeable prior to commencing the interview. Once a premises was approached the researcher asked to speak to the owner or operator. If this person was available the researcher introduced herself, indicated her affiliation with NZFSA (using an official badge) and asked the operator to participate in a brief anonymous questionnaire regarding the disclosure system in their area. Should the owner or operator not be available, the researcher would proceed in the same manner, and ask a food handler whether they would be comfortable in answering the questionnaire. A copy of the 
questionnaire is available in the Appendix (Questions for foodservice operators in districts operating a disclosure system at the time of national review). Nearly all of the approached operators willingly participated in the interview. On some occasions a food handler chose not to participate, simply suggesting the owner/operator would be better suited to provide such feedback. The researcher used pre-printed interview questionnaires to record responses from the operator. Interviews were scheduled to take no longer than 15 minutes (and the operator/food handler was informed of this prior to being interviewed). Premises remained anonymous, with only the premises' grade and the TA it was located in recorded.

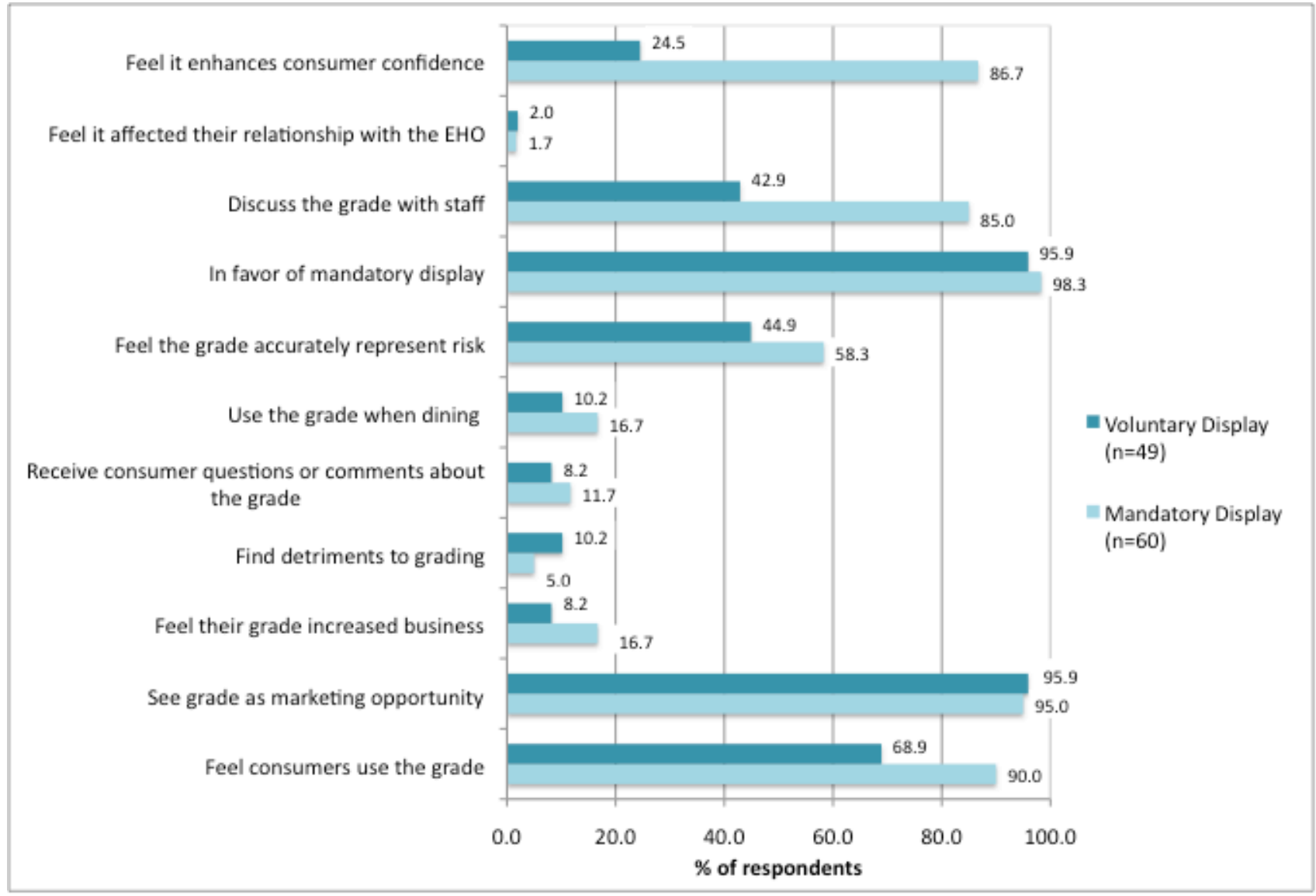

Figure 2.2 Summary of foodservice operator/food handler interviews regarding local inspection disclosure systems.

In total, 109 food premises operators/food handlers were interviewed in districts operating grading systems, 60 from districts with mandatory display and 49 from districts with voluntary display. A summary of operator responses is provided in Figure 2.2. 
Operators in districts with mandatory display indicated more frequently than those in voluntary regions ( $90 \%$ versus $68.9 \%$ of respondents, respectively) that they felt grades were something consumers look for when dining at a restaurant. Nearly all operators (95\% and 95.9\%) saw the disclosure system (or the concept of a national disclosure system) as a marketing opportunity, and a small number of operators $(16.7 \%$ and 8.2\%) felt that achieving a higher grade had helped boost business. Few operators (5\% and $10.2 \%)$ indicated there were detriments to having a disclosure system, with the detriment mentioned most being additions to inspection criteria requirements for grading (depending on the TA). This response was from operators in all grade levels, including those with lower grades. Few operators $(11.7 \%$ and $8.2 \%)$ indicated they receive consumer questions or comments about their assigned grade, and those that did mention consumer feedback indicated it was positive. A few of these operators indicated they had received comments from fellow food business operators about their grade, often in the form of playful teasing. Few operators (16.7\% and 10.2\%) indicated they used the grading system to make dining decisions; however, nearly all operators interviewed indicated they compared grades with other food businesses in the area. Often operators mentioned their knowledge of a business's performance and that this was what their personal dining decisions were based on. About half of all operators (58.3\% and $44.9 \%)$ felt that their assigned grade represented the level of food safety their premises was achieving, including those who had received low grades. Those with low grades often explained the situation at the time of the inspection as a reason for achieving this grade, and seemed to feel it was something that could be changed for the next inspection to achieve a better score. Some operators mentioned the difficulty in quantifying a premises inspection into a single card, indicating this may be one reason the cards may not necessarily always represent their level of food safety (as it is constantly changing). Often operators mentioned components of the grading inspection that were not necessarily related to food safety, and included this as reasoning for the grading system not accurately representing risk. Nearly unanimously (98.3\% and 95.9\%) operators felt disclosure should be mandatory, including operators with low grades, who seemed to feel that by the time a national system was introduced they would have made improvements 
to achieve a high grade. Operators often indicated that without mandatory disclosure there was no incentive for lower graded premises to improve, and that this could decrease the value of achieving a high grade. Most operators (85\%) in districts with mandatory display indicated they had discussed their grade with staff; while less than half $(42.9 \%)$ of operators in voluntary districts recalled doing so. Only a few operators $(1.7 \%$ and $2 \%)$ felt their relationship with the EHO had changed following introduction of grading (if disclosure had recently been introduced). Operators in TAs with mandatory display indicated more frequently than those in districts with voluntary display $(86.7 \%$ versus $24.5 \%$ ) that achieving a high grade was something they felt could provide consumers with confidence in their dining decision.

\section{Interviews with Consumers}

Semi-standardized consumer intercept interviews were conducted in the eight selected TAs. A convenience sample (excluding premises with low grades) was used to select food businesses within the CBD, and consumers exiting these premises were asked to participate in a brief interview. A premises was not targeted for more than 15 minutes. Food premises that were targeted were often selected because they appeared busy. As a significant number of questions for consumers involved discussing the grade of the food premises the consumer had just exited, the researcher intentionally avoided premises with lower grades where grade display was mandatory. This was done to avoid being seen as drawing negative attention to these businesses and potentially upsetting the business owner. In districts where grade display was voluntary (or in districts with mandatory display, but cards not required at the principal entrance) the researcher was often unaware of the grade of the premises from whence a consumer exited. Consumers exiting food businesses were asked to participate in a brief questionnaire regarding food safety and told the interview would take approximately seven minutes. The researcher wore an official NZFSA badge while conducting interviews and carried a clipboard with questionnaires. A copy of the interview format is available in the Appendix (Questions for consumers in districts operating a disclosure system at the time of national review). A summary of consumer responses is provided in Figure 2.3. 


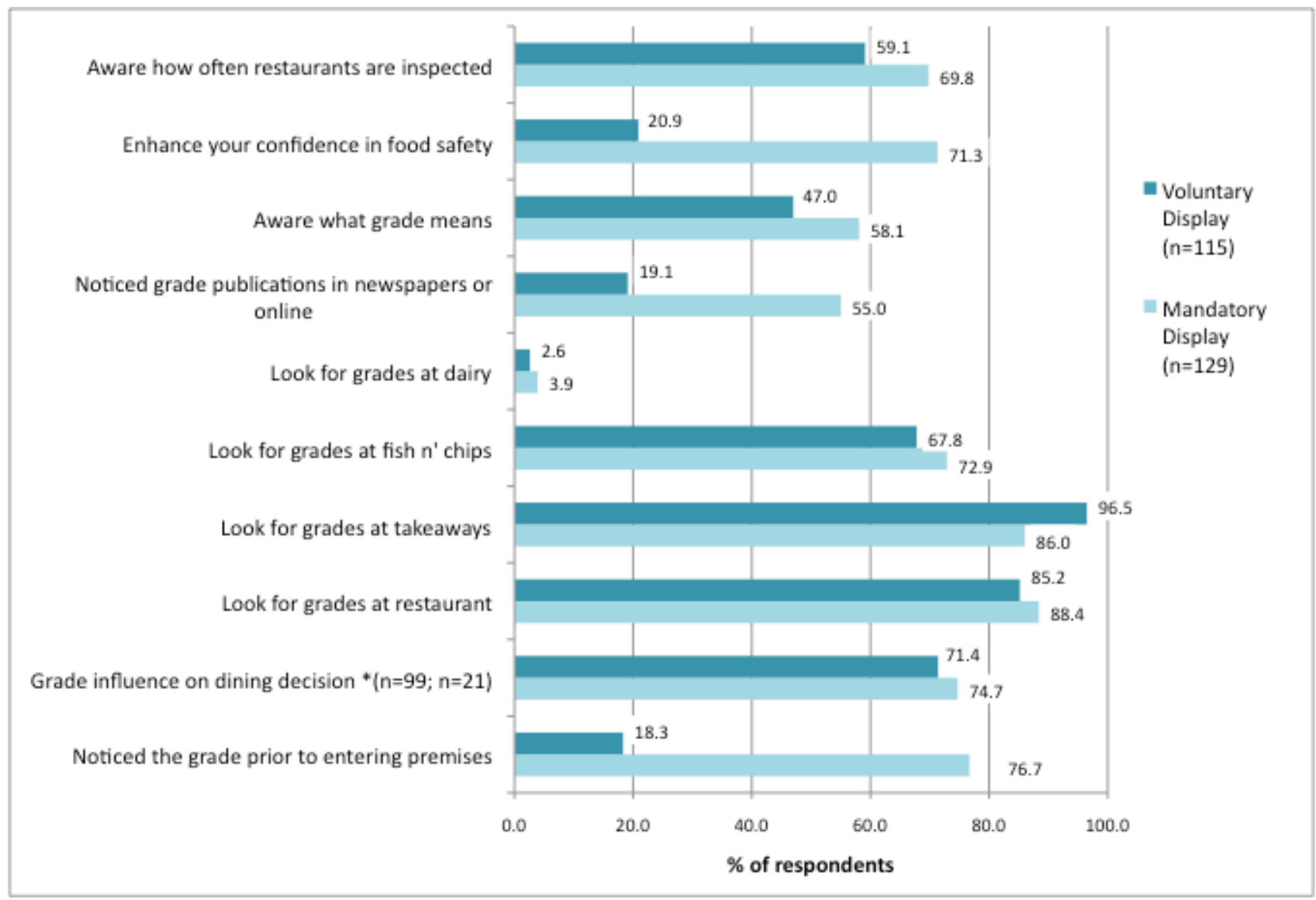

* Of consumers who noticed the grade prior to participating in interview; $n=99$ consumers in districts with mandatory display, $\mathrm{n}=21$ in districts with voluntary display.

Figure 2.3 Summary of consumer interviews regarding local inspection disclosure systems.

Of the eight TAs in which consumers were interviewed four required mandatory display of grade cards, and four operated on voluntary systems. In total 244 consumers were interviewed across the eight districts, with 115 interviews conducted in districts with voluntary display, and 129 in districts with mandatory display. Consumers were categorized as being from the TA in which the interview was conducted, or visitors to this TA. In total $88.5 \%(\mathrm{n}=244)$ of consumers interviewed were from the TA in question, with the remainder being from another TA or country. Of those consumers not from the selected TAs $(n=28), 60.7 \%$ of respondents indicated they were from a TA with an inspection disclosure scheme. 
To determine whether current disclosure systems attracted consumer attention, the researcher asked participants if they had noticed a grade card prior to dining at the establishment. The researcher did not use any leading words such as "food safety" or "inspection grade" when asking this question as not to sway responses to later questions; however, the researcher was wearing an identification badge with the NZFSA logo. On rare occasions a participant may have commented on this badge and affiliation. Consumers in districts with mandatory display were more likely to respond that they noticed the grade card prior to entering the premises $(76.7 \%$ of respondents vs. $18.3 \%$ in districts with voluntary display). The two TAs with the highest level of recognition were Waitakere City and Auckland City (both of which require mandatory display, but Waitakere also requires this display be at the principal entrance). Consumers in both TAs often indicated they had noticed the grade at the premises prior to eating there, with nearly all respondents in Waitakere City indicating they had noticed the card. This higher level of recognition may be based on card placement - grade cards were positioned at the principal entrance (required in Waitakere); card design - both Auckland City and Waitakere City use 8x10 inch grade cards with large letter grades taking up the majority of the certificate; and media coverage of the grading system in this region - grading systems in the Auckland region (which includes Auckland City and Waitakere City) are often targeted on television programs, in newspapers or on the radio. Media coverage of the letter grade systems in the Auckland region is so much so that often consumers in the other TAs would reference the Auckland disclosure systems when discussing grading with the researcher. The lower levels of recognition in other districts are likely due to similar factors. Card placement in the six other TAs was less obvious - displayed at the register (often near certificate of registration) or not at all; and card design - grade cards were smaller in some districts (3x5 inches) or the grade itself small on the $8 \times 10$ inch card (unlike Auckland City and Waitakere City where the letter took up the majority of the card).

Often if the interviewed consumer did not recognize the grade prior to eating at the restaurant the researcher would point to or describe to the consumer where the card was located. In districts with mandatory display, the majority of these consumers then indicated they were aware of what the grade looked like, but simply hadn't noticed it at 
this time. In Auckland City and Waitakere City, consumers often mentioned the television program Target $^{5}$ (hidden camera show) highlighting graded premises. In Dunedin (a TA with voluntary display) consumers often mentioned the television program The Inspectors, which follows health inspectors during routine visits (and often mentions the assigned letter grade for these premises). In districts with voluntary display, particularly Wellington City, Grey District and Porirua City, the majority of consumers were still unfamiliar with the concept of inspection grade cards, even after the researcher either pointed to or described the cards to them. Card recognition, or knowledge of a disclosure system, was extremely low in these TAs. All three TAs used a voluntary system. Wellington City and Porirua City used phrase cards, and only rewarded Excellent/ Excellent and Very Good premises (respectively). These awards were often displayed next to a premises' certificate of registration. Grey District used small (3x5 inch) grade cards with a letter.

Of the participants who indicated they had noticed the grade card prior to entering the premises ( $\mathrm{n}=99$ for mandatory; $\mathrm{n}=21$ for voluntary) $74.7 \%$ and $71.4 \%$, respectively, indicated the grade had influenced their decision to dine at that premises. This influence was often positive, with participants indicating the grade had solidified their decision to dine at that premises, or the grade had met their expectation for this type of premises.

Open-ended questions were asked to participants to determine at which types of premises they expected to find grades. The majority of participants in both mandatory and voluntary display TAs indicated they looked for cards at restaurants $(88.4 \%$ mandatory; $85.2 \%$ voluntary) and take-aways (86.0\% and 96.5\%). While most interviewed consumers indicated they look for grading at fish n' chips shops $(72.9 \%$ in districts with mandatory display; $67.8 \%$ with voluntary display), only a small percentage of participants looked for these at dairies (3.9\% mandatory; $2.6 \%$ voluntary). On several occasions participants indicated they were more likely to look for a grade when dining somewhere untrustworthy and mentioned looking for grades at places like take-aways and fish n' chips. The low percentage of participants indicating they look for grades at diaries is likely due to variable regulations regarding the grading of dairies - some TAs include these in grading and others do not. Additionally, depending on the TA, dairies

\footnotetext{
${ }^{5}$ Target is a consumer affairs television show in New Zealand.
} 
may or not be included in the regional grading system. As not all dairies provide hot food, it is common for some TAs to exclude dairies from grading, or only grade dairies that provide hot food.

Participants were asked whether they had noticed any type of grading in newspapers or online. Participants in districts with mandatory display indicated they had noticed this more frequently than those in districts with voluntary display $(55.0 \%$ mandatory; $19.1 \%$ voluntary). The two districts with the highest responses to this question were Auckland City and Waitakere City which use online databases to highlight premises grading. Often consumers in these districts would indicate they had used the database to look up a premises' grade. Additionally, these two districts often had mention of the television program Target, and in Dunedin the television show The Inspectors was commonly mentioned.

When asked which aspect of the restaurant the grade referred to most, consumers responded using the terms restaurant hygiene, quality or safety, and often mentioned the inspection process. Consumers whose response included something about restaurant hygiene, safety or the inspection process were recorded as being aware of what the grade meant. Consumers in districts with mandatory display were slightly more aware of what the grade meant (58.1\% vs. $47.0 \%$ ) than consumers in districts with voluntary display. The most accurate responses were found in Waitakere City ( $\mathrm{n}=32$ ), where $84.3 \%$ of participants understanding what the grade meant. This is likely because in Waitakere grade cards included the words "Food Hygiene Grade" and an interview with an EHO in this TA indicated a recent emphasis on grading project in this TA.

A significant number of participants (69.8\% mandatory; $59.1 \%$ voluntary) had a realistic idea of how often food premises were inspected, with most responding somewhere between once and twice a year. In Waitakere City $(n=32) 75.0 \%$ of respondents were aware how often premises were inspected, and several went as far as to recognize inspection frequency was correlated with risk, and high-risk premises were more frequently inspected. This was likely due to media coverage of the grading system and inspection process in this TA and the Auckland region.

Participants in districts with mandatory display were far more likely $(71.3 \%)$ than those in districts with voluntary display (20.9\%) to indicate the grade card provided them 
with enhanced confidence in the safety of food at restaurants. This is likely because of increased recognition of grading in districts with mandatory display. Participants in districts with voluntary display often indicated they were unaware a grading system existed. This is likely because grade display in voluntary districts was both less frequent and less prominent than in districts with mandatory display requirements.

Future research could evaluate the effectiveness of voluntary vs. mandatory display on consumer dining decisions, and particularly determine whether one location for card display (e.g. at the entrance or register) is preferred. Additionally, if a voluntary display system is highly recognized by consumers, is there a need to legally enforce card display, or will the pressure from consumers to see the card be enough for operators to display their card? 


\section{Chapter 3 - Grade Card Design and Evaluation}

With many of New Zealand's most popular inspection disclosure systems involving disclosure at the premises, NZFSA determined that a national system would also involve disclosure at the premises in the form of a card. Additionally, it was determined that a national disclosure system would likely require mandatory display of the assigned inspection card at the premises' principal entrance. This was determined by NZFSA based on international and national program success using mandatory display. Based on information obtained through the international and national reviews, the researcher designed inspection card prototypes.

\section{Initial Card Design}

Initial inspection card prototypes covered a variety of formats, including popular international and national formats, and 'shock' designs; however, perceived improvements were introduced based on literature findings and findings from TA visits. Initially 18 prototypes were created incorporating the following formats: letter grades, traffic lights, smiley faces, gauges, scores based on category, phrases, numerical values, and shock designs.

Initial prototype designs were created using the iWork program Pages, ${ }^{6}$ and cards exported as a PDF file. Cards were designed to fit an 8x10 inch cardstock. This size was selected as it is financially feasible to print grade cards on this size, and it is a popular inspection card format in both New Zealand and other developed countries.

The initial prototypes (see Appendix - Table A.3) included a distinct title section and incorporated the NZFSA logo and color scheme.

\section{Letter Grades}

Internationally, letter grades appear to be the most popular form of on-site disclosure, and they were also the most popular form currently implemented in New Zealand at the time of the national review. Letter grade schemes use a similar grading

\footnotetext{
${ }^{6}$ Pages is a word processor and page layout application developed by Apple, Inc., Cupertino,
} California. 
system to the education system, grading food premises much the same as children are graded in school. Examples of letter systems include Los Angeles, U.S., (A,B,C, Ungraded), New York City, U.S. (A,B,C, Grade pending) and Auckland City (Gold A, A,B,D,E, Grade pending). The international literature review determined that letter grade systems are popular but inconsistent. In designing a prototype letter grade card the following improvements were made based on international and national findings:

- A,B,C,D,F or A,B,C,F: Letter grade systems are made to be consistent with academic grading found in schools. Academic grading in New Zealand is typically A,B,C,D,E (Wikipedia, 2010); however, international research suggested consumers may be confused by the letter E, and mistakenly believe 'E for Excellent'.

- The letter $\mathrm{C}$, although sometimes viewed as being confusing (is it a passing or failing grade?), was suggested as the minimum acceptable level. This is meant to be consistent with academic grading where $\mathrm{C}$ equates to pass or higher. Additionally, this could avoid the confusion that a lack of the letter C may produce.

- F was suggested to clearly indicate those premises that have failed a recent inspection.

Three letter grade prototypes were designed. These cards included a variety of letter combinations and orders.

\section{Risk Colors (Traffic Lights)}

Risk indicator colors, or traffic light schemes, have been used to communicate the potential risk of dining at a premises. In these systems, green means go (or enter without worry), yellow means enter with caution, and red typically means stop (premises closed). The traffic light is popular in developed countries, and assumed to be a widely recognized symbol. Additionally, color has been widely used as a risk indicator and was used in the development of grade card prototypes. An example of this system is Toronto, Canada where green (pass), yellow (conditional pass) and red (fail) cards are issued to premises. Most of the initial prototype designs included risk indicator colors. A traffic light card was developed as one of the initial prototypes, and included a smiling face. 


\section{Smiley Faces}

Smiley faces are often considered a universal symbol for communicating emotions. Perhaps for this reason, several disclosure systems have used smiling faces to communicate to consumers a premises inspection result. The most popular example is Denmark, where a range of smiles from an 'Elite happy smiley' to a 'sour smiley' is awarded to premises. A smiley card was developed in the initial prototypes and smiles were additionally incorporated into a traffic light card. Unlike the Danish system, color was used as a risk indicator in the prototypes.

\section{Category Scores}

One of the main food safety messages from NZFSA is "Cook, clean, cover, chill" (recently changed to Cook, clean, chill). A few international disclosure system have disclosed the full inspection report at the premises with a categorical breakdown of violations. Expanding on this, a category prototype was designed to award marks for each category (cook, clean, cover and chill) based on the most recent inspection.

\section{Phrases}

Although often used in combination with colored cards, phrases alone have been used to communicate inspection results to the public. Several prototype phrase cards were designed, including 'Pass, conditional pass, fail' to represent a premises' ability to meet the minimum standards.

\section{Numerical Scores}

Popular in North American, some districts display a numerical score at a premises to disclose inspection results. A common system scores premises between 1 and 100, with 70 being a passing score. A numerical prototype was designed based on these systems.

\section{Graduated Scales}

The most popular U.K. Scores on Doors grading schemes initially used a graduated scale of stars (zero to five) to score food businesses. In a review of popular UK grading systems it was found that consumers prefer positive symbols, but some concern was raised regarding the similarity of the star system to a popular hospitality rating 
scheme (UK Scores on Doors Review, 2008). Additionally, research has indicated that some consumers confuse stars with quality rather than safety. For this reason an altered design was created in New Zealand, using a pie symbol rather than a star. The pie symbol was selected for both its positivity and symbolism of New Zealand culture. The prototype gradient card included risk colors.

\section{Gauges}

Although no known international grading systems use gauges, internally NZFSA has used gauges to communicate audit results in reports. The gauge prototypes emerged from this concept and incorporated risk colors.

\section{Shock Designs}

Much of Dr. Powell's (Kansas State University) research focuses on finding new ways to communicate food safety messages in a compelling and interesting manner. Research by Chapman (2009) found that food handlers were more likely to read food safety infosheets when a shocking or interesting photo was attached to the story. Additionally, research by Creedon (2003) suggests the use of disgust-evoking images may be effective at triggering hand hygiene behavior. Shock prototypes were designed based on this, and incorporated risk colors.

\section{Card Phrasing}

To reduce the possibility of consumers or operators misinterpretating the meaning of grade cards, phrases were included under certain prototype designs as an additional explanation (e.g. A - Excellent). Color was used in most prototypes as a risk indicator (green, yellow, red). Where necessary a scale was provided (e.g. A out of A, B, C, F). Potential titles were evaluated during the prototype phase as national interviews indicated consumer understanding of inspection cards was higher in districts where clear explanatory titles were present. Prototype titles included: Food Safety Inspection Result/Smiley/Grade/Conclusion, Food Safety Verification/Audit Result, or Food safety Risk-O-Meter. Titles were selected based on popular terminology for the inspection process, and terms commonly used by NZFSA for these operations. There was some debate over the use of the word 'inspection' - although commonly used by consumers 
and operators in reference to a visit from an EHO - the term used by NZFSA for these visits is 'audit' or 'verification'. Grades themselves (e.g. the letter or smile component) were intentionally designed to take up the majority of the $8 \times 10$ " card. This was based on information from the national review that suggested consumers are more likely to recognize the inspection card when the grade itself is large.

\section{Internal Review}

The 18 prototypes were included in a survey to NZFSA and Kansas State University personnel for feedback, and to narrow the 18 initial prototypes down to six for farther evaluation using focus groups. The survey was emailed out to participants using a Microsoft PowerPoint ${ }^{7}$ slideshow. The slideshow included a description of the project, examples of the 18 initial prototypes, and a summary slide asking for participant card preferences. Participants were asked to include general comments about format, design, and wording in the Notes section of the slideshow, below each of the displayed prototypes. On the final slide participants were asked to provide a list of their top and bottom three prototype designs. Completed slideshows with participant comments were then returned to the researcher, and data recorded.

Participants were given two working days to provide feedback. Between 500-600 NZFSA and nine Kansas State University personnel were emailed and asked to participate in the survey. Thirty-eight NZFSA and five Kansas State University personnel responded to the survey by the deadline. Of the 43 respondents, 24 responded with top and bottom three preferences; seven responded with only top three preferences; one responded with only one top and bottom preference; and one responded with only a bottom one preference. General feedback on the initial 18 prototypes is available in Appendix (Table A.3). This feedback was used to determine the six most preferred prototypes (see Appendix - Table A.4).

From internal feedback the researcher redesigned the top six initial prototypes to include suggested improvements. The edited six prototypes (See Appendix - Table A.5) were created using Pages ${ }^{5}$. To produce professional-looking prototype cards, a graphic

\footnotetext{
${ }^{7}$ Microsoft PowerPoint is a presentation program by Microsoft.
} 
design company, Cue Designs ${ }^{8}$, was contracted by NZFSA. Cue Designs, using the edited prototypes, and with guidance from the researcher, developed the professional final prototypes (See Appendix- Table A.6) for evaluation using focus groups.

\section{Focus Group Evaluation}

As focus groups can be used to both generate impressions of a new program and diagnose potential problems with an existing program (Berg, 2009), the six final prototype cards were evaluated by 11 focus groups selected to represent the New Zealand population. Ultimately the focus groups aimed to narrow the six final prototypes to two cards for further redesign prior to implementation in a grading trial. Focus groups were arranged by Nui Pacific Ltd. ${ }^{9}$ who worked with the researcher to achieve the goals of the focus groups. The researcher provided Nui Pacific Ltd. with the general target participants (e.g. represent the New Zealand population, including ethnic groups, tourists, food business operators and EHOs) and the budget supplied by NZFSA. Nui Pacific Ltd. ${ }^{8}$ selected participants and provided venues and mediators for focus groups. Participants were selected from the Wellington region. Eleven focus groups were selected to represent the New Zealand population: young urban professionals, young families, tourists, students and trainees, middle-aged, elderly, Chinese, Maori, Samoan, foodservice operators, and TA representatives. TA representatives (or EHOs) were selected by the researcher. This group consisted of one representative for each of the six New Zealand TAs that would participate in the grading trial (see Chapter 5).

Focus groups were six participants in size, with the exception of the students and trainees group which had eight participants. Focus groups were moderated by the same Nui Pacific Ltd. ${ }^{8}$ employee, with the exception of the Maori, Samoan and Chinese groups, which were led by Maori, Samoan and Chinese members respectively. This was done for two reasons: to mitigate potential language barriers, and to encourage honest responses. The researcher was present at all focus groups except the Maori, Samoan and

${ }^{8}$ Cue Designs is a Wellington, New Zealand graphic design company.

${ }^{9}$ Nui Pacific is a Wellington, New Zealand consultancy focusing on communications and research. 
Chinese groups as a note-taker and to provided answers or clarification regarding the grading project. It was suggested the researcher not be present at the Maori, Samoan and Chinese groups to produce honest discussion, and due to language barriers. For these groups notes were translated and supplied to the researcher by the respective mediator. Groups were conducted in the following venues:

Table 3.1 Arrangement and location of focus groups evaluating grade card designs.

\begin{tabular}{|l|l|}
\hline Focus Group & Location \\
\hline Tourist & Base Backpackers $(\mathrm{n}=6)$ \\
\hline Young families & Day care centre $(\mathrm{n}=6)$ \\
\hline Students and trainees & Cricket club $(\mathrm{n}=8)$ \\
\hline Young urban professionals & Nui Pacific Ltd. office $(\mathrm{n}=6)$ \\
\hline Middle-aged & Nui Pacific Ltd. office $(\mathrm{n}=6)$ \\
\hline Elderly & Retirement home $(\mathrm{n}=6)$ \\
\hline Maori & Country store $($ after hours) $(\mathrm{n}=6)$ \\
\hline Samoan & Café $(\mathrm{n}=6)$ \\
\hline Chinese & Chinese language office $(\mathrm{n}=6)$ \\
\hline Foodservice operators & Operator's restaurant $(\mathrm{n}=6)$ \\
\hline TA representatives (EHOs) & NZFSA office $(\mathrm{n}=6)$ \\
\hline
\end{tabular}

Focus groups were formatted as follows:

1. The six grade card prototypes were laid on the table and participants were asked to record which card they preferred at a glance. Cards only remained on the table for less than a minute. This was recorded as the participant's initial card preference.

2. Grade card prototypes were then placed on the table one at a time and discussed individually. Participants were asked to discuss design likes and dislikes; were they aware of what the card was communicating?; did they know who was responsible for assigning the card?; did they trust the card?

3. After evaluated individually, the two letter grade cards were compared for evaluation. 
4. Final questions were asked regarding overall prototype designs: did the cards attract their attention?; what types of businesses did participants expect to find cards at?; did they trust the cards?; where else did they expect to find inspection information?; who would they contact with queries?

5. Participants were then asked to record their card preference at the end of the session, and discuss their initial vs. final card preference.

6. Finally, general questions about inspection disclosure were asked: were participants aware grade cards were posted? (participants were from Wellington City region which used a mandatory display disclosure system); how did they feel about the ideal of a national grading scheme?.

\section{Card Feedback - Individual Designs}

The six grade card prototypes evaluated by focus groups can be found in Appendix, Table A.6.

\section{Kiwi Letter/Letter Card}

Two letter grade cards were presented to focus group participants. The first card, termed the Kiwi letter, incorporated the design of a Kiwi bird and used a scale of A,B,C,D,F; the second had no additional design components and used a scale of A,B,C,F. Overall the plain letter card was favored to the Kiwi letter card. Although a significant number of participants (and all members of the Maori group) found it more interesting than the letter card, a significant number of participants who found it confusing.

"The kiwi makes it less boring and makes me want to take a second look at the card."

"I know I'm in New Zealand, I don't need a kiwi on the card to tell me that."

The Kiwi card was generally liked for being Kiwiana and more visually interesting than the letter card; however, often similarities between the kiwi design and Kiwihost (a national tourist service program for rating hotels) were mentioned. Additionally, after discussing the cards, participants would often later agree that although the Kiwi letter was more visually interesting, the plain letter card would better stand out 
and relay the message more clearly. Similarly, several times it was suggested that the kiwi be changed to a watermark to increase clarity in the Kiwi letter card.

It was unanimous across focus groups that four letters, A,B,C,F, were sufficient (as opposed to A,B,C,D,F). Participants were unsure whether D was a pass, and found the addition of it confusing rather than beneficial. Participants were also confused as to whether an F (fail) premises would be closed. It was suggested that if failing premises are closed this should be written in the legend (e.g. F - Fail, premises closed). The majority of participants also suggested defining each letter on the scale as opposed to just those at the beginning and end of the scale. It was suggested that if it was known that B was "good" and C "acceptable" the cards would be less confusing.

\section{Gauge}

There were conflicting opinions on the gauge card. Many noted its similarity to the New Zealand Fire Danger billboards. While some participants indicated they would only associate the card with fire risk, others indicated that because it was similar to the fire risk gauge it was familiar to read and understand. A small proportion of participants, particularly those in the Maori and Samoan groups, were appalled with the design, indicating it was blatant copying the Fire Danger signs.

Although not the initial preference for some participants, the gauge card often became a preference following discussions. After discussion they found it easy to see

where on the scale a premises lay in one glance, as opposed to other cards where the scale was a separate entity.

"I like it. It shows exactly where you are on the scale -- you don't have to think about what the letter means."

A few participants suggested making the arrow on the gauge card thicker. Most participants found the awards section of the gauge card confusing, although a few participants saw it as a bonus identifying those premises exceeding expectations. Typically the reaction was,

"I think excellent is excellent, and you can't get much better than that."

The operator group was not totally opposed to the gauge card, but they did not see the benefit of the awards section, 
"It all comes back to instilling confidence, and the awards section doesn't add value or confidence- either you're making safe food or you aren't."

\section{Numerical Card}

Only a select few participants favored the numerical card (with the exception of the tourist group). The majority of participants found it confusing. Often participants commented that the card resembled a speed-limit sign, or the street number of the food premises, and indicated they would not associate it with an inspection score.

Additionally, participants indicated that if they knew it represented an inspection result, the score was still confusing because they were uncertain what a passing inspection score was. A few participants indicated they would even question high-scoring premises with numerical scores because they would want to know where points went- for example, if a premises received a 98, participants said they would want to know what the missing points were for. For the majority of participants the numerical card was too much information, with one participant saying,

"I'm not an inspector. I don't know what a 96 means in terms of the inspection - maybe it's sweet, maybe it's not."

The majority of participants in the tourist group initially selected the smile card as their favorite, but after discussion changed their preference to the numerical card at the end of the focus group. This may be in part due to the persuasion of one group member who particularly enjoyed the increased information the numerical card provided. A few participants suggested the numerical breakdown as a complimentary tool on a website, but that it was too much information to obtain at premises.

\section{Traffic Light/Smiley Card}

Both the traffic light and smile cards were initial favorites for a large number of focus group participants (with the exception of the operator and TA participants). Following discussion however participants often mentioned what they saw as childishness of these cards and their inappropriateness for the subject. While often initially debated that these cards may be useful for non-English speaking consumers, a common rebuttable was that the symbol could be describing any component of the business. 
"It could mean kid-friendly restaurant for all I know."

At the end of the focus group session when discussing initial versus final card selection, participants often indicated they had initially selected the traffic light or smiley card because of its positive and colorful nature, but they changed opinion because the card no longer fit the seriousness of the subject matter.

The operator group was completely opposed to both the traffic light and smile designs,

"It would look horrible in my restaurant. It's not serious and it pokes fun at my food safety efforts."

In the end, most participants indicated that the traffic light and smile cards would draw attention to a premises, but for the wrong reasons.

Finally, it should be noted the Samoan, operator and TA groups had strong opinions on the cards. All eight members of the Samoan group did not like any of the prototypes, with four of these members refusing to select a top card. The operator group was appalled by the traffic light and smile cards because of their lack of seriousness, and indicated they would only select the letter card. The TA group was completely opposed to the numerical card having suggested many difficulties implementing such a grading system based on the inspection process.

\section{Card Feedback - Overall Design}

\section{Color}

The majority of participants found the use of turquoise on the card dull, and did not see the relationship between it and NZFSA branding. It was apparent that the use of color highly influenced participant reaction to the cards. The traffic light and smile cards, with the most use of bright colors, were often selected as an initial favorite. Those cards with a high proportion of turquoise drew less initial attention. It was also noted that "green means go" seemed appropriate for an A card. A small number of participants indicated the turquoise gave the cards "professionalism." Similarly, a small number of participants indicated that the color selection (colors from the visible spectrum ROYGBIV) were elementary and childish, and suggested dulling down these bright colors. 


\section{Missing Components}

When asked whether there was any information missing on the card, most participants suggested having a telephone number or website for farther information. Participants also reiterated that the use of "inspected twice a year" was a positive addition.

\section{Responsibility and Trustworthiness}

When asked who is responsible for assigning the grade and who they would contact with an issue about the grade, the majority of participants were unsure. With both the council and the NZFSA logos on the card in equal proportion, participants indicated it was unclear which authority to contact. Many members indicated they were unfamiliar with NZFSA. Most indicated they would call the council or the local health department with a query (though some participants indicated this was from experience, and not because of the logo on the card). Participants suggested removing the council logos to more clearly indicate NZFSA assigns the cards.

Most participants indicated they would trust the information on the card more if the logo of the governing body was larger and more prominent. Participants often suggested moving the NZFSA logo to the title section of the card, and creating a watermark to make the card appear "difficult to reproduce." Several participants indicated that knowing how often a premises was inspected increased their trust in the assigned result. Often participants indicated they would not trust the juvenile-looking cards (traffic light and smile).

\section{Card Feedback - Card Placement}

Most participants indicated that they would expect to see the grade card near the premises' certificate of registration, but would like to see it displayed at the primary entrance. A small number of participants suggested having multiple cards at a premises -one at the entrance and one at the cash register. As one participant said,

"I'd like to see it before I enter. I don't want to be paying for my food and then notice they got a poor grade."

The operator group indicated that having the card displayed at the entrance would be an excellent marketing opportunity for those businesses meeting excellent standards, 
but doubted poor premises would display their card (regardless of whether it was mandatory).

"The dodgy [operators] will find a way around putting the card up in their window. Unless there's a fine or something, but even then..."

\section{Card Feedback - Complimentary Tools and Contact Information}

Most participants indicated they would like to see information on a website. Several suggested a searchable database. Others suggested having more information on the website, such as the numerical inspection score, for those consumers who may seek more information. Several participants agreed that posting grades in the newspaper was a good idea - with some suggesting shaming restaurants, others rewarding them. The tourist and Maori groups suggested having a smaller version of the grade and scale available on the menu or at the table. Members of the tourist group felt this would allow them an opportunity to "read a little more about what the grade means." One member of the operator group suggested providing operators with a package of information leaflets for consumers when a premises receives its grade in the mail.

The majority of participants indicated they would contact the council or health department if they had an issue with the grade card. Most felt that contacting the council was the better route to answers, and that if NZFSA was to be contacted the council would likely direct them there. Participants found the use of both council and NZFSA logos repetitive and suggested removing the council logo if they were not responsible for card assignment.

\section{Card Feedback - Knowledge of Foodservice Grading}

The majority of participants were aware foodservice premises had to display registration, but most were confused by the difference between grading and registration. This is likely because most participants were from the Wellington region where Excellent awards cards are provided (and not often recognized). A small portion of participants indicated they had seen letter grade cards in other districts, or on the television program Target. 


\section{Card Feedback - Reaction to the Grading Project}

The majority of participants felt the development of a national grading system was a positive step,

"I think it's a great idea that is long overdue."

A small portion of participants raised concerns with calibrating and enforcing such a grading system. Operators were eager for a card to market their food safety efforts, but skeptical of creating a calibrated inspection and grading system. TA representatives were eager for the start of the grading trial, and finding out which grade cards would be awarded to their respective districts.

\section{Conclusion and the Selection Process}

The smiley card, although a top choice for three of the 11 focus groups, was also a bottom choice in three of the groups. This indicates the difficulty in designing a grade card that will be favored by all consumers, operators and EHOs however; the smiley card was both loved and hated, a quality not necessarily desirable in a national grade card. The other top selections, the letter and gauge cards, were more neutral. Participants may not have selected these cards as being their favorite, but they also did not select it as being their least favorite. It was determined the final two grade cards for use in the trial be the letter and gauge cards.

For redesign of the trial cards it was suggested the letter card be four-tiered, A,B,C,F and include a scale with both letters and description for all possible grades (e.g. A - excellent, B-good, C-acceptable, F-Fail). It is suggested that F-fail include "premises closed" for clarity. The gauge card was also suggested to be four-tiered, red, orange, yellow, green, with the awards section removed.

Focus group participants did not link the color turquoise to NZFSA branding and therefore suggested it only be used in the title section of the card. Instead risk-indicator colors green, yellow, orange and red were suggested as these colors were found to attract attention while being appropriate for communicating food safety results.

It was recommended the NZFSA logo be larger and placed in the title section of the card, and council logos be removed to better identify NZFSA as the governing body responsible for card assignment. It was also recommended that a watermark be 
introduced to make card reproduction less likely, and a website URL added to provide further information for consumers.

\section{Final Trial Cards}

The final two cards, a letter grade card and a gauge card, were redesigned by Nui Pacific Ltd. and the researcher based on focus group feedback. These cards can be found in Figure 3.1 below. 


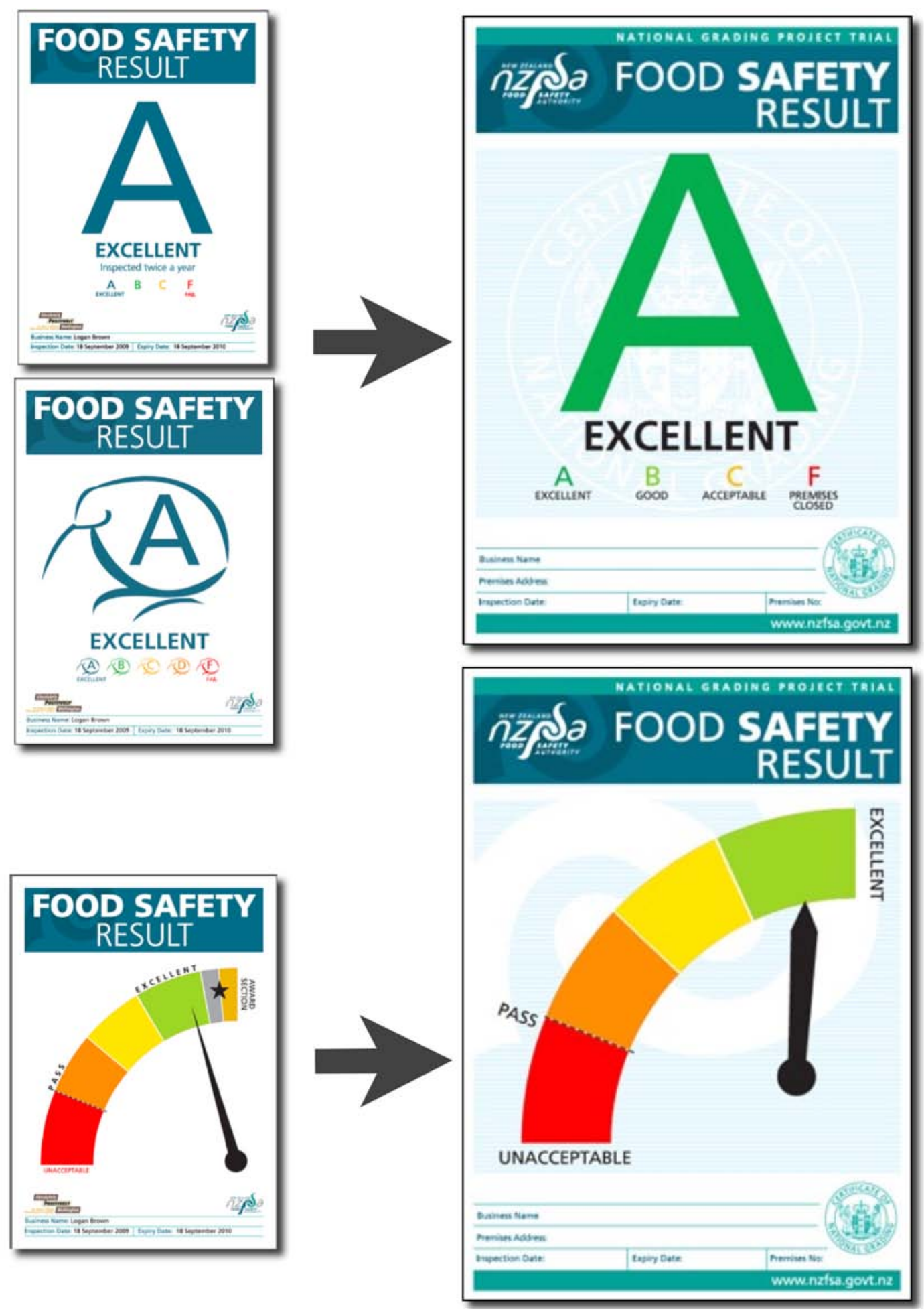

Figure 3.1 Final two cards (right), letter grade and gauge card, following redesign based on focus group feedback. 
Both the letter grade and gauge card contained the same title, branding and information about the premises. This ensured the only differences between the two cards were in the actual design meant to communicate the inspection result - the gauge or letter grade. Final cards used the title Food Safety Result, with the NZFSA logo (and full name) in the title space. Council logos were not included on the cards. NZFSA branding was decreased, with NZFSA's color, turquoise, only being used in the title and certification section of the card. An additional title at the extreme top of the card was introduced, stating National Grading Project Trial. This was designed to only be included in trial cards, and in the even either of the cards was to be the national card, this would be removed. Cards included the following information: business name, premises address, inspection date, expiry date (for all cards March 31,2010) and premises number (a reference number for the researcher). Both cards received a "Certificate of National Grading" stamp in the bottom right of the card to make cards appear more official than prototypes. Watermarks were introduced on both final cards to make them appear official, and to prevent replication. Although the watermarks on the letter grade and gauge cards were different, this was solely because these watermarks best fit their respective grade. Final cards also included a bottom title with a website address to the NZFSA homepage, where a brief outline of the national grading project was provided, as well as contact information for the researcher.

The letter grade card was redesigned based on feedback from both the plain letter and Kiwi letter prototypes. Changes included removing the letter D, and using $\mathrm{A}$ (Excellent), B (Good), C (Acceptable) and F (Premises Closed). The scale was altered to include a phrase for each letter (e.g. A - Excellent). The phrasing "Premises Closed" was selected for grade $\mathrm{F}$ to clarify which premises would receive this card. However, for the grading trial $\mathrm{F}$ cards were not printed, as it was deemed unlikely a premises would voluntarily display this card; and premises may not be closed for more than one day prior to re-inspection (and therefore card mailing would not arrive in sufficient time). The color turquoise was not used on the actual letter, but rather risk-indicator colors were selected, with green (A), lime green (B), amber (C) and red (F) being selected. Lime green was selected to represent B (Good) as internal conversations between NZFSA and the researcher suggested having amber and yellow on the scale would be confusing (B is 
meant to be a good grade, not a cautionary grade) and the color yellow may not show up clearly on cards. The subtitle "Inspected twice a year" was not included on the trial letter grade card because it was not possible to know how frequently premises were inspected in each district, as at the time of the trial this was inconsistent between TAs. It was suggested that inspection frequency be included in the national grade card design.

The gauge card was redesigned based on feedback from the gauge prototype. The main change was removal of the awards section of the card, resulting in only Excellent, Good, Acceptable and Fail categories. These categories remained unlabeled as focus group participants did not suggest this. The pass line on the gauge was made more prominent, and the arrow larger and thicker.

The back of grade cards included an explanation of the trial aim, premises involved, and dates of the trial. This was included to provide information for both the operators and consumers. The letter included on the back of grade cards is provided in Appendix (Information provided on the back of final grade cards for the national trial). 


\section{Chapter 4 - National Grading Trial}

\section{Selection of Participating TAs}

In order to determine which of the two proposed grade cards best communicated inspection information to consumers in a clear, compelling and trusted manner, and provide food business operators further incentive to produce safe food, a national grading trial was completed from January 1, 2010 to March 31, 2010. The trial aimed to introduce one of the two proposed grade cards into New Zealand TAs that at the time of the trial did not have an existing disclosure system.

At the time of the trial proposal, 24 of the 74 TAs were operating a disclosure system. It was proposed that six TAs partake in the national trial: three TAs in the North Island, and three in the South Island. The researcher aimed to select TAs that best represented the New Zealand population and tourist population. The aim was to select one larger urban center, one smaller rural center, and one city known for its tourist activities. An attempt was made to select TAs that were similar in size to represent each island (e.g. one large urban center in the North Island that was similar in size to its counterpart in the South Island); however, it was understood that this may be challenging, with the majority of the country's population being located in the North Island. Additionally, the majority of regional disclosure systems existed in the North Island at this time. This limited the number of TAs in the North Island that met criteria for participation in the trial.

Discussion with TAs regarding participation in the national trial began during the national review of disclosure systems. While contacting TAs to determine whether a disclosure system was currently implemented, the researcher took note of TAs that showed interest in the national disclosure system. Additionally, through discussions between NZFSA and a few TA representatives it was understood that two TAs were eager to implement their own regional disclosure system, but had put this agenda on hold with news of a national system introduction. These two TAs (Christchurch City and Queenstown City, both major cities located in the South Island of the country) and other interested TAs were contacted first and asked to participate in the national trial. 
Participation by TAs in the trial was voluntary. The researcher contacted potential TAs by telephone to first determine their level of interest in participating in the national trial, and later followed this with an email better outlining the details of the trial. This letter is available in Appendix (Letters to Foodservice Premises Operators in Trial TAs). The main concern raised by most TAs considering participation in the trial was personnel. With the trial aiming to commence January 1, 2010 for duration of three months, TAs questioned the amount of personnel time that would be required to answer queries, complete the required restaurant inspections and provide information to the researcher. In order to best accommodate TAs in the trial, the researcher suggested trial TAs be as involved as they saw possible.

Six TAs, New Plymouth City, Napier City and Upper Hutt City in the North Island, and Blenheim City, Christchurch City and Queenstown City in the South Island, were ultimately selected for the trial. Selecting three trial TAs in the North Island was challenging. Of the 24 regional disclosure systems operating in New Zealand, 21 existed in the North Island. The national trial required that participating TAs not have an existing disclosure system, therefore fewer TAs were eligible for trial selection. Additionally, many of the North Island urban TAs and popular tourist destinations were among those with existing disclosure systems. Selecting the three trial TAs in the South Island was relatively straightforward. Both Christchurch City and Queenstown City agreed to be part of the national trial early in the project. These cities had begun development of regional disclosure systems after experiencing consumer and operator pressures, but put development on hold once it was understood that a national system would replace regional systems in the near future. 


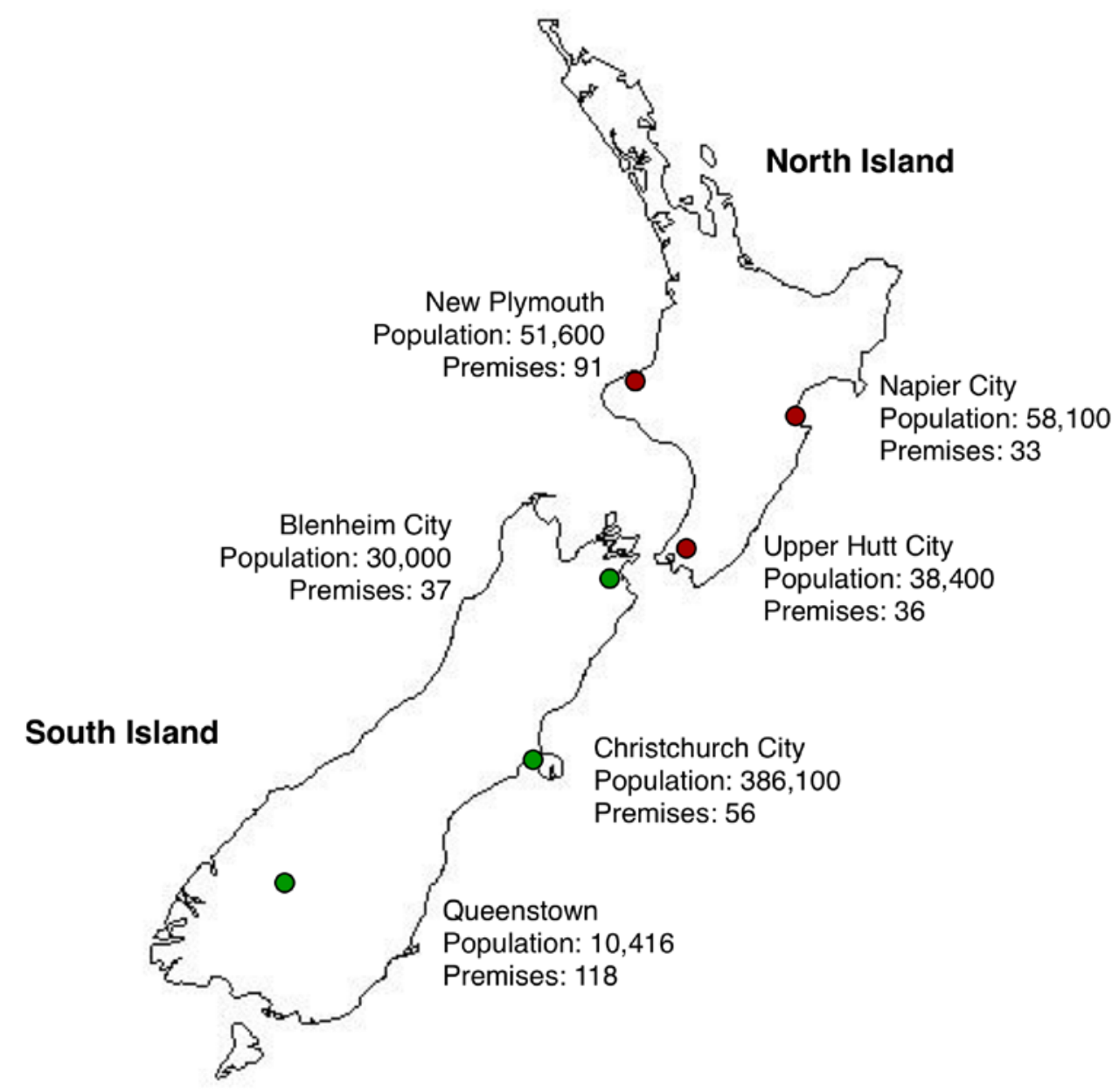

Figure 4.1 Six trial TAs and respective location, population and premises involved in the grading trial.

The six trial TAs were selected for the following reasons:

- New Plymouth and Christchurch were selected to represent larger urban centers in the country. Although the population of Christchurch's urban center is nearly eight times the size of New Plymouth's, New Plymouth was one of the larger centers in the North Island available for participation in the trial (as most large urban centers in the North Island already have grading systems).

- Napier and Queenstown were selected to represent popular tourist locations in New Zealand. 
- Upper Hutt and Blenheim were selected to represent smaller New Zealand cities. Although Queenstown's population is significantly smaller than Blenheim, Queenstown is well known for its tourist activities. Upper Hutt was selected for its close proximity to Wellington.

The central business district (CBD) of involved cities was selected as the boundaries of the trial (with the exception of Christchurch, where only a portion of the CBD was included due to its large population), and any registered food premises in this area were proposed to be involved in the trial. The researcher attempted to keep the numbers of involved premises consistent between the two islands to ensure consistent results.

\section{Media Influence}

Participating TAs were asked to not use local media to promote the national trial as this may have compounded results. Instead, TAs were asked that media queries be directed to the researcher. Although it was understood that the media could not be controlled, and grading may be a popular topic, the researcher aimed to keep media attention at a minimum. A brief article was included in NZFSA's quarterly magazine Food Focus (target audience food operators, handlers and regulators), explaining that a national trial would commence January 1, 2010 in six New Zealand TAs. Little more explanation was provided at this time.

\section{Grading for the Trial}

During the trial there were six possible grade cards provided to the participating premises. Depending on the location of the premises, they received a gauge card (North Island) or letter grade card (South Island), and each of these was divided into three levels of pass (with no fail card being administered for the trial period). The six potential cards can be found below. It was decided the gauge card would be assigned to North Island TAs to avoid confusion with existing letter grade systems operating in surrounding North Island TAs (e.g. Auckland City). The letter grade card was therefore assigned to South Island TAs. 

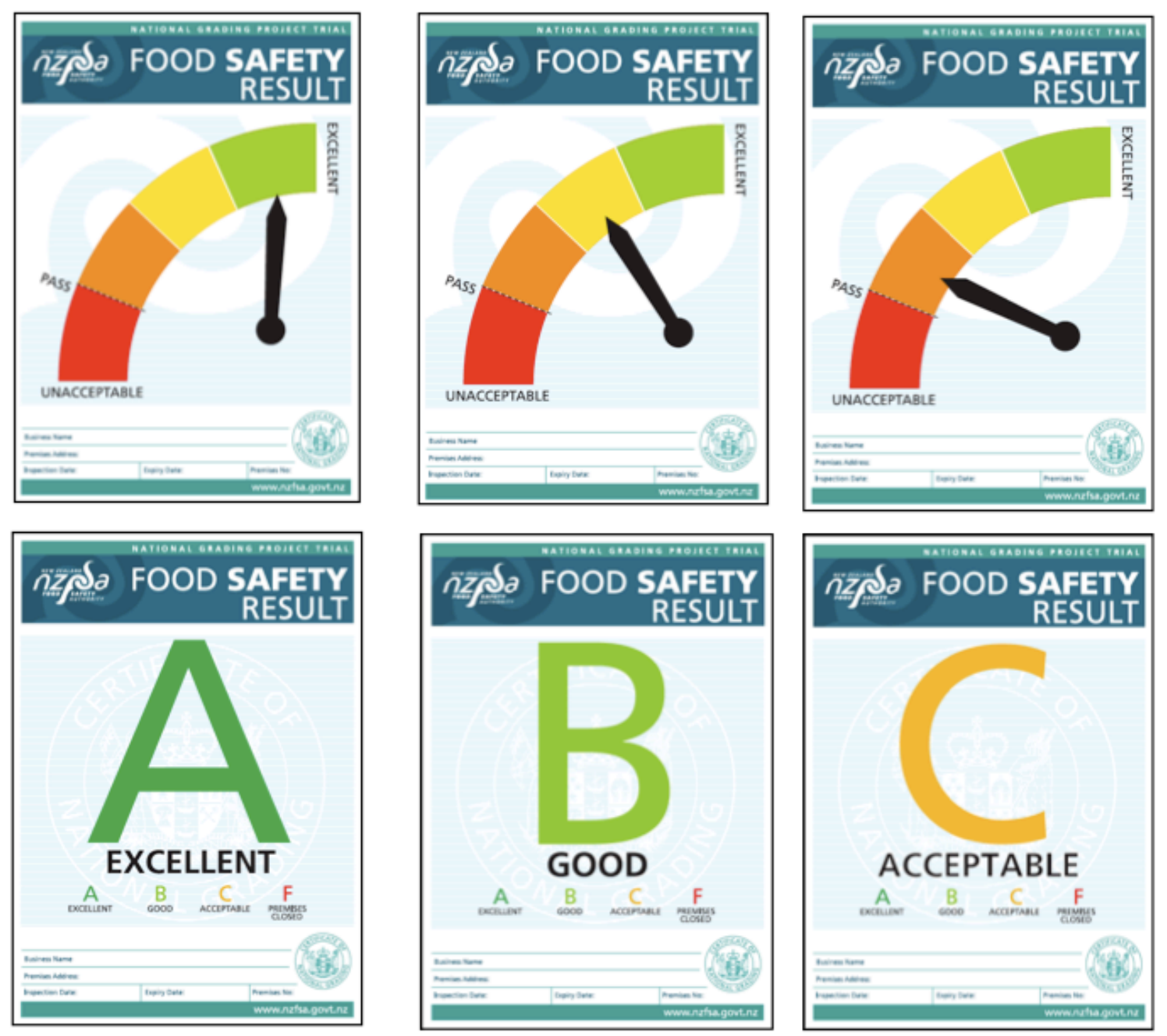

Figure 4.2 The six grade cards provided to foodservice premises during the national grading trial.

The national grading trial aimed to have involved food businesses in trial TAs display the respective card (either letter grade or gauge) at their principal entrance. The grade card assigned to premises was based on the most recent inspection conducted by the TA. Trial TAs provided the researcher with current inspection reports for all food businesses within the boundaries of the trial, and provided updated reports as new inspections were completed during the trial period. From these reports the researcher determined the appropriate grade to assign each premises.

Although theoretically based on the same food regulations, at the time of the trial inspection criteria across New Zealand was inconsistent. The level of information 
available on inspection reports varied from minimal (pass, improvements required, fail) to extensive (with listed violations and required improvements). With inspection information variable it was difficult for the researcher to ensure grading was consistent across TAs; however criteria for a grade within the TA was consistent, with only the researcher grading premises based on criteria assigned to each TA by the researcher. The researcher evaluated each of the six TA inspection reports, and categorized violations into risk categories (if this was not already done by the TA) and assigned grades based on risk of causing harm. Following grade assignment, reports were sent to TAs with premises lists and respective assigned grades. This ensured both the researcher and TA were consistent regarding grade assignment. Throughout the trial premises inspection continued as scheduled. As a premises received a new inspection report this report was forwarded to the researcher, and the researcher assigned a new grade. At the time of the trial proposal Queenstown had begun development of a grading bylaw. This bylaw had been put on hold with news of the national disclosure system, however, upon agreement to participate in the trial Queenstown requested the bylaw be used as criteria for grading Queenstown premises. The researcher used the bylaw criteria to grade premises in Queenstown. The bylaw and its criteria are available in the Appendix - Table A.7.

\section{Grade Card Display}

Ideally, card display by food businesses would have been mandatory. However, because there was no bylaw placement in TAs at this time, mandatory display was not possible for the trial. Recognizing that some premises, predominantly those with low inspection scores, were unlikely to display a card with a poor grade the researcher erred on the side of a higher grade during assignment. This is consistent with grade assignment during the beginning stages of disclosure system implementation - often grading is more lenient when initially introduced, and as premises become accustomed to the system the standard increases ${ }^{10}$.

Food businesses located within the Central Business District (CBD) of trial TAs were mailed three letters informing them of their region's participation in the national trial, its aim, duration and businesses involved (all registered food premises in the CBD).

\footnotetext{
${ }^{10}$ Correspondence with Auckland-region EHOs during national visits.
} 
Letters were mailed out within the month prior to trial start date. The third letter included the premises' assigned grade, a letter grade or gauge, and asked the business post the assigned card at the primary entrance. Letters to food businesses and information on the back of the distributed cards is available in the Appendix.

\section{Grading Trial}

The national grading trial aimed to commence January 1, 2010 and finish March 31,2010 . The trial duration was set at three months to allow significant time for the researcher to visit each of the six TAs on three occasions to collect data, and to allow sufficient time for the grade cards to be recognized by consumers and operators. The aim of the national trial was to determine which of the two potential cards, letter grade or gauge, best communicated food safety information to consumers in a compelling, trusted and clear manner; and it was seen as an incentive for operators to comply with or exceed food safety standards. With restrictions of the holiday season the trial actually began January 10, 2010, with most of the involved food businesses having received cards at this time. In total 371 premises were involved in the grading trial - 160 located in the North Island and 211 located in the South Island. These numbers are based on successful card delivery calculated at the end of the trial. Additional premises were delivered cards at the beginning of the trial, however a number of premises had closed and therefore are not included in this total. Of the 160 premises in the North Island 36 were located in Upper Hutt, 33 in Napier and 91 in New Plymouth; in the South Island 37 were located in Blenheim, 56 in Christchurch and 118 in Queenstown. Throughout the trial the researcher was contacted by a small number of premises that had either not received their grade in the mail, or had noticed grades at other businesses but had not received a grade. The researcher resolved this by contacting the TA for the business' inspection report (if missing) and mailing an assigned grade.

Semi-standardized interviews were conducted with foodservice operators/food handlers in trial districts over three periods (per trial TA) throughout the National Grading Trial. The three visits were scheduled as to be evenly distributed over the three month trial period. Intercept interviews were conducted with consumers in trial TAs on three occasions throughout the trial. Consumers were interviewed individually and classified as independent observations. Information from interviews was used to evaluate 
the effectiveness of the designed grade cards. Descriptive statistics were used to analyze responses to questions regarding grade card format, and the binomial test for statistical significance was used to analyze differences between gauge and letter grade cards. Interview questions can be found in Appendix.

\section{Grade Distribution}

Due to the varied grading criteria, grade distribution was inconsistent between the six TAs. Grade distribution (at the end of the trial) by district can be seen below.

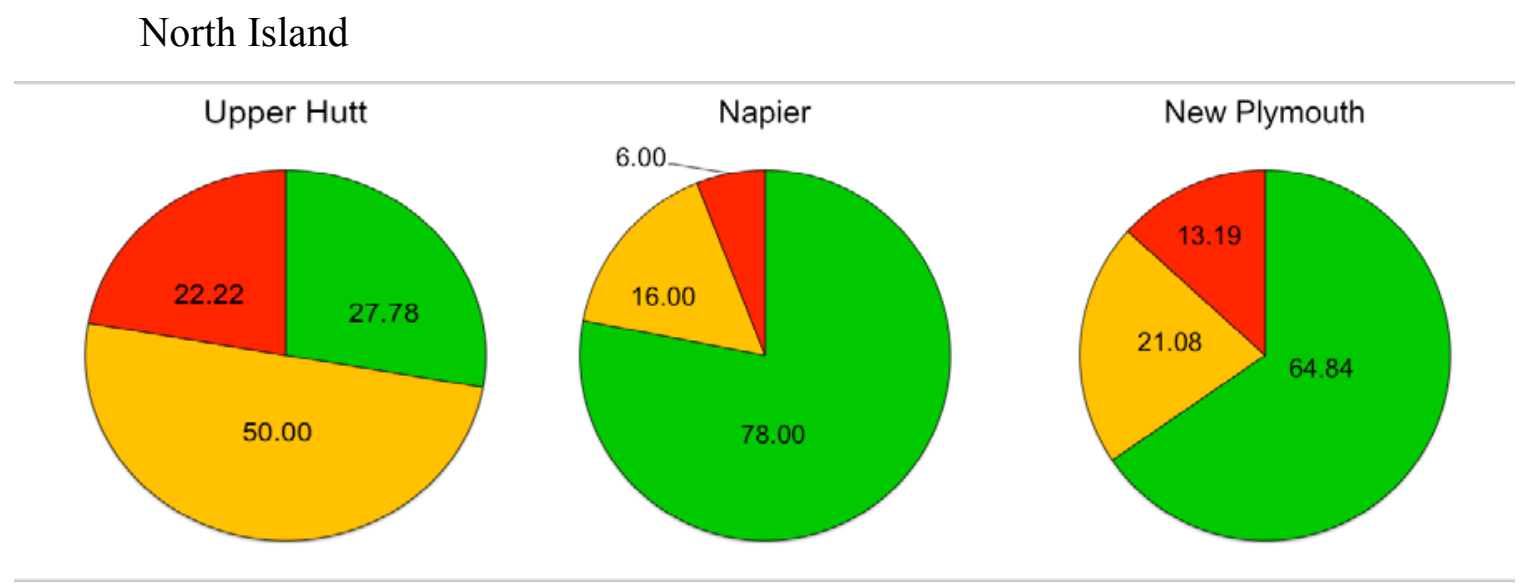

South Island
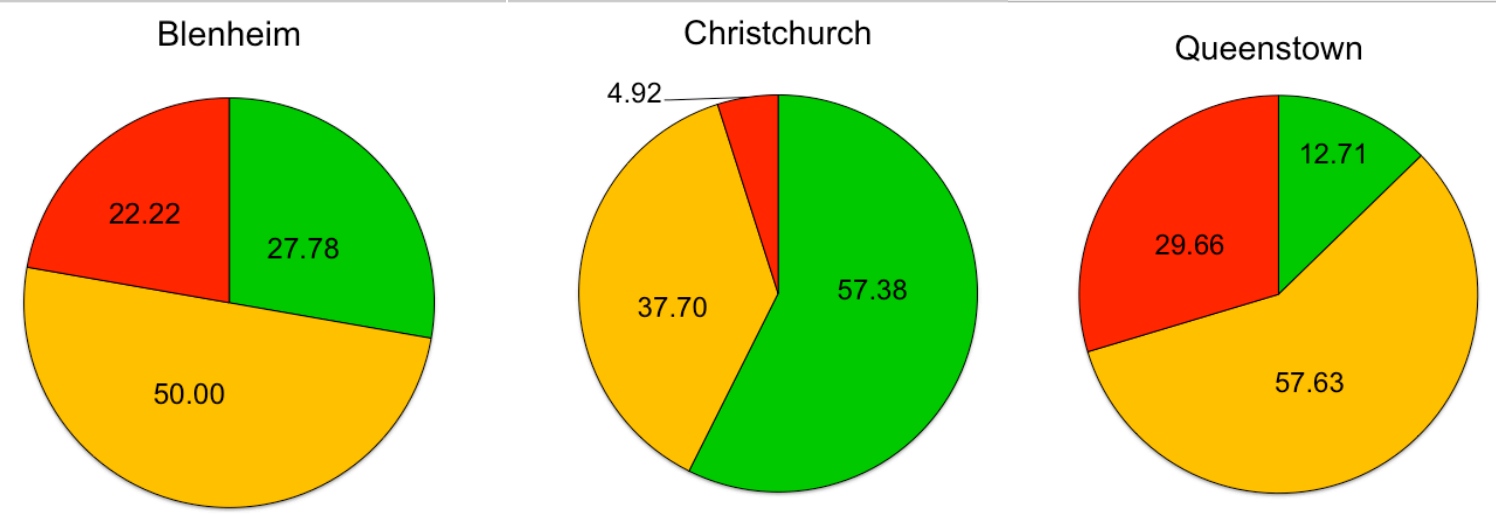

*Note: Green, amber and red represent Excellent/A, Good/B and Acceptable/C, respectively.

Figure 4.3 Grade distribution by TA at the end of the national grading trial. 


\section{Grade Display}

As with grade distribution, grade card display varied between trial TAs. This may be attributed to grade distribution and operator attitudes, as well as EHO attitudes. Throughout the trial data was collected on grade card display, with the researcher noting where or whether cards were being displayed. Due to the quantity of premises involved in the trial $(n=371)$, it was impossible to visit each premises on every visit and record where their card was displayed. For this reason, card display and location was recorded over the three visits. Display data was recorded as at the entrance, inside the premises, not displayed (operator indicated they had received the card but would not display it) or no card (operator indicated they had not received the card). Additionally, at the end of the trial when grade cards were collected (either physically or through mail-back), it was noted which premises had indicated they had not received a card but had indeed returned one - these premises were then categorized as 'not displayed.'

As initially predicted, operators receiving a high grade (Excellent/A or Good/B) were most likely to display their card at the principal entrance or inside the premises. Operators receiving lower grades were more likely to not display the card, or to indicate they had not received a card. In Figure 4.4, operators who chose to display the card at the entrance or inside the premises were combined to form the "displayed" group; while operators who chose not to display the card or indicated they had not received a card were combined to form the "not displayed" group. 


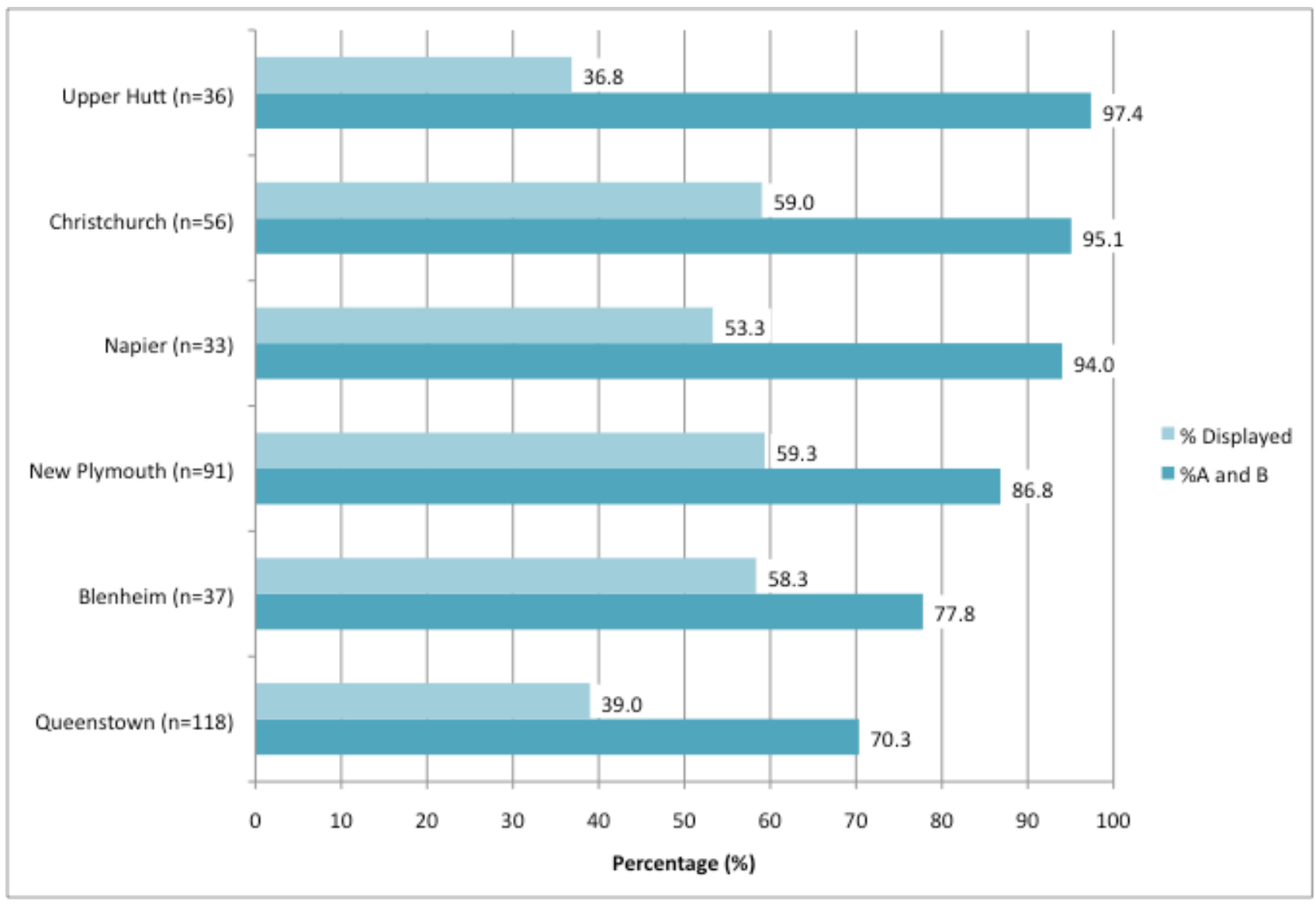

Figure 4.4 Percentage of premises achieving an Excellent/A or Good/B Card vs. percentage of premises displaying assigned card by TA.

As seen in Figure 4.4, grade distribution alone did not contribute to levels of grade display. Upper Hutt and Blenheim clearly divide from the predicted relationship. Upper Hutt, with the highest percentage of premises graded in the Excellent and Good categories at $97 \%$, had the lowest level of grade display of the six trial TAs. This may be due to both operator and EHO attitudes in this TA. Each Environmental Health Unit participating in the trial was permitted to be as involved or uninvolved in the grading trial as their schedule permitted. This was done to limit the required resources from TAs and initially to encourage participation in the trial. Upper Hutt was perhaps the TA with the least involvement in the trial, with little or no contact being made between Environment Health $(\mathrm{EH})$ and both the researcher or operators. 
Blenheim posed the opposite result; where it may have been predicted the lower grade distribution would result in low grade display levels, display levels in Blenheim were 58\% -- higher than Napier, and near identical to Chirstchurch and New Plymouth (who had greater numbers of high graded premises). In Blenheim this may be due to a proactive EH team (although with the exception of Upper Hutt all EH teams were highly invested in the grading trial), but it also may be due to operator attitudes. Operators in Blenheim did not seem to feel the grade card would impact their business the same as operators in other districts (particularly Queenstown and Napier where the grade card was seen to be more influential). This may suggest that operators in tourist-locations were more prone to see the grade as a consumer tool; or it may suggest that operators in more rural or smaller areas would not see grading as a deciding factor for their patrons. Farther research could focus on gauging operator and $\mathrm{EH}$ attitudes and the impact it has on grade card display. (see chapman, 2010, in press)

\section{Operator Attitudes}

Semi-standardized interviews provided data on operator attitudes towards the grading trial and a National Grading Scheme. Interviews were conducted at the operator's premises, during a time convenient for operators.. Operators, for the purpose of this report, refers to the duty manager or owner of a premises involved in the grading trial.

The majority of operators interviewed reacted positively to the idea of a National Grading Scheme, with most emphasizing the need for consistency throughout the inspection system. Interviews began with a brief introduction, and often a discussion of the grade allocation for that premises. As predicted, operators with Excellent/A grades were happy to discuss the card. Operators in the Good/B category were typically open to interviews, and often indicated they were content with their card, but would prefer an Excellent/A card (or aim for one in the future). Acceptable/C operators were the least likely to have an interview with, and often appeared to be put-off by the researcher's presence. For this reason it should be noted that operator interviews were mainly conducted with those in the Excellent/A or Good/B categories. 


\section{Grade Card Design and Consumer Responsiveness}

To determine how operators felt about grade card designs, and the level of consumer response to the cards, the following questions summarized in Figure 4.5 were included in the interview process.

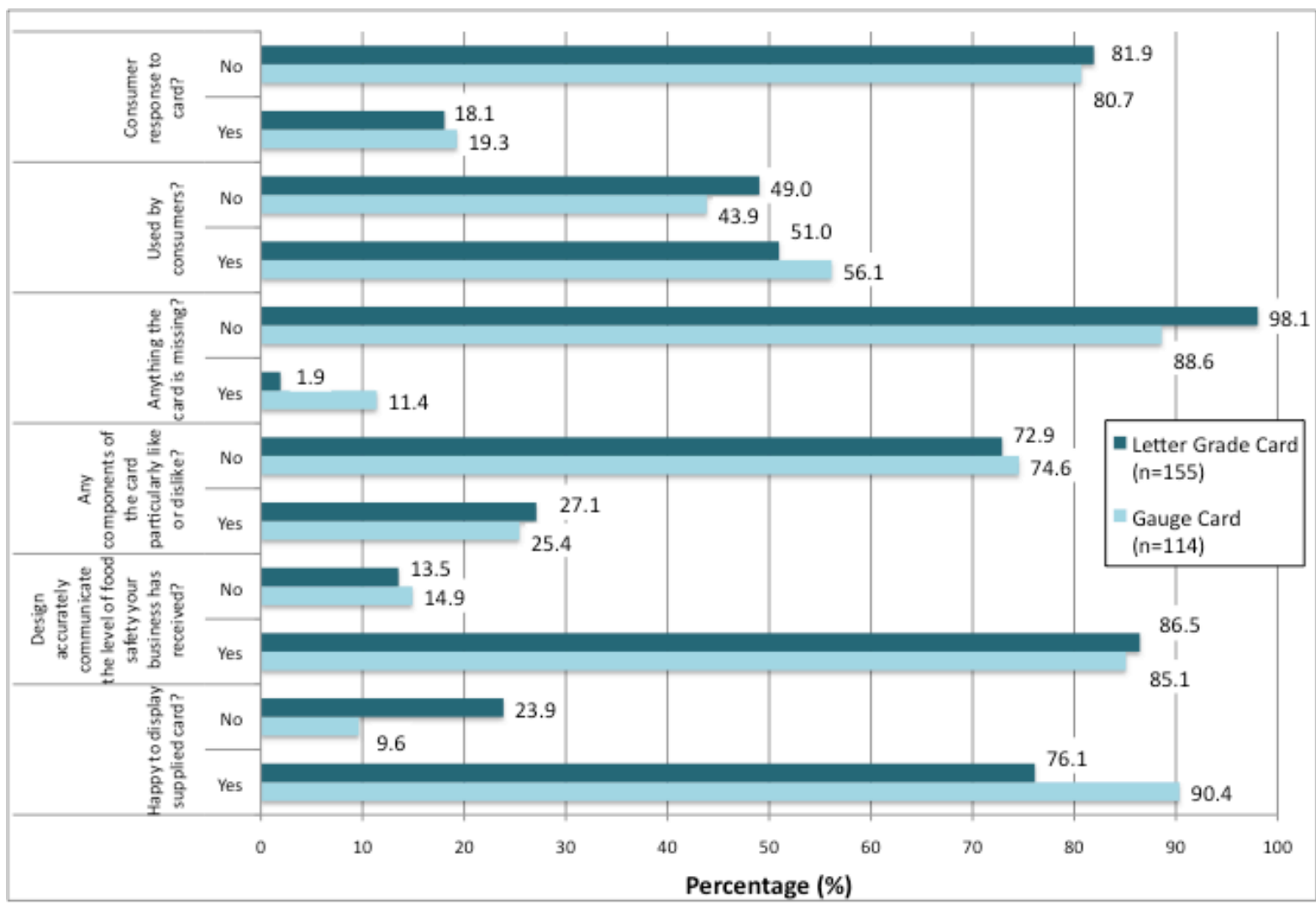

Figure 4.5 Operator responses to grade card design, and operator indication of consumer response to the card at their premises.

Over the three month duration of the grading trial 269 food service operators were interviewed, with 114 interviews conducted in the North Island (gauge card) and 155 in the South Island (letter grade). Interviews revealed that the majority of both gauge (81\%) and letter grade card (82\%) operators indicated they had not had much consumer response to the card (with no significant difference between cards, $p=0.392$ ); and often those who had response indicated it was from fellow foodservice operators. When operators were asked whether they felt consumers would use the grade cards repondents 
were divided in their thoughts - half indicating they felt consumers would use it, and half indicating they did not feel consumers would (with no significant difference between cards, $\mathrm{p}=0.263$ ). It should be noted this was a personal opinion by the operator being interviewed, and did not necessarily reflect that premises' consumer response to the card. The gauge card was seen to require more improvements than the letter $(p=0.021)$, with $11 \%$ of operators indicated they felt the gauge card required improvements (mainly to the gauge scale) while only $2 \%$ felt the letter grade required improvements. Most operators indicated they did not have any issues with the current card designs; however the previous question "Is there anything the card is missing" allowed participants to describe design improvements, and in the case of the gauge card an additional scale was suggested frequently. The letter grade card was percieved to communicate the inspection result more accurately than the gauge card $(\mathrm{p}=0.015)$. Eighty-six per cent of letter grade opeartors and $85 \%$ of gauge operators indicated they felt the resepective grade card in their district commincated inspection information accrurately. Ninety percent of operators provided with a gauge card indicated they were happy to display the supplied card; while $76 \%$ of those provided with the letter grade card made this indication, however this difference was not significant between islands $(\mathrm{p}=0.346)$. This may not be directly related to operator satisfaction with the design of the letter grade card, but rather grade distribution in some of the South Island TAs.

\section{Grade Card Placement}

Throughout the trial there appeared to be a miscommunication between where cards were ideally to be placed (principal entrance, as indicated on the back of the grade card) and where operators felt cards should be placed. A summary of operator reasoning for display location can be found in Figure 4.6 below. 


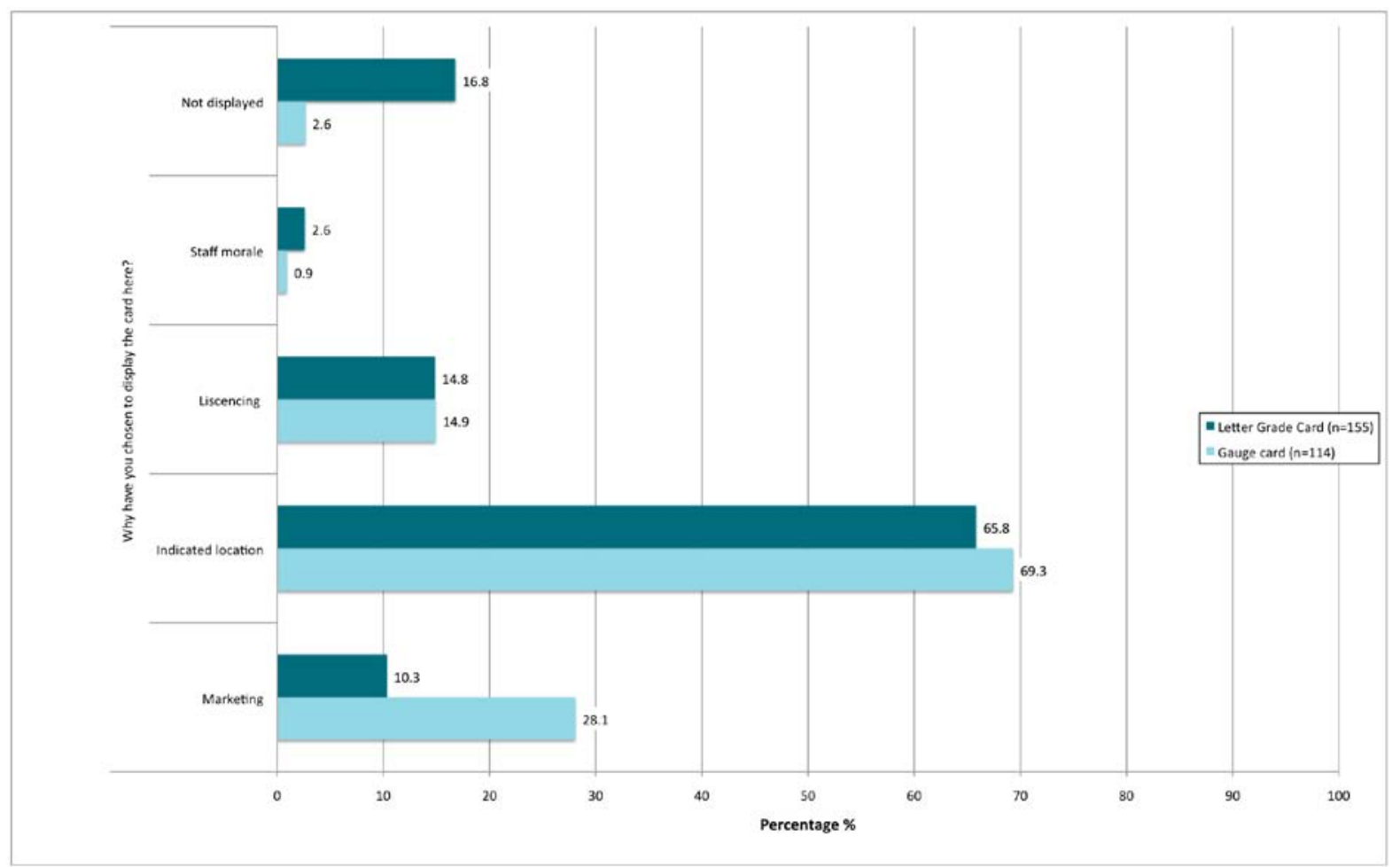

Figure 4.6 Gauge and letter grade card operator reasoning for placing grade card in the chosen location.

Operator interviews indicated that $66 \%$ of operators in the South Island and $69 \%$ of those in the North Island felt the grade card was meant to be placed inside the premises. Less than $30 \%$ of operators mentioned the benefit of using the grade card as a marketing opportunity. A substantial portion of operators (15\%) felt that the grade card was to be displayed inside next to their liscencing certificate.

\section{Consumer Interviews}

Semi-standardized intercept interviews were conducted in trial districts with consumers exiting food premises displaying a grade card (preferably at the entrance). In total 991 consumer interviews were conducted during the 3 month grading trial. In the North Island (gauge card) 467 interviews were conducted, and 524 in the South Island (letter grade card). Consumer interviews aimed to determine whether the designed grade 
cards met consumer expectations for a grading system, and whether they communicated information in a clear and compelling manner.

\section{Local and Tourist Populations}

Demographic data was not collected during interviews, however participants were asked: "Are you from this district? If no, are you from New Zealand?" This was used to determine the percentage of participants from New Zealand, and the percentage of tourists.
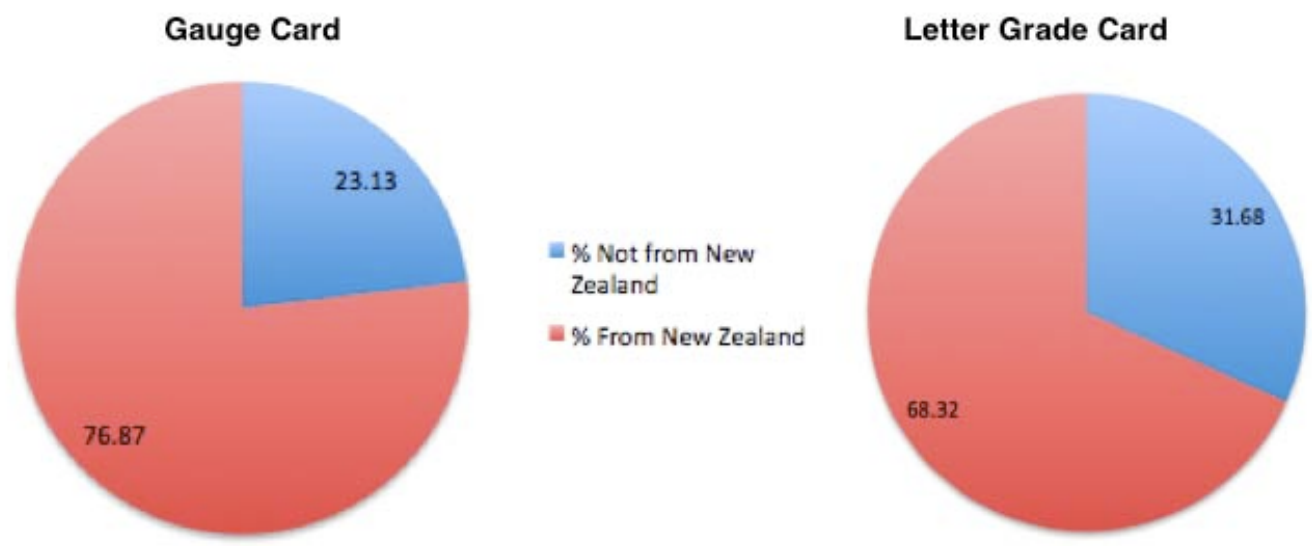

Figure 4.7 Percentage of consumers interviewed from New Zealand and overseas.

Initially it was predicted that the interviewed tourist population in the South Island district would be significantly larger than the North Island due to selected TAs in these respective islands (Napier vs. Queenstown and Christchurch); however, a visit to Napier during a popular tourist weekend appeared to provide a significant amount of tourist responses. Final data indicated the islands were not far off eachother, as seen in Figure 4.7 .

\section{Card Ability to Attract Attention}

In total 467 consumers in the North Island and 524 in the South Island participated in the grading trial intercept interviews. 174 consumers $(37 \%)$ of those in the North Island (gauge card) indicated they had noticed the card prior to entering the 
premises; while 206 (39\%) of those in the South Island (letter grade card) made this indication.

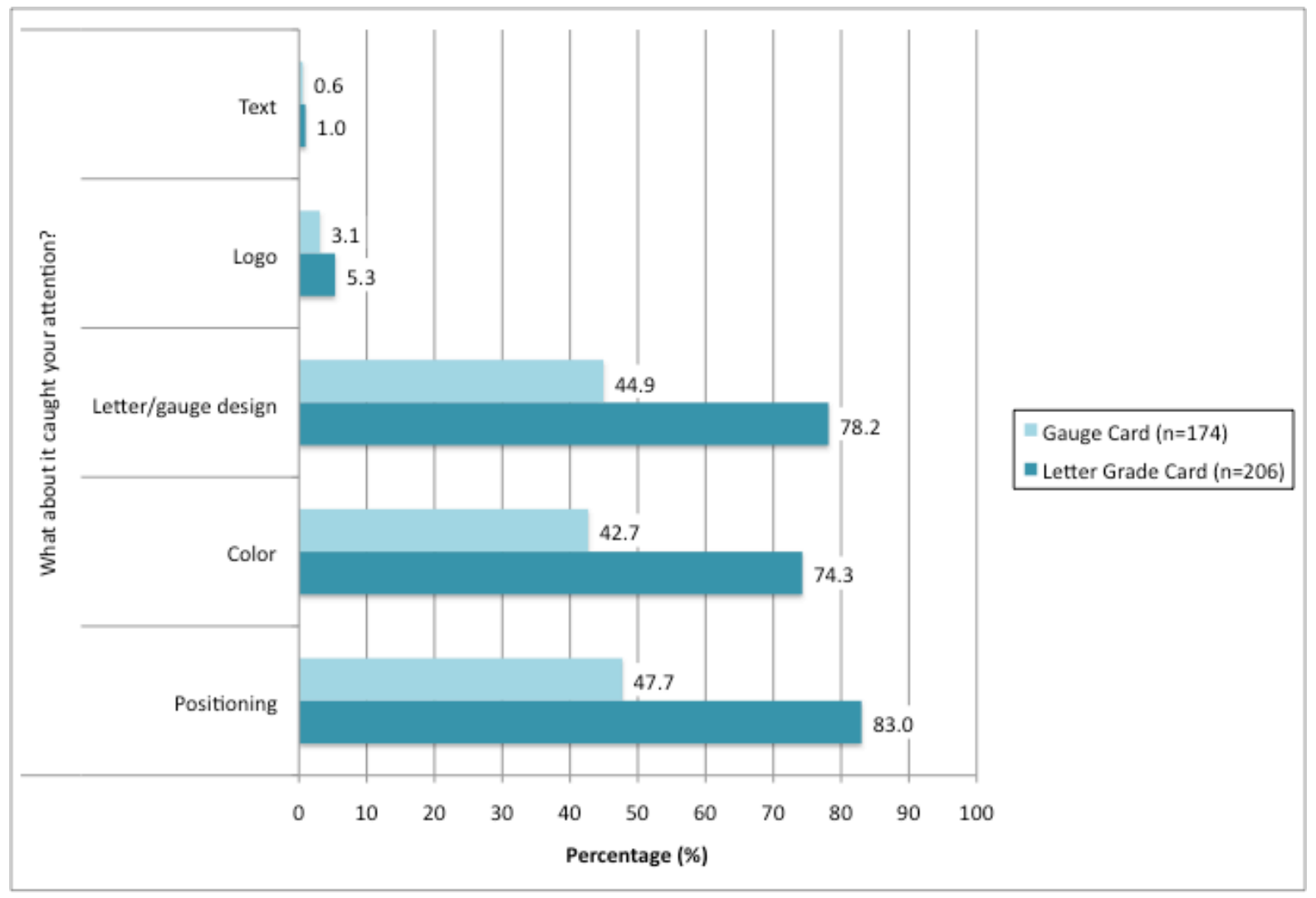

\section{Figure 4.8 Elements of the grade card that caught consumer attention by consumers who noticed the card prior to participating in interviews.}

Consumer intercept interviews suggest the letter grade design attracted more attention initially than the gauge card, with $78 \%$ vs. $45 \%(\mathrm{p}=0.00)$ of respondents selecting the card design (letter or gauge) as a contributing factor in recognizing the card. The use of color on the letter grade card was selected as a factor in attracting attention more than the gauge card $(74 \%$ vs. $43 \%$; $=0.043)$. Both consumer groups indicated location (e.g. card placed at the premises entrance, near the register, in the kitchen) was important for them to notice the card, with $47 \%$ of respondent in the North Island and $83 \%$ of those in the South Island acknowledging this; however, there was not a significant difference $(p=0.74)$ between the two islands. Few respondents incated the logo or text on the card was what drew their attention, and there was no difference $(p=1.00)$ between gauge and letter card designs for these responses. As mentioned above, only 
$37 \%$ of those in the North Island and 39\% of those in the South indicated they had noticed the card prior to entering the premises. The remainder of consumers did not notice the card until it was pointed out by the researcher.

Of the 467 participants in the North Island 293 (62.7\%) did not initially notice the card, and in the South Island 318 of 524 participants $(60.7 \%)$ did not notice the card. Participants who had not noticed the card were asked "Why do you think you didn't notice the card?", and results are summarized in Figure 4.9.

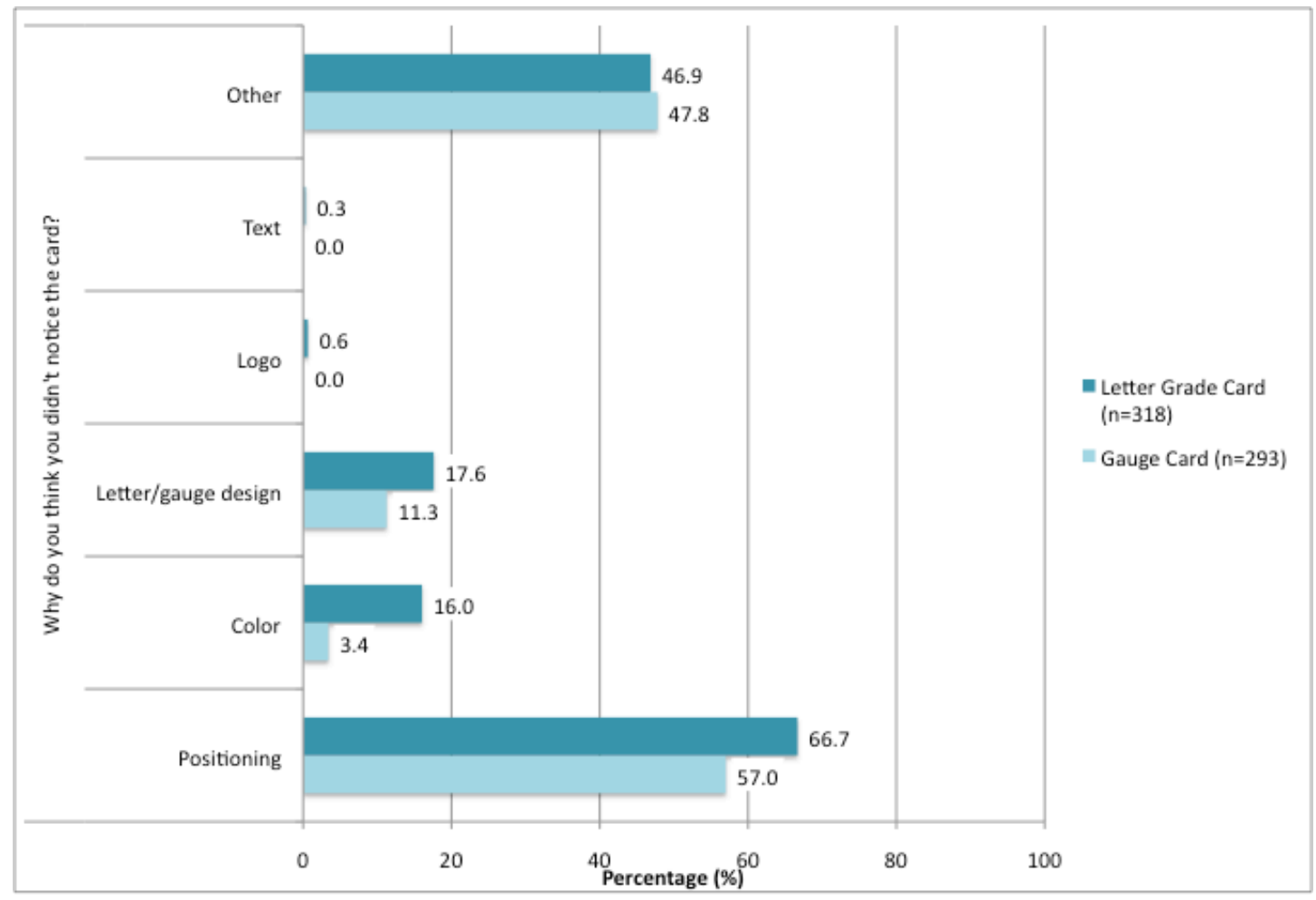

Figure 4.9 Consumer responses for card inability to attract initial attention by consumers who did not notice card prior to participating in interviews.

The results suggest that $48 \%$ of consumers in the North Island and $47 \%$ of those in the South Island indicated they did not notice the card for 'Other' reasons; these reasons often were one of the below examples:

"I didn't know there was a grading system here," or,

"I didn't know to look for a grade card" 
This may indicate the importance of promoting a grading system in districts where grade cards have not previously existed. If consumers are unaware of the grading system they will not look for the card, and the system will have less value.

Consumers who didn't notice the card indicated card color was a factor for this (3.4\% gauge, $16 \%$ letter) and respondents in letter districts indicated this more frequently than in gauge districts $(\mathrm{p}=0.00)$. The position of the card was also a contributing factor for consumers who did not recognize the card prior to entering a premises, with 57\% (North Island) and 67\% (South Island) of respondents indicating they did not notice the card because of its location. Respondents in the South Island were more likely to indicate it was the card position that contributed to them not noticing the card $(\mathrm{p}=0.028)$. This often referred to premises where the card was displayed inside, or at the entrance but in an obscure location (e.g. the bottom of a door or surrounded by menus). Consumers who noticed and did not notice the grade cards indicated position was a key factor in this. Ensuring grade card display is at the principal entrance, at eye level and unobscurred by other signage or menus is key in attracting initial consumer attention.

\section{Types of Locations for Grading}

Implementing a National Grading Scheme will be an enormous task. Grading all food businesses would only exacerbate these efforts. By asking consumers which premises they expect to find cards at NZFSA can meet consumer expectations when initially implementing the grading scheme, and consider expansion once the scheme is successful.

This section of the interview process was open-ended, asking participants "What types of locations would you look for a grade at?" and recorded data for the most popular responses (Figure 4.10). Although a small number of consumers mentioned the deli counter of grocery stores (less than 1\%) these results are not shown in Figure 4.10. 


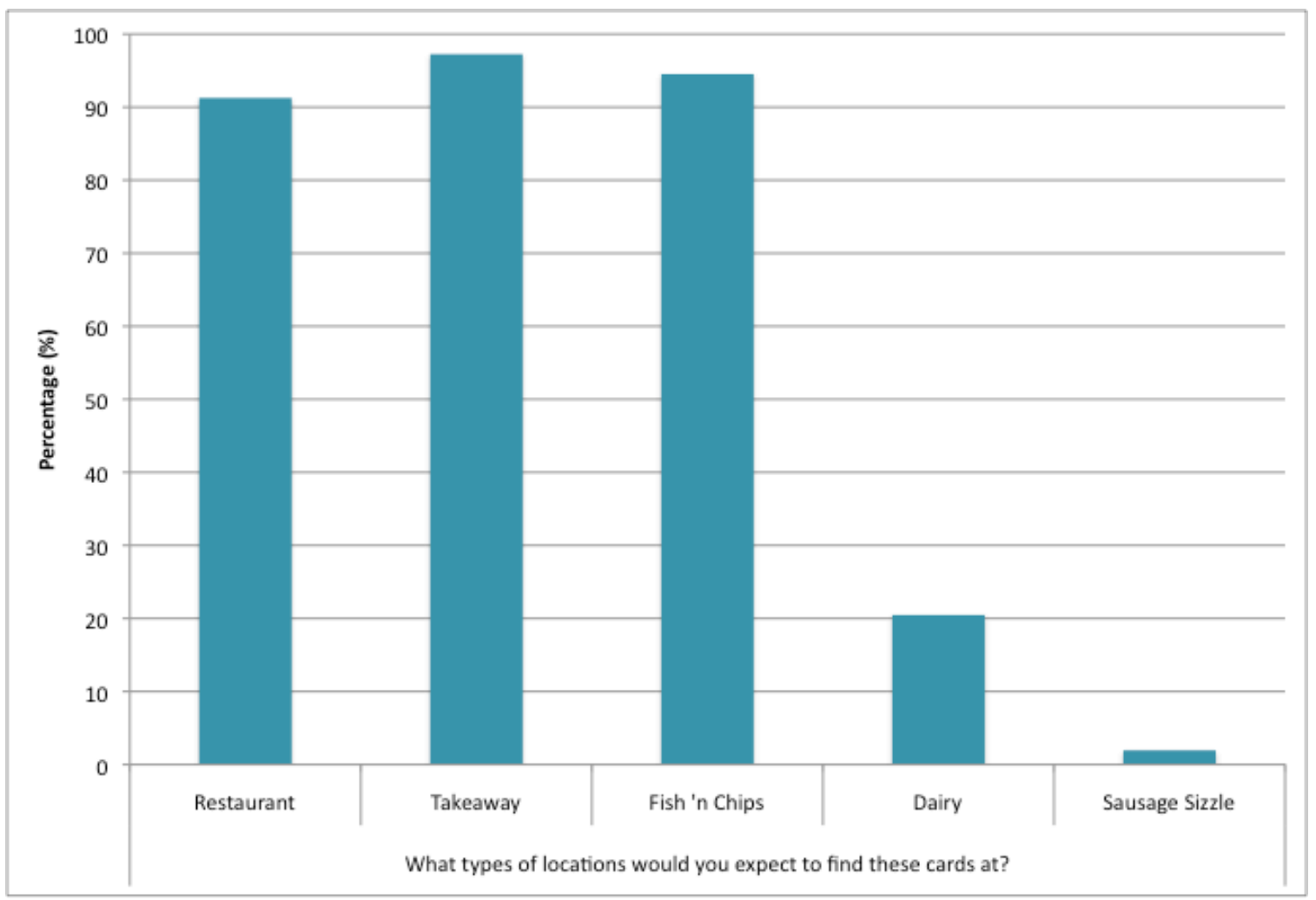

Figure 4.10 Foodservice locations consumers expect to find grade cards at.

Fig. 4.10 illustrates the majority of interviewed consumers, 91\%, 97\% and 95\%, expect to find grading cards at restaurants, take-aways and fish n' chips shops (respectively). Only $20 \%$ and $2 \%$ of interviewed consumers expected to find grading at the likes of dairies and sausage sizzles (respectively).

This may suggest that NZFSA can successfully manage consumer expectations if a grading scheme is first implemented to foodservice premises, and potentially expand to premises outside of foodservice (such as dairies or sausage sizzles) once implementation is successful.

\section{Letter Grade vs. Gauge Communication}

The main focus of the National Grading Trial was to determine which of the two, if either, prototype cards best communicated inspection results to the consumer. While other research has suggested this requires consumer education schemes, a well-designed grade card should be able to communicate the result clearly to the majority of consumers. The following table summarizes findings from interviews that attempted to ascertain how well the letter grade and gauge card conveyed this information. 


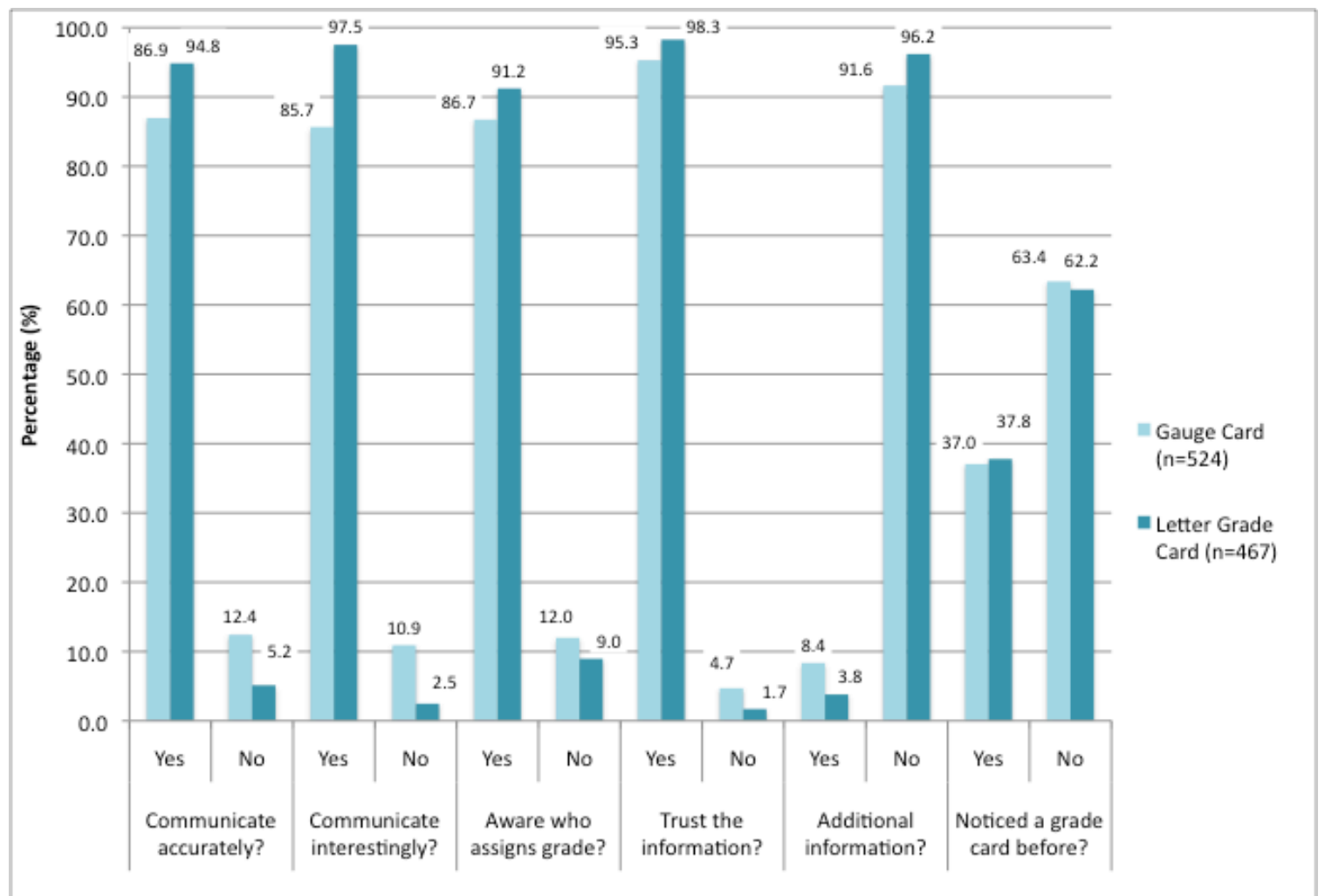

Figure 4.11 Comparing gauge and letter grade card ability to communicate food safety information.

The letter grade was perceived to communicate results of a restaurant inspection more accurately than the gauge card $(\mathrm{p}=0.002)$, with $95 \%(\mathrm{n}=467)$ of respondents in letter districts indicating this, and $87 \%(\mathrm{n}=524)$ of respondents in gauge districts indicating this. The letter grade was also perceived to communicate the inspection information in a more interesting manner than the gauge $(p=0.00)$, at $96 \%(n=467)$ versus $86 \%(n=524)$ of respondents. The letter card was perceived to communicate the role of the inspecting authority better than the gauge ( $\mathrm{p}=0.02$ ), with $91 \%$ (letter; $\mathrm{n}=467$ ) and $87 \%$ (gauge; $\mathrm{n}=524$ ) of respondents indicating they knew who (EH or NZFSA) was responsible for supplying the card. Although both card designs received high levels of trustedness, with 98\% $(n=467)$ and 95\% $(n=524)$ of letter grade and gauge card respondents (respectively) indicating they trusted the information on the card, the letter grade was perceived to be more trusted $(p=0.026)$. The letter grade card appeared to be fine as designed, while the gauge card was seen to require some improvements, with $96 \%(n=467)$ of letter grade 
respondents indicating the card was fine as is, compared with $92 \%(n=524)$ of gauge respondents $(\mathrm{p}=0.027)$. Both groups had a small percentage of respondents who indicated they had noticed a grade card prior to the interview $(38 \%, \mathrm{n}=467$ and $37 \%, \mathrm{n}=524$, letter and gauge respectively), and there was not a significant difference between letter and gauge districts $(\mathrm{p}=0.163)$.

\section{Effect on Dining Decision}

One of the primary goals of a National Grading Scheme is to provide consumers with a tool to make an informed dining decision. During the National Grading Trial consumers were asked whether or not they noticed the card at the premises, and whether or not the card did/would have influenced their decision to dine at the premises. The following summarizes the findings from the National Grading Trial.

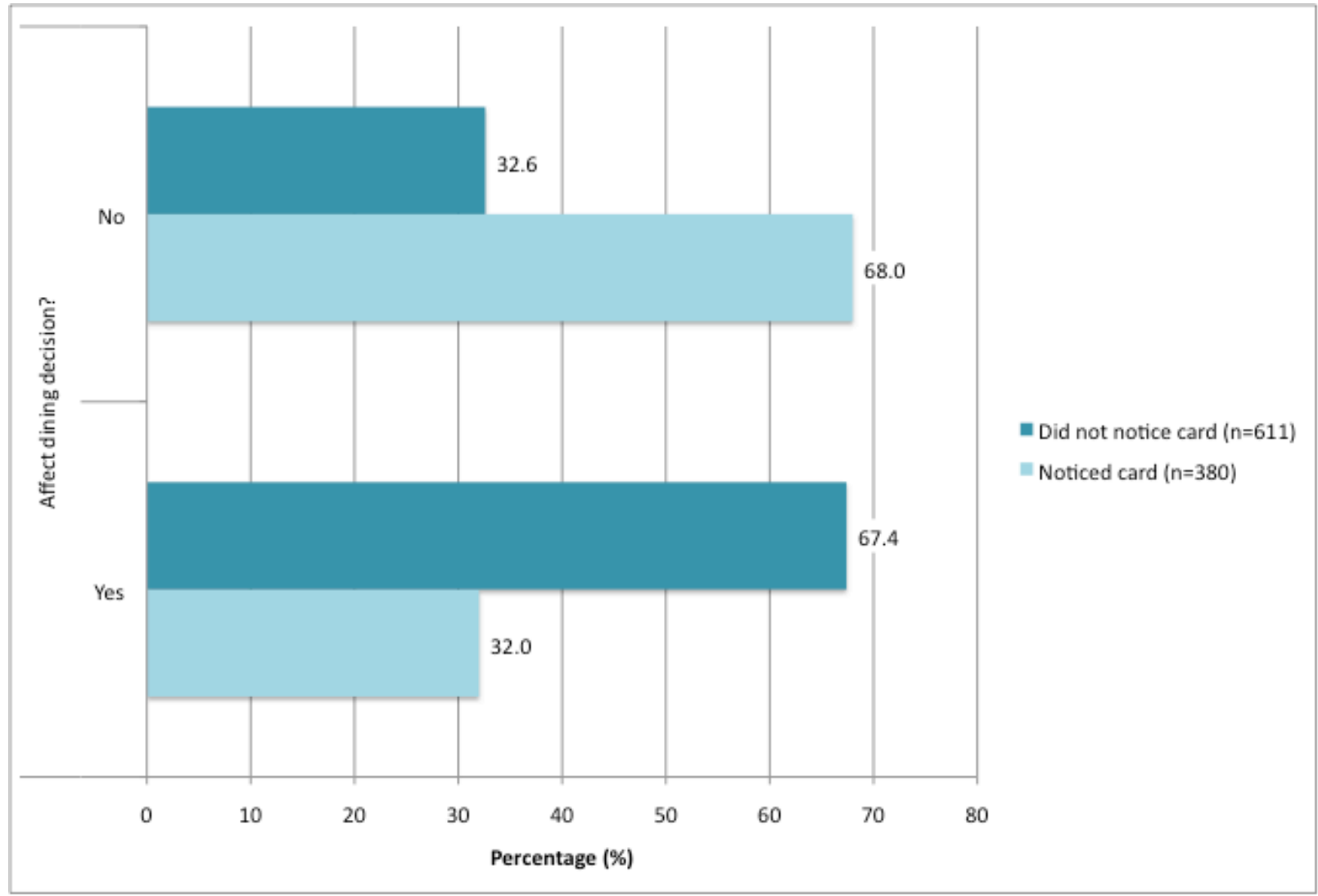

Figure 4.12 Consumer responses to grade card effect on dining decision.

Of the 991 consumers who participated in interviews, $380(38.3 \%)$ noticed the card and 611 (61.7\%) did not notice the card prior to participating in the interview. Of consumers who noticed the grade card at the premises prior to eating, 32\% said the card 
had influenced their dining decision; the remainder (68\%) indicated that although they had noticed the card it did not change their decision to eat at this location. Of those consumers who did not notice the grade card before eating at the premises $67.4 \%$ indicated it would have affected their dining decision, while the remaineder $(32.6 \%)$ indicated it would not have. For the purpose of the grading trial the majority of premises targeted for consumer interviews were Excellent/A or Good/B grades. This was done for two reasons: to avoid drawing negative attention to lower-graded premises, and because often Acceptable/C-grade premises were not displaying the provided card. This would have impacted the responses from consumers regarding dining decisions at these premises. Consumers who noticed the card typically indicated they did not pay much attention to it. Often the interview provided an opportunity for the respondent to further examine the card. Most participants who indicated they saw the card and it affected their dining decision said it only reinforced their decision to dine there (as most cards were Excellent/A or Good/B). Consumers who indicated it had not affected their decision typically indicated they simply did not pay much mind to the card.

Consumers who had not initially noticed the card but indicated it would have affected their decision typically indicated it would have reinforced their decision to dine at the location (again, most targeted premises were Excellent/A or Good/B grades). Those consumers who indicated the card would not have influenced their dining decision indicated they were eating at the premises for other reasons, whether it be cuisine, loyalty, price, etc.

\section{Grade Card Preference}

During final visits to the six trial TAs the researcher showed participants the alternate grade card design (in districts with the gauge card the researcher showed the letter card, and vice versa), asking consumer and operators which of the two cards they preferred. In the North Island (gauge card) 38 operators and 133 consumers were interviewed during final visits; and 47 operators and 161 consumers were interviewed in the South Island. Interviews suggested that the letter grade card better met both consumer $(\mathrm{p}=0.011)$ and operator expectations $(\mathrm{p}=0.00)$. Of the operators provided with the gauge card $(n=38) 58 \%$ indicated they would have preferred the letter grade card, while $79 \%$ 
$(n=47)$ of those operators provided with the letter card indicated they preferred the letter. As one operator indicated "The A is just stronger. I would be more proud to put an A up than this [gauge]." The majority $(88 \%)$ of interviewed consumers in gauge districts $(n=133)$ indicated they preferred the letter design to the gauge; and $72 \%(n=161)$ of those in letter districts preferred the letter to the gauge card. Although there appeared to be little difference in either card's ability to communicate information or attract attention at the premises, the letter grade card appeared to better meet New Zealand consumer and operator expectations for a national at-the-premises grading scheme.

\section{Interest in the Grading Trial}

\section{Media Stories in Trial TAs}

The Grading Research Project focused on the ability of potential grade cards to accurately and clearly communicate to consumers and operators a premises' food safety result in a compelling manner. For this reason media exposure on the grading trial was kept at a minimum. Participating TAs were asked to direct any media queries to the researcher, and to limit their own media exposure of the project. It was assumed that a media story about the grading project in a TA may increase consumer awareness of the

grade cards, and therefore adversely affect the researcher's ability to collect data on card recognition.

Although it was suggested media exposure be limited during the trial, New Plymouth and Queenstown local newspapers ran a story on the grading project. Both stories were run in the final month of the trial, with the Queenstown story running the week that grade cards were collected from premises. For this reason it is difficult to gauge the impact these stories may have had on consumer card awareness. Additionally, a newspaper in Christchurch ran a story post-trial explaining why the city had grade cards between January and March, 2010.

The use of local media could be used as an additional incentive for operators to increase their grade. In Queenstown after the grading story ran in the local paper highlighting a select few A graded premises, many operators commented to the researcher about why they too had not been highlighted in the story. 


\section{International Interest}

An open information exchange exists between the NZFSA and Australian Food Safety Authorities. During the development of New Zealand's National Grading Scheme, one of the Australian Food Safety Authorities, New South Wales (NSW) Food Authority, showed great interest in the project as they themselves were working to develop a regional restaurant grading scheme for their state. Following the completion of the National Grading Trial, NSW Food Authority invited the researcher and NZFSA to present findings from the trial and suggestions for NSW's development of a grading scheme. The presentation involved key findings and the preferred letter grade card format. Shortly after this visit the researcher was informed of the implementation of a new grading scheme in NSW. The designed grade card is below.

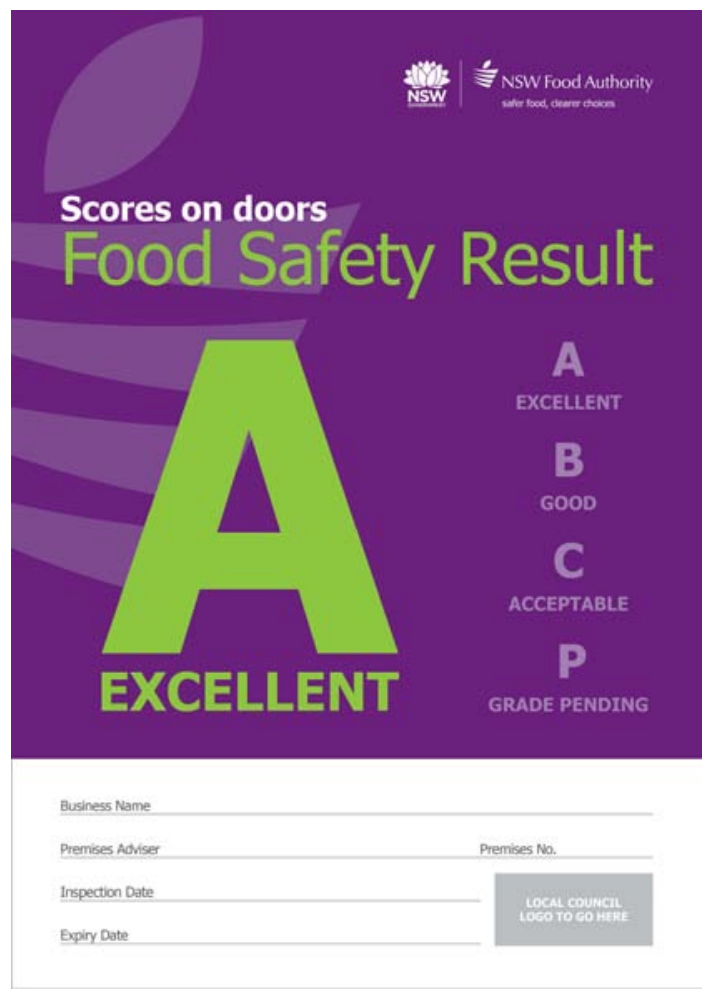

Figure 4.13 NSW Food Authority's Scores on the Doors grade card.

Prior to the meeting between NZFSA and NSW Food Authority the preferred card format was not a letter grade, but rather stars similar to the UK's Scores on Doors 
program. The letter grade card chosen resembles the NZFSA trial card in that it contains A, B, C, however the authority has changed F (Fail) to P (Grade Pending). The title of the card "Food Safety Result" and the subtitles for each category (Excellent, Good, Acceptable) remain the same as the trial cards. 


\section{Chapter 5 - Final Focus Groups and Card Redesign}

\section{Final Focus Groups}

For the purpose of the National Grading Trial, cards included the term "Fail" for lowest attainable grade on either the gauge or letter card; however, no cards were distributed in this category during the trial. This was for several reasons:

- It was assumed if a premises received a "Fail" card they would likely not display it willingly

- If a "Fail" card was awarded, under normal circumstances (depending on the TA) the premises would require immediate re-inspection, and therefore only hold the "Fail" card for a few days, making distribution of the card an unnecessary cost

Throughout discussions on grade card design, the "Fail" card was continually a point of interest. The grade cards aimed to communicate clearly at which grade level a premises failed an inspection, while indicating that this premises is making improvements. NZFSA was concerned about the impact of using the word "Fail" on the final grade card design as they felt operators would receive it negatively. Additionally, the term "Fail" was not necessarily true - these premises would have failed an inspection, however to be open they must have passed a re-inspection. Ideally the card would communicate that these premises have failed an inspection and are now operating following re-inspection with a close watch from $\mathrm{EH}$.

\section{Focus Group Format}

A final round of focus groups was conducted by Nui Pacific Ltd. ${ }^{5}$ to determine the best phrasing for the lowest grade card. Seven focus groups were conducted, structured similarly to focus groups conducted for evaluating the initial grade card designs. Focus groups contained 5 persons per group, and included individuals from the following populations:

- 2 Operator groups 
- Elderly

- Young urban

- Students/trainees

- Middle aged

- 30-somethings with young families.

During focus groups participants were given a brief introduction to the purpose of the group, indicating that NZFSA was developing a National Grading Scheme for restaurants, and four categories of grading existed, Excellent, Good, Acceptable, and the last category required a name. Twenty-eight NZFSA staff members with a vested interested in the National Grading Project were emailed to suggest terms for focus groups. Seven phrasing suggestions were made and brought to the focus groups:

- On Probation

- Conditional Operation

- Provisional Operation

- Under Scrutiny

- Caveat Emptor (enter/consumer at own risk)

- Restricted Operation

- Under Surveillance or Under Review

\section{Focus Group Findings}

It became clear early in focus group discussions that the issue was more complex than just commenting on a phrase or suggesting an alternative. Many of the phrases were initially and quickly dismissed yet as the discussion went on and respondents began to get a better understanding of the overall context there was some reconsideration. Generally throughout the discussions "on probation' was seen as the best option, with "conditional operation" and "under review" also being seen as possibilities. After much thought these options were considered.

During the seven group discussions there was a noticeable trend by respondents towards trying to gain a broader understanding when introducing the proposed phrases. "What does that mean?" or "there needs to be more of an explanation" or similar questions were raised in nearly all groups. To get the message across to patrons that an 
establishment is safe to eat at but is displaying a sub-par grade indication is counter intuitive and respondents made it clear that it needed some explanation.

Suggestions for alternative phrases were made ranging from "rules of operation" to "secondary pass." A suggestion that seemed more consumer-friendly was a food safety certificate displaying the current operating grade with a negative phrase. This way the customer clearly sees the current operating food safety standard but can see that the premises has been "on probation" with one of these phrases and an explanation underneath.

Only a few of the participants said they would trust eating at an establishment displaying a sub-par safety rating, regardless of the phrase or explanation. This seems to indicate that people would see a negative grade and their decision would be made; the task of negating the stigma of the negative grade with a small phrase seems almost impossible. But to put a current grade in context with an associated phrase and explanation is seen as more comprehendible.

\section{Selection}

The explanatory phrase cannot be viewed in isolation from the overall certificate and the given grade in particular. Respondents would first like to see that the outlet has an acceptable grade (otherwise it should not be open). Any phrase or sentence on the certificate explaining that the premises had failed but was now able to open or continue operating because it had brought itself back up to standard was secondary to this. Where an explanatory phrase or sentence was required the consensus was that this should clearly explain that the premises had failed, made improvements, but was "on probation" or "operating conditionally." On average a clear explanatory sentence was seen as better than a short and possibly ambiguous phrase.

The final decision on "F-Fail" grade phrasing remains with NZFSA. Members of different sections of the organization have suggested changing the "F-Fail" to two C's either $\mathrm{C}-$ Good or $\mathrm{C}-$ On Probation; however the researcher suggested against this, because findings from initial focus groups suggested two letter C's would be confusing, while decreasing the value of the $\mathrm{C}$ - Good grade (when compared to $\mathrm{C}$ - On probation). The researcher suggests using F - On Probation, and including an explanation notice for 
these premises. Initial focus groups found the letter D confusing (was it a pass, was it not a pass?), therefore the researcher suggests staying with F. Although F may be seen as too harsh by some members of the organization, the researcher suggests this is necessary to accurately communicate that the premises has indeed failed to meet the standard inspection criteria.

\section{Grade Card Redesign}

The National Grading Trial suggested that either of the two trial cards (gauge or letter grade) might be appropriate for a National Grading Scheme; however, the letter grade better met consumer expectations. Initial consumer focus groups indicated that inspection frequency ("Inspected $\mathrm{x}$ times per year") was a desired component of the grade card. Once the National Grading Scheme is implemented and inspection frequency is consistent nationally, this addition should be a simple task. Should NZFSA decide to use the gauge card, a few design improvements could be made to increase clarity of this card, such as incorporating scale words (Excellent, Good, Acceptable, Fail) on the gauge scale. 


\section{Chapter 6 - Study Limitations}

The various inconsistencies in the restaurant inspection process provided limitations to the research conducted in this study. Although the aim of this study was to determine which grade card design communicated inspection results to New Zealand consumers and operators in a clear, compelling and trusted manner, the backbone of the grade cards, the inspection process, lacked consistency at this time. NZFSA is working to create a nationally consistent inspection process, complete with EHO training and grade calibration, and this may prove beneficial when introducing the national grading scheme.

While preparing for the grading trial portion of the study the researcher contacted the six participating TAs for copies of their foodservice inspection reports. Although inspection reports for all New Zealand TAs have been developed based on the same food regulations, interpretations of these regulations, and areas of emphasis on inspection reports varied between districts. The researcher attempted to ensure all six TAs involved in the trial were graded similarly, however the variation in inspection data provided a challenge. Where one TA simply cited the number of violations, providing few details of the severity of an infraction, another TA provided a full list of violations and required improvements. The reseracher attempted to grade premises across the six TAs consistenty, however, it is unknown how consistent grade assignment was in actuality. The researcher did provide lists of assigned grades to TA representatives to ensure both the TA and researcher were in agreement. Additionally, for the grading trial the researcher alone was responsible for assigning grades based on a premises' inspection report. This was done to avoid inconsistencies in grade assignment, however, there is potential the researcher overlooked this as an opportunity for bias. At the time of grade assignment the researcher had not previously visited any of the food premises being graded.

Throughout the research convenience sampling was used to collect interviews from foodservice operators and consumers. The study may have been improved if a random sampling technique had been used, where the researcher randomly selected premises from a complete list of premises in the $\mathrm{CBD}$ of a district. While lower graded 
premises were not selected during the national trial, random sampling may still have been used simply by randomly selecting premises in the $\mathrm{A} /$ Excellent and $\mathrm{B} / \mathrm{Good}$ categories at random from a complete list.

Intercept interviews conducted during the national review and national grading trial used open-ended questions to collect data on grading system preferences. In the future it is recommended the researcher include rating scales ${ }^{11}$ in interview questions. By using rating scales the researcher could better analyze data regarding card communication, format and position. For example, when comparing the gauge and letter grade cards' ability to communicate information interestingly it is difficult to compare responses for the two cards because participants simply indicated yes or no to this question. Had the researcher asked "On a scale of 1 to 10 how would you rate this card's ability to communicate the information interestingly?" the data may have provided more information regarding card preference.

${ }^{11}$ A rating scale is a set of categories designed to elicit information about a perceived quality of a product, for example a 1-10 scale. 


\section{Bibliography}

Allwood PB, Lee P, Borden-Glass P (1999). The vital role of restaurant health inspections. Journal of Environmental Health 61:25-28.

Almanza AB, Ismail J, Mills J (2002). The impact of publishing foodservice inspection scores. Journal of Foodservice Business Research 5:45-62.

Auckland City Council (2007). Food grading search. Available at http://www.aucklandcity.govt.nz/council/services/foodsearch/grading.asp (accessed 15 July 2008).

Barrick R (2009). Food safety watchdog looks to restore website popularity. The Record, 10 February 2009. Available at:

http://news.therecord.com/News/Local/article/485193 (accessed 25 February 2009).

Basrur S (2003). Evaluation of the food premises inspection and disclosure system. Toronto Public Health, City of Toronto. Available at: http://app.toronto.ca/food2/pdf/food_safety_evaluation.pdf (accessed 5 June 2008).

Berg BL (2009). Focus Group Interviewing. In: Lasser J. Qualitative Research Methods For the Social Sciences, Seventh Edition. Allyn\&Bacon, Boston, MA.

Bruhn CM (1997). Consumer concerns: motivating to action. Emerging Infectious Diseases 3(4):511-515.

Center for Science in the Public Interest (2008). Dirty dining: restaurants need food safety letter grades, says CSPI. 7 August.

Centers for Disease Control and Prevention (2008). Preliminary FoodNet data on the incidence of infection with pathogens transmitted commonly through food - 10 states, 2007. Morbidity and Mortality Weekly Report 57:366-370.

Central District Health Department (2007). Inspections. Idaho Health District 4. Available at: http://www.cdhd.idaho.gov/EH/food/inspect.htm (accessed 18 July 2008). 
Cerro Gordo County (2008). 5 star program on the web. Department of Public Health. Available at: http://data.netconx.net/cghealth/default.cfm (accessed 21 August 2008).

Chapman B. (2008) Put food safety on the menu. New Zealand Food Safety Authority, Food Focus - February 2008. Available at: http:/ / www.nzfsa.govt.nz/publications/food-focus/2008-02/page-18.htm (accessed 2 June 2008).

Chapman B, Eversley T, Filion K, MacLaurin, T, Powell D (2009). Evaluating food safety infosheets by measuring behaviour change through video observation at foodservice. Journal of Food Protection (submitted).

Chapman B, Eversley T, Filion K, MacLaurin T, Powell D (2010). Assessment of food safety practices of food service food handlers (risk assessment data): Testing of a communication intervention (evaluation of tools). Journal of Food Protection 73(6):1101-1107.

Collins G (2009). Diners get a quick guide to cleanliness. The New York Times, 30 January 2009. Available at:

http://www.nytimes.com/2009/01/31/nyregion/31health.html?_r=1\&ref=nyregion (accessed 24 February 2009).

Columbus Public Health (2006). Columbus Public Health SIGNS. City of Columbus. Available at:

http://www.publichealth.columbus.gov/media/Feature_Section_Page_2.asp (accessed 21 July 2008).

Creedon SA (2003). Healthcare workers' hand decontamination practices: Compliance with recommended guidelines. Journal of Advanced Nursing 51(3):208-16. 
Cruz MA, Delores K, Swarez JA (2001). An assessment of the ability of routine restaurant inspections to predict food-borne outbreaks in Miami-Dade County, Florida. American Journal of Public Health 9:821-823.

Danbury Public Health (2010). City of Danbury, CT: Public Health Inspections. Available at: http://www.ci.danbury.ct.us (accessed 9 November 2010).

Danish Veterinary and Food Administration (2008). Smileys keep food safety high in Denmark. Ministry of Food, Agriculture and Fisheries Denmark. Available at: http://www.uk.foedevarestyrelsen.dk/Inspection/Smiley/forside.htm (accessed 18 July 2008).

DPR Online Services (2008). Licensee search. Florida Department of Business and Professional Regulation. Available at: https://www.myfloridalicense.com/wl11.asp?mode=0\&SID=\&brd=H (accessed 18 July 2008).

Dundes L \& Rajapaksa S (2001). Scores and grades: A sampling of how college students and food safety professionals interpret restaurant inspection results. Journal of Environmental Health 64:14.

Farmington Valley Health Department (2009). Ratings and inspections for local food service establishments. Available at: http://www.fvhd.org/fr_a main.asp (accessed 14 April 2009).

FDA (2000). Report of the FDA retail food program database of foodborne illness risk factors. Available at:

http://www.fda.gov/downloads/Food/FoodSafety/RetailFoodProtection/Foodborn ellnessandRiskFactorReduction/RetailFoodRiskFactorStudies/UCM123546.pdf (accessed 12 July 2009).

Fein S, Lin CT, Levy A (1995). Foodborne illness: perceptions, experience and preventative. Journal of Food Protection 58:1405-1411. 
Fielding JA, Aguirre A, Palaiologos E (2001). Effectiveness of altered incentives in a food safety inspection program. Preventative Medicine 32:230-244.

Foley T (deh.fhdutyeh@sdcounty.ca.gov). Personal communication. (2 June 2009). Implementation of restaurant grading system in San Diego County. E-mail to: Filion K (misskatiefilion@gmail.com).

Food Marketing Institute (2008). FMI Grocery shopper trends 2008: economic concerns shaping how consumers shop, cook and dine. FMI News Release. Available at: http://www.fmi.org/news_releases/index.cfm?fuseaction=mediatext\&id=935 (accessed 14 April 2009).

Food Safety Authority of Ireland (2008). Enforcement. Available at: http://www.fsai.ie/enforcement/index.asp (accessed 21 July 2008).

Gregory S \& Kim J (2004). Restaurant choice: the role of information. Journal of Foodservice Business Research 7:81-95.

Hahn MI (2000). Should inspection scores be published? [Letter to the Editor] Journal of Environmental Health 62:31.

Hatfield TH \& Siever OH (2001). Preference reversals in grading systems for retail food facilities. Journal of Environmental Health 63:19-25.

Hensen S, Majowicz S, Masakure O, Sockett P, Jones A, Hart R, Carr D, Knowles L (2006). Consumer assessment of the safety of restaurants: The role of inspection notices and other information cues. Journal of Food Safety 26:275-301.

Irwin K, Ballard J, Grendon J, Kobayashi J (1989). Results of routine restaurant inspections can predict outbreaks of foodborne illness: the Seattle-King County experience. American Journal of Public Health 79:586-590.

iTunes (2010). iPhone Application: Food Hygiene. Available at: http://itunes.apple.com/gb/app/food-hygiene/id378087298?mt=8 
(accessed 30 October 2010).

Jacob CJ \& DA Powell (2009). Where does foodborne illness happen - in the home, at foodservice, or elsewhere-and does it matter? Foodborne Pathogens and Disease (in press).

Jin GZ \& Leslie P (2003). The effect of information on product quality: evidence from restaurant hygiene grade cards. The Quarterly Journal of Economics 118:409-51.

Jones TF, Boris IP, LaFleur BJ, Ingram A, Schaffer W (2004). Restaurant inspections scores and foodborne diseases. Emerging Infectious Diseases 10:688-692.

Jones TF \& Grimm K (2008). Public knowledge and attitudes regarding public health inspections of restaurants. American Journal of Preventive Medicine 34:510-513.

Leach J (2003). A guide to customer perception of food hygiene. London: Chadwick House Publishing.

Lee M \& Middleton D (2003). Enteric illnesses in Ontario, Canada, from 1997 to 2001. Journal of Food Protection 66:953-961.

Lexington-Fayette County (2008). Restaurant inspection scores. Health Department. Available at: www.lexingtonhealthdepartment.org/ (accessed 14 April 2009).

Mobile County Health Department (2008). Mobile County Health Department restaurant ratings. Available at:

http://www.mobilecountyhealth.org/Default.asp?p='Restaurant' (accessed 21 August 2008).

Nashville Metro Public Health (2010). Metropolitan Government of Nashville and Davidson County, Tennessee: Inspections, Permits and Service Requests. Available at: http://health.nashville.gov/IPSR.htm (Accessed 9 November 2010). 
New South Wales (NSW) Food Authority. Register of Penalty Notices. Available at: http://www.foodauthority.nsw.gov.au/penalty-notices/ (accessed 26 October 2010).

New York City (2008). Restaurant inspection information. New York City Department of Health and Mental Hygiene. Available at: http://www.nyc.gov (accessed 20 June 2008).

North Carolina Administrative Code (2005). Public display of grade card. North Carolina Department of Environmental and Natural Resources, Division of Environmental Health, Environmental Health Services, T15A.18A.2603, 1 April 2005.

Norwalk Health Department (2009). Restaurant ratings. Available at: http://www.norwalkhealthdept.org/resources_restaurants.htm (accessed 14 April 2009).

Office of Environmental Health Services. Food safety. Virginia Department of Health. Available at: http://www.healthspace.ca/vdh (accessed 21 July 2008).

Olsen SJ, MacKinnon LC, Gouldin JS, Bean NH, Slutsker L (2000). Surveillance for foodborne disease outbreaks - United States, 1993-1997. Centers for Disease Control and Prevention. Mortality and Morbidity Weekly Report 49:1-51.

Powell D (2002). Communication of restaurant inspection results, public perception and the correlations between restaurant inspections and incidence of foodborne illnesses. Toronto Public Health Summary Report.

Pytka E \& Fellows L (2005). Publicly posted health inspection grade cards. Connecticut General Assembly. Available at: http://www.cga.ct.gov/2005/rpt/2005-R0403.htm (accessed on 20 April 2009).

Regional Municipality of Niagara (2007). NiagaraInfoDine. Niagara Region Public Health. Available at: http://www.regional.niagara.on.ca/government/initiatives/infodine/NiagaraInfoDine.aspx (accessed 15 July 2008).

Reske KA, Jenkins T, Fernandez C, VanAmber D, Hedberg CW (2007). 
Beneficial effects of implementing an announced restaurant inspection program. Journal of Environmental Health 69(9):27-34.

Riben PD, Mathias RG, Wiens M, Cocksedge W, Hazelwood A, Kirshner B, Pelton J (1994). Routine restaurant inspections and education of food handlers: recommendations based on critical appraisal of literature and survey of Canadian jurisdictions on restaurant inspection and education of food handlers. Canadian Journal of Public Health Suppl:1:S67-S70.

Seiver O \& Hatfield T (2000). Grading systems for retail food facilities: A riskbased analysis. Journal of Environmental Health 63:22-27.

Simon PA, Phillip L, Grace R, Jin GZ, Reporter R, Aguirre A, Fielding JE (2005). Impact of restaurant hygiene grade cards on foodborne disease hospitalizations in Los Angeles County. Journal of Environmental Health 67(7):32-36.

Spear S (2006). Scores on doors. Environmental Health Practitioner 114(6):8-10.

Teledas Co. (2004) RestaurantWatch.com. Available at: http://www.restaurantwatch.com/ (accessed 20 June 2008).

Todd EDC (1998). Foodborne and waterborne disease in Canada: annual summaries: 1992-93. Polyscience Publications, Laval, QC. Todd and colleagues (2008).

Toronto Staff Report (2002). City auditor 2002 follow-up: Review of food safety program, Toronto Public Health (June 2000). Available at: http://www.toronto.ca/legaldocs/2003/agendas/committees/h1/h1030127/it005.pdf (accessed 3 June 2008).

Williams B \& Armendariz A (2007). A recipe for trouble. San Diego UnionTribune, 22 July 2007. Available at: http://www.signonsandiego.com/news/metro/20070722-9999-lz1n22recipe.html (accessed 18 July 2008).

Wiant CJ (1999). Scores, grades and communicating about food safety. Journal of 
Environmental Health 61:37-38.

Wikipedia (2010). Academic Grading In New Zealand. Available at:

http://en.wikipedia.org/wiki/Academic grading_in_New_Zealand (Accessed 28 October 2010).

World Health Organization (2007). Food safety and foodborne illness. Available at: http://www.who.int/mediacentre/factsheets/fs237/en/ (accessed 3 June 2008).

Worsfold D (2005). Protecting consumers: a review of hygiene award schemes. British Food Journal 107(3):162-172.

Worsfold D (2006a). The Freedom of Information Act and hygiene inspection reports. British Food Journal 108:904-915.

Worsfold D (2006b). Eating out: consumer perceptions of food safety. International Journal of Environmental Health Research 16:219-229.

Worsfold D \& Worsfold PM (2008). 'Scores on Doors': hygiene disclosure schemes for consumers. Nutrition and Food Science 38:22-31.

Worsfold D \& Worsfold PM (2007). Evaluation food hygiene inspection schemes: 'Scores on Doors' in the U.K. International Journal of Consumer Studies 31:582-588. 


\section{Appendix A}

\section{National Review}

\section{Questions for EHOs in Districts Operating Inspection Disclosure Systems}

\section{Background}

Following a review of districts within New Zealand with grading systems the principal EHO (or an EHO at that district when the principal EHO was unavailable) was contacted to participate in a focus group discussion about grading systems in their districts. Session length wass scheduled for approximately 1 hour after pre-test results indicated this was appropriate. The session was audio recorded using a digital camera pending participant permission. Focus groups consisted of 2-7 participants (EHOs), and on two occasions the district contact from New Zealand Food Safety Authority (Kathryn Manning, Bob Hutchinson, or Glenys Henshaw), and the facilitator.

\section{Session format}

Brief introduction

- Graduate student at Kansas State University was working with the New Zealand Food Safety Authority collecting data on restaurant inspection disclosure in New Zealand for the development of a national grading system.

- The project phase (at the time of interviews) involved discussing any positive or negative outcomes EHOs in districts with inspection grading systems had encountered.

- The session was designed to collect honest feedback about the grading systems in these districts, and there were no incorrect responses.

\section{Questions}

Grading system implementation

- What issues have you encountered following implementation of the grading system [or award scheme/ online disclosure]?

- Cost, personnel issues, consumer demands (increased call-ins, web queries), operator demands (increased visit/ training request), media coverage?

- Do you feel the grading system at your district accurately represents the risk associated with dining at an establishment? 
- If not is this related to the inspection process (snapshot in time), or the format of the grading system?

- How does a food premise go about changing its grade and how frequently (or in what time) can it be changed? Does it cost for reinspection?

- Variations between districts?

- Do you feel grading should be a separate visit to general inspection? [If the district has grading as a separate visit, is this beneficial or a nuisance]

○ Cost, time, personnel issues with separate visits?

- Do you feel mandatory display of grades at the premise is a good approach to disclosure?

- Some districts with award schemes may have different takes on mandatory disclosure than those districts with bylaws requiring mandatory display

\section{Operator response}

- Have you had much operator feedback about the grading system? Staff feedback?

○ How do EHOs rate operator/staff attitudes for grades vs. actual operator/staff attitudes? Are there many questions, comments or concerns operators/ staff have? Increased contact with the EHO following grading implementation or a bad score?

- Do you feel the grading system has affected the relationship EHOs have with operators? If so, in what way?

○ Do EHOs feel it has created a negative relationship? And how does this compare to what operators say about the relationship?

\section{Consumer response}

- What kind of patron feedback have you received on the grading system? In what form has this feedback been received (e.g. queries at the establishment [they may not know this, but I will ask operators this as well], queries to the district council, other)

- Do consumers ask most questions at the premise or to the council? (This will help in developing tools for the disclosure system) How do most consumers ask these questions (phone, internet, at the premise)? Is most consumer response positive?

- Do you feel the grading system enhances consumer confidence in dining at restaurants in your district?

- How does this compare to what operators and consumers say?

- Are there any tools you feel would enhance consumer/operator understanding of the grading system or its process?

$\circ$ Leaflets at the premise, increased operator training, more visits etc. (In an ideal world what would EHOs feel would most benefit the grading system).

- Do you know of any other grading systems in other countries? Do you feel you feel that system better demonstrate the risk associated with dining at an establishment? If they have not heard of other systems, show examples of the Toronto coloured cards, numerical scores (NYC or Nashville example), or symbols (Danish smileys, Scores on Doors UK Star scheme). 
○ How do EHOs feel their grading system stacks up against other grading systems? Do they think they are interesting, or wouldn't be useful in New Zealand?

Concluding thoughts or questions

\section{Questions for Foodservice Operators in Districts Operating Inspection Disclosure Systems}

\section{Background}

Following the review of districts within New Zealand with grading systems, operators within these districts were contacted for a brief interview. Operators were selected from a list provided by senior EHOs in the district. The list was to provide operators from various tiers of the implemented grading system. Operators were contacted by the researcher or senior EHO prior to the interview and asked whether they were willing to participate. Participation was voluntary. The session did not record personal details of participants or their premise other than the grade-level of the premise. The interview was not recorded; rather the observer took brief anonymous notes.

\section{Session format}

Brief introduction (when the operator was contacted via phone or email)

- Graduate student from Kansas State University was working in partnership with the New Zealand Food Safety Authority on a project about restaurant inspection grading systems in New Zealand.

- There were no right or wrong answers, participation was voluntary, and the session did not take more than 15 minutes.

\section{Questions}

- Do you think the grading system in you district is something consumers look for when dining at your establishment? Has it affected business?

- What do you see as the benefits or detriments to you, an operator, of the grading system?

- Do you receive many consumer questions or comments regarding your grade? If so, how? (Prompts: telephone inquiry, inquiry at the premise)

- Do you look for the grade when you eat at other restaurants? 
- Do you think the grade accurately represents the risk associated with eating at a restaurant?

- Do you think grade display should be mandatory or voluntary?

- Do you discuss your grade with staff? Do they discuss it?

- Do you feel the grading system has affected your relationship with the EHO?

- Do you think the grading system has enhanced consumer confidence in the safety of your food?

\section{Questions for Restaurant Consumers in Districts Operating Inspection Disclosure Systems}

\section{Background}

Following a review of districts in New Zealand with grading systems, consumers within these districts were contacted via an intercept interview. Customers leaving restaurants in popular dining areas of the district were asked to answer a brief questionnaire regarding the grading system in their district. The session did not record personal details of these participants; the observer took brief anonymous notes. Participation was voluntary. Particular foodservice establishments were not targeted; rather locations were selected at random based on popular dining areas of a district and their grade. Operators of the premises consumers were leaving would not be contacted prior to intercept interviews; however, if they approached the researcher during this period the following details were explained: The consumer intercept questions did not focus on the selected food premise, rather they were evaluating the effectiveness of the grading system. Operators were not informed as to not influence the results of the consumer intercept interview. Interviews were conducted during lunch or dinner hours (peak patronage times) and noted by the researcher.

\section{Questions}

- Are you from this district? (If yes, proceed with SECTION A questions. This includes persons who work in the city but may live elsewhere. If no, proceed with SECTION B)

\section{SECTION A}

- Did you notice the grade at the premise prior to dining there? (If yes: Can you tell me what it was?) 
O In districts with award schemes (e.g. "Excellent" cards) patrons will be asked if they noticed the award card

- Has a grade influenced your decision to dine at an establishment before? Have you searched for a restaurant's grade online before (For districts with this tool)

- What types of locations do you look for grades at? (Prompts: grocery store, takeaway stand, dairy, fine dining etc.)

- Have you noticed grades [or awards] being published in the local paper? Online?

- Are you aware of what the grade means? (Prompts: what aspect of the restaurant is it referring to?)

- Does the grade enhance your confidence in the safety of food prepared in this city/district? (Should participants not know the grade represents food safety in the above question, the researcher will inform them of this, indicating the grade is based on the most recent restaurant inspection)

- How often do you believe restaurants in your district are inspected?

\section{SECTION B}

- Did you notice the grade at the premise prior to dining there?

- Did this make a difference (Prompt: Did the consumer chose to eat or not eat at a previous premise based on a grade; look online first?)

- Are you aware of what the grade at the premise represents?

- Are you from a district that has a grading system?

Table A.1 Inspection Disclosure Systems Operating in New Zealand at the Time of the National Review (July 2009).

NORTH ISLAND

\begin{tabular}{|l|l|}
\hline Far North District & No system \\
\hline Whangearei District & \begin{tabular}{l} 
Disclosure at the premise in the form of a letter grade: \\
A+(excellent plus food safety programme), A (high standard of \\
food hygiene), B+(satisfactory standard of food hygiene), \\
B(moderate standard of food hygiene) and C(unsatisfactory \\
standard-remedial work required) \\
Online database searchable by: Food premise name, street name, \\
suburb and food grade; provides information on: business name, \\
street address and grade (no full report or inspection date) \\
\hline Kaipara District
\end{tabular} \\
\hline
\end{tabular}

Auckland Regional Public Health Service 


\begin{tabular}{|l|l|}
\hline Rodney District & $\begin{array}{l}\text { Disclosure at the premise in the form of a letter grade: A (high } \\
\text { compliance), B (moderate compliance), D (not achieving a } \\
\text { satisfactory level of compliance), E (serious deficiencies in } \\
\text { compliance level) and O (pending). } \\
\text { Online documents available for download with inspection grade } \\
\text { results per ward (Rodney district is broken into different } \\
\text { areas/ward) including license, trade name, license type, location } \\
\text { (address), grade and inspection date. } \\
\text { http://www.rodney.govt.nz/EnvironmentalCare/serviceshealth/Pag }\end{array}$ \\
\hline North Shore City & $\begin{array}{l}\text { Disclosure at the premise in the form of letter grades: A (high } \\
\text { standard of food safety practices), B (satisfactory standard), C } \\
\text { (some concerns about food safety practices), D (serious concerns } \\
\text { about food safety practices) and EXEMPT (NZFSA approved } \\
\text { food safety program implemented; regularly audited by NZFSA); } \\
\text { To Be Graded (TBG) (for new premises) and No Grade } \\
\text { (NOGRAD) (not graded at this time) } \\
\text { Online database searchable by premise name, suburb, food grade } \\
\text { or street; information includes premise name, address, grade, } \\
\text { grading description, date grade achieved and licensee } \\
\text { http://www.northshorecity.govt.nz/ }\end{array}$ \\
\hline $\begin{array}{l}\text { Disclosure at the premise in the form of a letter grade: A (high } \\
\text { compliance), B (moderate compliance), D (not achieving a } \\
\text { satisfactory level of compliance), E (serious deficiencies in } \\
\text { compliance level) and Grade Pending (given to new premises); } \\
\text { Gold A (very high level of compliance; consistently safe } \\
\text { practices). } \\
\text { Online database of inspection grades } \\
\text { - able to search by premise, address, suburb or grade; includes } \\
\text { name, address, grade and inspection date } \\
\text {-only shows most recent grade; does not give details of the }\end{array}$ \\
\hline City
\end{tabular}




\begin{tabular}{|c|c|}
\hline & $\begin{array}{l}\text { inspection (e.g. McDonalds on Anderson, "B", and an explanation } \\
\text { of a "B" grade) } \\
\text { http://www.aucklandcity.govt.nz/council/services/foodsearch/defa } \\
\text { ult.asp }\end{array}$ \\
\hline Manukau City & $\begin{array}{l}\text { Disclosure at the premise in the form of a letter grade: A (high } \\
\text { compliance), B (moderate compliance), D (not satisfactory } \\
\text { compliance) and E (serious deficiencies in compliance level) } \\
\text { Online document for download according to ward, with trade } \\
\text { name, address, inspection date, grade, history (in the form of an } \\
\text { arrow indicating, upgrade, stay same or downgrade) and notes } \\
\text { http://www.manukau.govt.nz/default.aspx?id=425 }\end{array}$ \\
\hline Papakura District & $\begin{array}{l}\text { Disclosure at the premise in the form of a letter grade: A (high } \\
\text { compliance), B (moderate compliance), D (not satisfactory } \\
\text { compliance) and E (serious deficiencies in compliance level) } \\
\text { Data is not available online. }\end{array}$ \\
\hline Waitakere City & $\begin{array}{l}\text { Disclosure at the premise in the form of a letter grade: A (superior } \\
\text { standard), B (minimum statutory requirement), D (just below } \\
\text { standard) and E (well below standard) } \\
\text { Online database searchable by trade name, street name, suburb } \\
\text { and food grade; provides this same information for each restaurant } \\
\text { (e.g. just letter grade, not the full report, and no inspection date). } \\
\text { http://www.waitakere.govt.nz/CnlSer/eh/foodgrades.asp }\end{array}$ \\
\hline Franklin District & $\begin{array}{l}\text { Disclosure at the premise in the form of a letter grade: A (fewer } \\
\text { than } 5 \text { faults; no critical or repeats), B (fewer than } 10 \text { faults; no } \\
\text { critical or repeats), D (more than } 10 \text { faults; no critical and/or one } \\
\text { or more repeat faults) and E (one or more critical faults) } \\
\text { Online document for download monthly, with trade name, } \\
\text { address, area (ward) and grade } \\
\text { http://www.franklindistrict.co.nz/LinkClick.aspx?fileticket=hxwg } \\
4 \% 2 \mathrm{fMK} 0 \mathrm{os} \% 3 \mathrm{~d} \& \text { tabid=606 }\end{array}$ \\
\hline
\end{tabular}

Waikato PHU 


\begin{tabular}{|l|l|}
\hline $\begin{array}{l}\text { Thames- } \\
\text { Coromandel District }\end{array}$ & No system \\
\hline Hauraki District & No System \\
\hline Waikato District & No System \\
\hline $\begin{array}{l}\text { Matamata-Piako } \\
\text { Distrct }\end{array}$ & Letter grades: A, B, Ungraded \\
\hline Hamilton City & Excellent and Merit certificates awarded to premises \\
\hline Waipa District & No System \\
\hline $\begin{array}{l}\text { South Waikato } \\
\text { District }\end{array}$ & No System \\
\hline Otorohanga District & No System \\
\hline Waitomo District & No System \\
\hline
\end{tabular}

\section{Taranaki PHU}

\begin{tabular}{|l|l|}
\hline $\begin{array}{l}\text { New Plymouth } \\
\text { District }\end{array}$ & No System \\
\hline Stratford District & $\begin{array}{l}\text { Letter grades A, B, D, E } \\
\text { A (less than 5 faults, none critical, no repeat, with min. 50\% } \\
\text { trained staff including managers/supervisors); B (less than 10 } \\
\text { fauts, none critical, no repeat, with trained manager/supervisor); C } \\
(10 \text { faults, none critical, and/or one or more repeat faults and/or no } \\
\text { trained staff members); E (one or more critical vaults) }\end{array}$ \\
\hline $\begin{array}{l}\text { South Taranaki } \\
\text { District }\end{array}$ & No System \\
\hline
\end{tabular}

\section{Toi Te Ora PHU}

\begin{tabular}{|l|l|}
\hline Tauranga City & No System \\
\hline $\begin{array}{l}\text { Western Bay of } \\
\text { Plenty District }\end{array}$ & No System \\
\hline Rotorua & $\begin{array}{l}\text { No grading system but publishes closed premises on website } \\
\text { http://www.rdc.govt.nz/Services/EnvHealth/FoodPremises.aspx }\end{array}$ \\
\hline Kawerau & No System \\
\hline
\end{tabular}




\begin{tabular}{|l|l|}
\hline Whakatane District & No System \\
\hline Opotiki District & No System \\
\hline Taupo District & No System \\
\hline
\end{tabular}

Tairawhiti PHU

\begin{tabular}{|c|c|}
\hline Gisborne District & $\begin{array}{l}\text { A-grades and ungraded (this is being phased out with FCP } \\
\text { voluntary implementation) } \\
\text { To get the A-grade registration the applicant; } \\
\text { Must be fully aware of the risks that food may impose. } \\
\text { Have a food safety programme in place for at risk products. } \\
\text { Operate an approved cleaning programme. } \\
\text { Have at least one full year with full compliance with legislative } \\
\text { requirements. } \\
\text { Produce evidence that staff comply with the Gisborne District. } \\
\text { Food Hygiene Bylaw's training requirements. } \\
\text { A food safety plan must include: } \\
\text { A documented policy of the business to ensure sound food } \\
\text { safety. } \\
\text { Details of the processes involved in receiving, storing, preparing } \\
\text { and selling high risk food products. } \\
\text { Identify control points in the process and implement measures to } \\
\text { manage these. Includes: cleaning schedules, record keeping, } \\
\text { temperature checking, staff training, problems and rectification } \\
\text { measures. } \\
\text { To keep the A-grade registration a high standard must be } \\
\text { maintained in the premises, records kept and compliance with } \\
\text { legislative requirements met. Ongoing use of the plan must also } \\
\text { be demonstrated. }\end{array}$ \\
\hline
\end{tabular}

Napier PHU

\begin{tabular}{|l|l|}
\hline Wairo District & No System \\
\hline Hastings District & $\begin{array}{l}\text { No disclosure at the premise, but recognition of "Excellent" } \\
\text { premises. }\end{array}$ \\
\hline
\end{tabular}




\begin{tabular}{|l|l|}
\hline & $\begin{array}{l}\text { Premises that receive an "Excellent" on inspection receive an } \\
\text { additional "Excellent" card to display at the premise with the food } \\
\text { premise license; premises that do not receive an "Excellent" are } \\
\text { only required to display a food premise license. }\end{array}$ \\
\hline Napier City & No System \\
\hline $\begin{array}{l}\text { Central Hawke's } \\
\text { Bay District }\end{array}$ & No System \\
\hline $\begin{array}{l}\text { Chatham Islands } \\
\text { Council }\end{array}$ & No System \\
\hline
\end{tabular}

\section{MidCentral PHU}

\begin{tabular}{|l|l|}
\hline Ruapehu District & No System \\
\hline Wanganui Distriict & $\begin{array}{l}\text { Disclosure at the premise in the form of a letter grade: A(<5 minor } \\
\text { faults; full complement are qualified; no repeat faults; no critical } \\
\text { faults; approved cleaning schedule), B (<10 minor faults; no } \\
\text { repeat faults; full complement of staff qualified; no critical faults; } \\
\text { approved cleaning schedule), C(neither A, B, D or E grade), D(no } \\
\text { complement of staff qualified and/or a critical fault identified) and } \\
\text { E(no complement of staff qualified and/or more than one critical } \\
\text { fault) } \\
\text { Online database searchable by: Food premise name, street name } \\
\text { and food grade; provides information on: business name, street } \\
\text { address and grade (no full report or inspection date) } \\
\text { http://www.wanganui.govt.nz/services/foodgrading/index.asp }\end{array}$ \\
\hline Rangitkei District & $\begin{array}{l}\text { No System } \\
\text { No System }\end{array}$ \\
\hline Manawatu District & $\begin{array}{l}\text { Disclosure at the premise in the form of a letter grade: A } \\
\text { (Excellent, inspection score 17-20), B (Satisfactory, inspection } \\
\text { score 12-16), D (Unsatisfactory, inspection score 6-11) or E } \\
\text { (Substandard, inspection score below 6, and prosecution or } \\
\text { closure). } \\
\text { Document available for download with premise name and grade }\end{array}$ \\
\hline
\end{tabular}




\begin{tabular}{|l|l|}
\hline & $\begin{array}{l}\text { achieved, available at: } \\
\text { http://www.pncc.govt.nz/ServicesAndFacilities/EnvironmentalPro } \\
\text { tectionServices/EnvironmentalHealth/Detail.aspx?id=483 }\end{array}$ \\
\hline Tararua District & No System \\
\hline District & $\begin{array}{l}\text { Disclosure at the premise in the form of A (Risk Factor between 1 } \\
\text { and 5) or B (Risk Factor between } 6 \text { and 10); premises that receive } \\
\text { a risk factor of 11 to 15 are termed Ungraded and are required to } \\
\text { take all remedial actions within 30 working days to all further } \\
\text { inspection; if no improvement premise will be closed until all } \\
\text { remedial actions are taken; No grade (new premises are not } \\
\text { graded during their first period open). Additionally, award } \\
\text { scheme: "Merit premises" are those premises that have a record } \\
\text { with the Council that shows they are consistently maintaining } \\
\text { excellent food safety standards } \\
\text { No online disclosure. }\end{array}$ \\
\hline
\end{tabular}

Regional Public Health

\begin{tabular}{|l|l|}
\hline Kapiti Coast District & $\begin{array}{l}\text { Disclosure at the premise in the form of A (Excellent), B (Good), } \\
\text { D (Poor), E (Closure or prosecution likely) or N (New owner). } \\
\text { No online disclosure. }\end{array}$ \\
\hline Masterton District & No System \\
\hline Caterton District & No System \\
\hline $\begin{array}{l}\text { South Wairarapa } \\
\text { District }\end{array}$ & No System \\
\hline Upper Hutt City & No System \\
\hline Porirua City & $\begin{array}{l}\text { Excellent and Very Good certificates are provided but are not } \\
\text { required to be displayed. }\end{array}$ \\
\hline Wellington City & $\begin{array}{l}\text { No disclosure at the premise, but recognition of "Excellent" } \\
\text { premises. Premises are inspected and termed "Excellent" (Score at } \\
\text { least } 4 \text { in } 3 \text { of } 4 \text { risk factor categories and a } 5 \text { in at least 1 of } \\
\text { them), "Very good" or "Ungraded"; new premises are not graded }\end{array}$ \\
\hline
\end{tabular}




\begin{tabular}{|l|l|}
\hline & $\begin{array}{l}\text { until operating for 3 months. Premises that receive an "Excellent" } \\
\text { on inspection receive an additional "Excellent" card to display at } \\
\text { the premise with the food premise license; premises that do not } \\
\text { receive an "Excellent" are only required to display a food premise } \\
\text { license. } \\
\text { No online disclosure. }\end{array}$ \\
\hline Hutt City & $\begin{array}{l}2 \text { stage grading scheme (A-grades and Ungraded) } \\
\text { The majority of the A grade premises dealing in food service are } \\
\text { gradually being signed up for a FCP. } \\
* \text { Standard application form for an A grade certificate which } \\
\text { outlines the qualifying conditions found in email or hard copy. }\end{array}$ \\
\hline
\end{tabular}

\section{SOUTH ISLAND}

Nelson PHU and Marlborough PHU

\begin{tabular}{|l|l|}
\hline Tasman District & No System \\
\hline Nelson City & No System \\
\hline $\begin{array}{l}\text { Marlborough } \\
\text { District }\end{array}$ & No System \\
\hline
\end{tabular}

Community and Public Health

\begin{tabular}{|l|l|}
\hline Buller District & Letter grade system: A, B, D, E \\
\hline Grey District & $\begin{array}{l}\text { Disclosure at the premise in the form of letter grades (on } \\
\text { registration certificate): A (5 or less minor faults) B (more than 5 } \\
\text { but less than 10 minor faults) D (more than 10 minor faults) E (1 } \\
\text { or more critical faults; may elicit closure) } \\
\text { No online disclosure. }\end{array}$ \\
\hline Kaikoura District & No System \\
\hline Hurunui District & No System \\
\hline Selwyn District & No System \\
\hline Waimakariri District & No System \\
\hline
\end{tabular}




\begin{tabular}{|l|l|}
\hline Christchurch City & No System \\
\hline Ashburton District & $\begin{array}{l}\text { Disclosure at the premise in the form of letter grades: A } \\
\text { (excellent) B (good) D (ungraded) E (ungraded high risk) } \\
\text { No online disclosure. }\end{array}$ \\
\hline Westland District & No System \\
\hline Mackenzie District & No System \\
\hline Timaru District & No System \\
\hline Waimate District & No System \\
\hline
\end{tabular}

Public Health South

\begin{tabular}{|l|l|}
\hline $\begin{array}{l}\text { Queenstown Lakes } \\
\text { District }\end{array}$ & No System \\
\hline $\begin{array}{l}\text { Central Otago } \\
\text { District }\end{array}$ & No System \\
\hline Waitaki District & No System \\
\hline Dunedin City & $\begin{array}{l}\text { Letter grades A, B, C, and D } \\
\text { A 'Excellent' (inspection score between 20-17); B 'Good' (score } \\
\text { between 16-14); C 'Acceptable Grade' (score 12-13); D 'Poor' } \\
\text { (score 11-0) } \\
\text { Note: If Conduct score + Cleaning and Sanitizing is =<4 then } \\
\text { Training score automatically =0; if manager or supervisor is not } \\
\text { trained max rating is 3. } \\
\text { To receive Excellent must score at least 4 in each category. } \\
\text { To receive Good must score at least 3 in each category. }\end{array}$ \\
\hline Southland District & No System \\
\hline Gore District & No System \\
\hline Clutha District & No System \\
\hline Invercargill City & No System \\
\hline
\end{tabular}

Table A.2. Summary of EHO Interviews Conducted in New Zealand TAs Already Operating Disclosure Systems 


\begin{tabular}{|c|c|}
\hline Question & Response \\
\hline \multicolumn{2}{|c|}{ Disclosure System Implementation and Operation } \\
\hline $\begin{array}{l}\text { What issues have you } \\
\text { encountered following } \\
\text { implementation of the } \\
\text { grading system [or award } \\
\text { scheme/ online disclosure]? }\end{array}$ & $\begin{array}{l}\text { Consumer demand } \\
\text {-TV show (Target) and media coverage (of Auckland } \\
\text { system) has increased consumer demand for more } \\
\text { information (e.g. want a searchable online tool) } \\
\text {-Receive a lot of calls into the council, mainly about a } \\
\text { grade not being displayed } \\
\text { Staff Training } \\
\text {-Creating consistent grade assignment so disclosure the } \\
\text { system is trusted }\end{array}$ \\
\hline $\begin{array}{l}\text { Do you feel the grading } \\
\text { system at your district } \\
\text { accurately represents the } \\
\text { risk associated with dining } \\
\text { at an establishment? }\end{array}$ & $\begin{array}{l}\text {-Districts work towards training EHOs to assign consistent } \\
\text { grades, therefore grades accurately represent what the } \\
\text { criteria is based grades on; however, grading criteria may } \\
\text { take into account aspects of the business that do not } \\
\text { necessarily represent a food safety risk (e.g. in Wellington } \\
\text { City cannot get a Very Good unless a recognized training } \\
\text { program has been completed) }\end{array}$ \\
\hline $\begin{array}{l}\text { How does a food premise } \\
\text { go about changing its grade } \\
\text { and how frequently (or in } \\
\text { what time) can it be } \\
\text { changed? Does it cost for } \\
\text { reinspection? }\end{array}$ & $\begin{array}{l}\text {-Minimum amount of time before premises can request } \\
\text { reinspection (2-3 months), however this is dependent on } \\
\text { the grade issued (e.g. in Dunedin if a D is issued it must be } \\
\text { visited within } 72 \text { hours) } \\
\text {-Apply for re-grade and typically pay a reinspection fee }\end{array}$ \\
\hline $\begin{array}{l}\text { Do you feel grading should } \\
\text { be a separate visit to } \\
\text { general inspection? [If the } \\
\text { district has grading as a } \\
\text { separate visit, is this } \\
\text { beneficial or a nuisance?] }\end{array}$ & $\begin{array}{l}\text {-No, it would take too much personnel time and in the end } \\
\text { be an additional cost to the operator }\end{array}$ \\
\hline Do you feel mandatory & -Agree it should be mandatory, otherwise the low grades \\
\hline
\end{tabular}




\begin{tabular}{|c|c|}
\hline $\begin{array}{l}\text { display of grades at the } \\
\text { premise is a good approach } \\
\text { to disclosure? }\end{array}$ & won't/don't get displayed \\
\hline \multicolumn{2}{|l|}{ Operator Response } \\
\hline $\begin{array}{l}\text { Have you had much } \\
\text { operator feedback about the } \\
\text { grading system? Staff } \\
\text { feedback? }\end{array}$ & $\begin{array}{l}\text {-Operator demand for consistency in grade assignment } \\
\text {-Operator feedback is related to disclosure system } \\
\text { requirements - where mandatory display is present there is } \\
\text { more of an incentive for operators therefore more feedback }\end{array}$ \\
\hline $\begin{array}{l}\text { Do you feel the grading } \\
\text { system has affected the } \\
\text { relationship EHOs have } \\
\text { with operators? If so, in } \\
\text { what way? }\end{array}$ & $\begin{array}{l}\text {-Perhaps when initially introduced, but not long-term } \\
\text {-Some stress with EHOs in the beginning with having to } \\
\text { assign a grade, and consistency between EHOs }\end{array}$ \\
\hline $\begin{array}{l}\text { What do you see as the } \\
\text { benefits of grading for } \\
\text { operators? }\end{array}$ & $\begin{array}{l}\text {-Lower fees in some districts } \\
\text {-Tool for their own staff (can clearly see the standards and } \\
\text { consequences of going below them) } \\
\text {-Marketing opportunity for those doing a good job }\end{array}$ \\
\hline \multicolumn{2}{|l|}{ Consumer Response } \\
\hline $\begin{array}{l}\text { What kind of patron } \\
\text { feedback have you received } \\
\text { on the grading system? In } \\
\text { what form has this } \\
\text { feedback been received } \\
\text { (e.g. queries at the } \\
\text { establishment, queries to } \\
\text { the district council, other) }\end{array}$ & $\begin{array}{l}\text {-Consumer feedback is more noticed in districts with } \\
\text { mandatory display or where media coverage is present (e.g. } \\
\text { newspapers publish weekly reports) } \\
\text {-Most consumers call the council with an issue }\end{array}$ \\
\hline $\begin{array}{l}\text { Do you feel the grading } \\
\text { system enhances consumer } \\
\text { confidence in dining at } \\
\text { restaurants in your district? }\end{array}$ & $\begin{array}{l}\text {-Yes, it can be a good visual indicator for consumers, but it } \\
\text { should be made clear this is only a snapshot in time } \\
\text { (districts with mandatory display) } \\
\text { OR } \\
\text {-No, not many consumers are aware there is a grading }\end{array}$ \\
\hline
\end{tabular}




\begin{tabular}{|l|l|}
\hline & system (districts with voluntary display) \\
\hline Are there any tools you feel & -Clarifying the inspection and grading criteria may help \\
would enhance & -Providing more information on a website \\
consumer/operator & \\
understanding of the \\
grading system or its \\
process?
\end{tabular}




\section{Grade Card Design}

\section{Letter to Operators Located on the Back of Trial Grade Cards}

\section{New Zealand Food Safety Authority National Grading Project Trial}

Please display this card conspicuously at the principal entrance in full view and unobscured for the duration of January 1, 2010 to March 31, 2010. After March 31, 2010 this card is no longer valid, and must be removed from the premises.

This card represents the Food Safety Result for the foodservice business at the indicated address on the front of this card. This Food Safety Result is based on the premise's most recent food hygiene inspection (or audit for FCP premises) as completed by the local council.

If you are dissatisfied with the provided Food Safety Result your premises has received you may choose to be re-inspected, however the following should be noted:

Re-inspection is voluntary. To arrange a re-inspection contact your city council. A re-inspection fee will be charged in accordance with the usual fees and charges rates for your council. The timeframe for re-inspection will be conducted as soon as reasonably possible, as determined by the council taking into account other workload demands.

If the premise for which this card belongs is scheduled for an inspection (or audit) within the trial period, a new Food Safety Result will be provided to the premise to replace the current card. It is requested that the old card be returned, and the new card displayed.

This certificate remains the property of the New Zealand Food Safety Authority. If there are any questions or comments about the National Grading Project Trial, or the conditions of this card, please visit: www.nzfsa.govt.nz, or contact:

Katie Filion

Project Manager, NZFSA National Grading Project Trial misskatiefilion@gmail.com 
Table A.3 The 18 Initial Prototype Grade Card Designs and General Feedback from NZFSA and Kansas State University Survey Respondents.

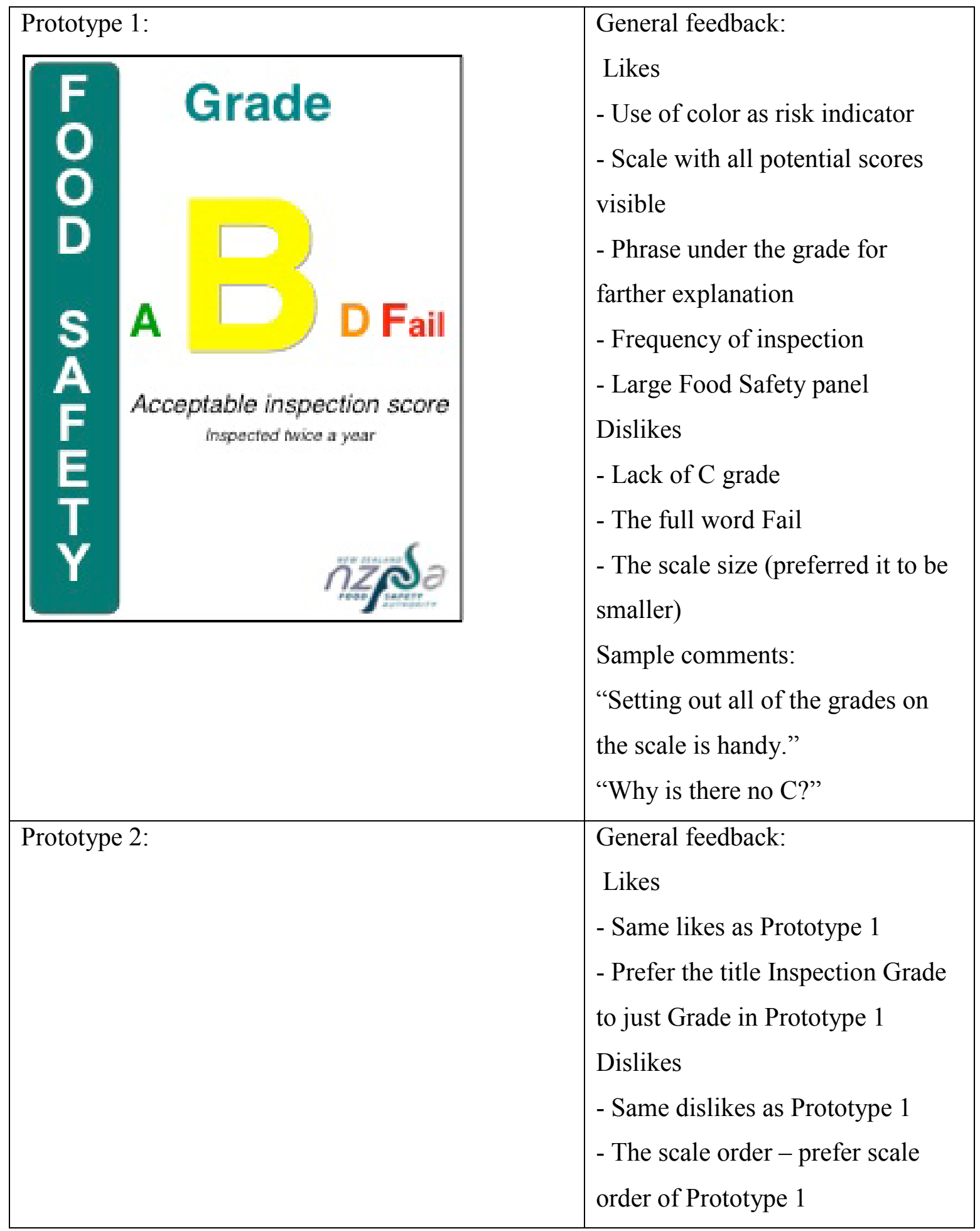




\begin{tabular}{||l|l|}
\hline Grade & - The arrow \\
Sample comments: \\
"The reverse order of the grades is \\
confusing." \\
“The arrow makes it too busy."
\end{tabular}




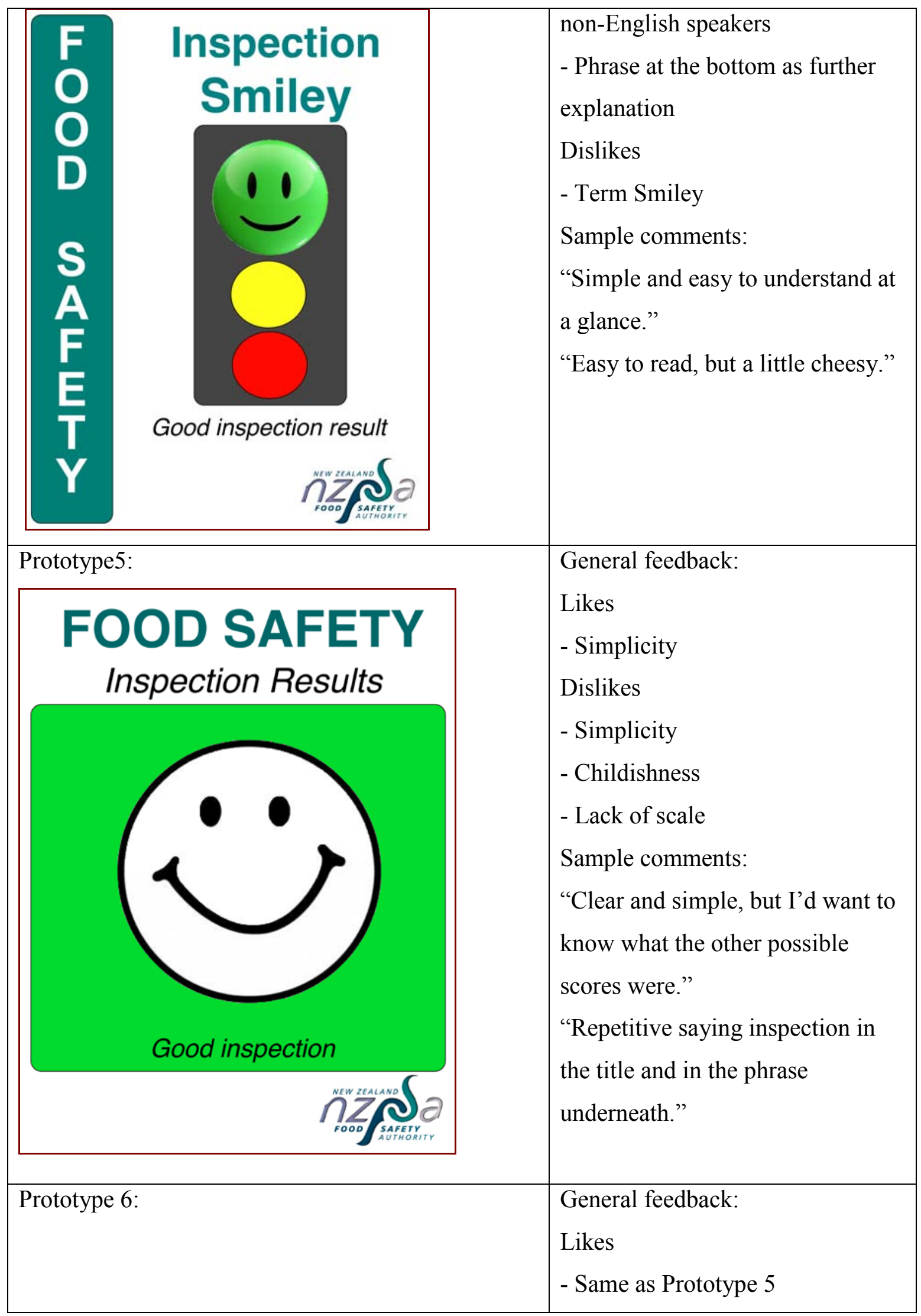




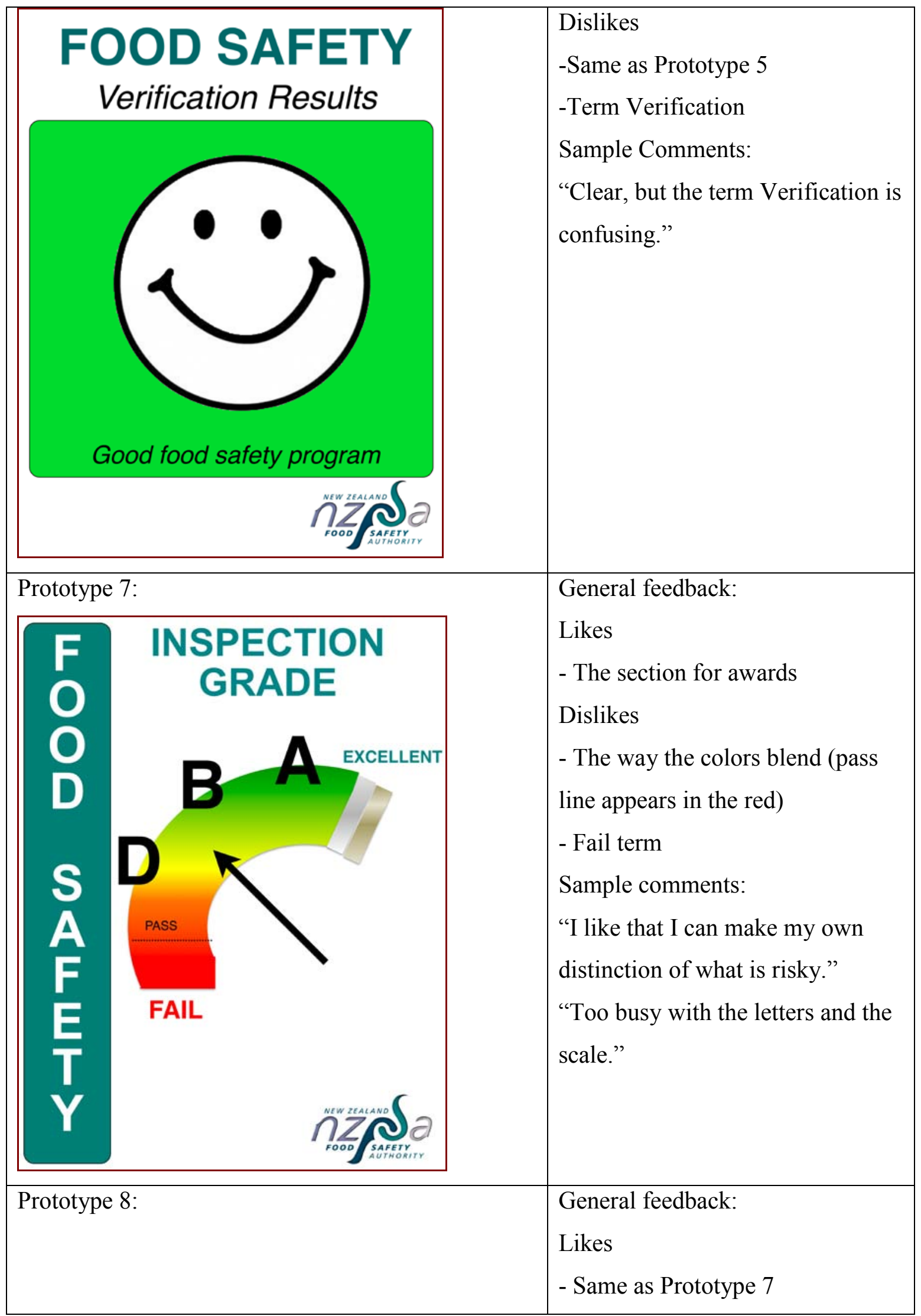




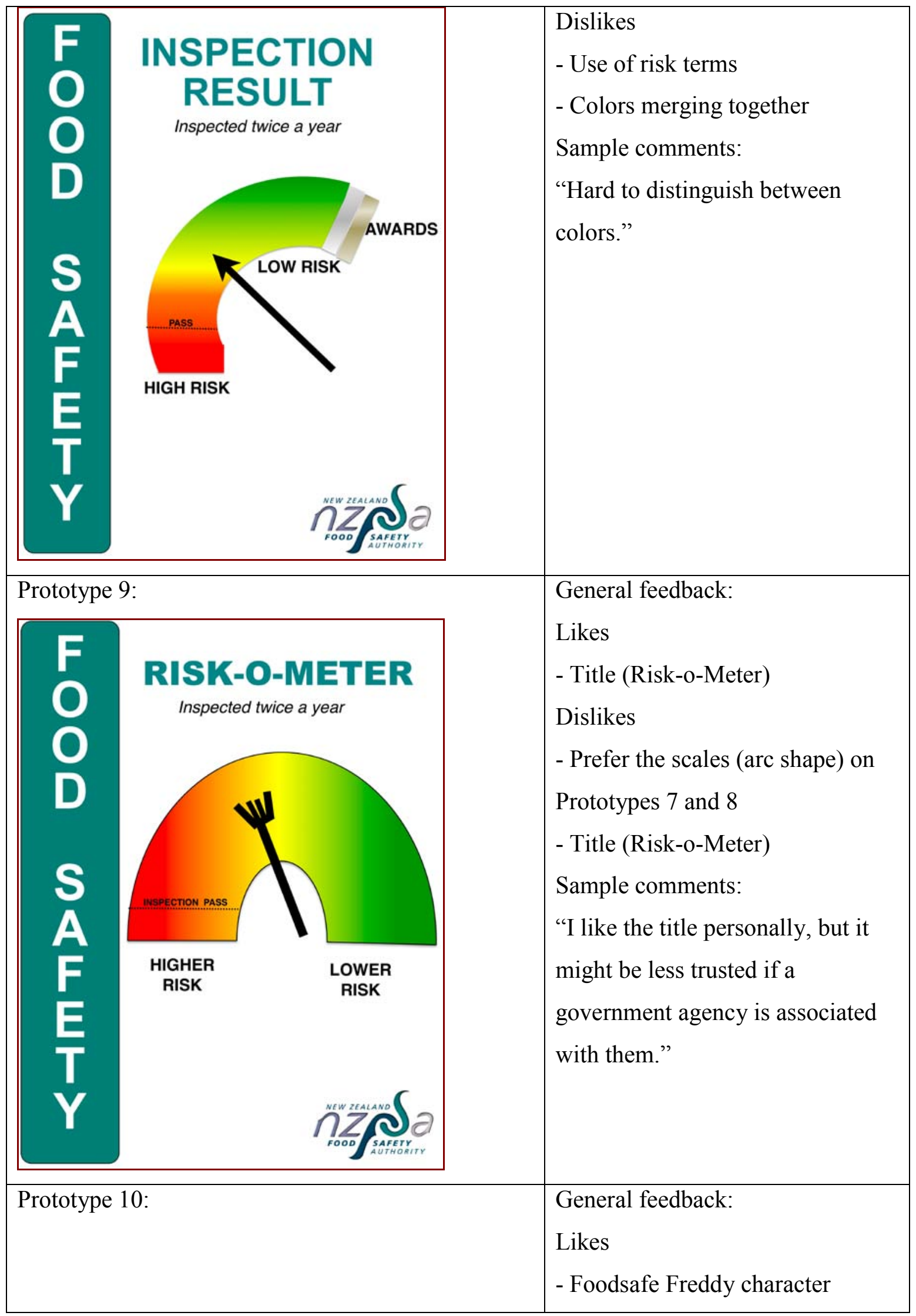




\begin{tabular}{|l|l|l|}
\hline Inspection Results & Dislikes \\
- Too much information \\
- Foodsafe Freddy character \\
Sample comments: \\
"Good promotion of NZFSA's 4 \\
S
\end{tabular}




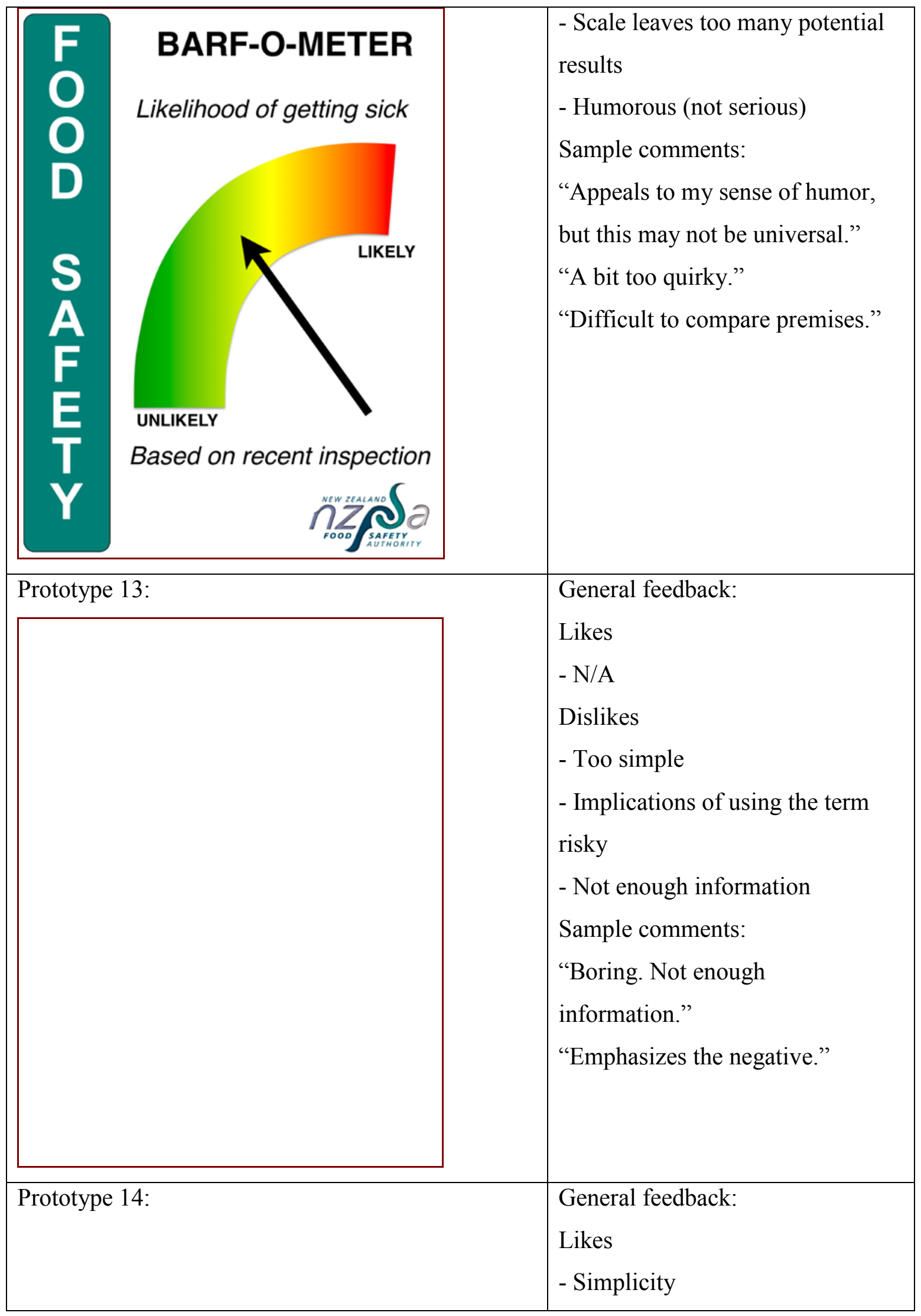




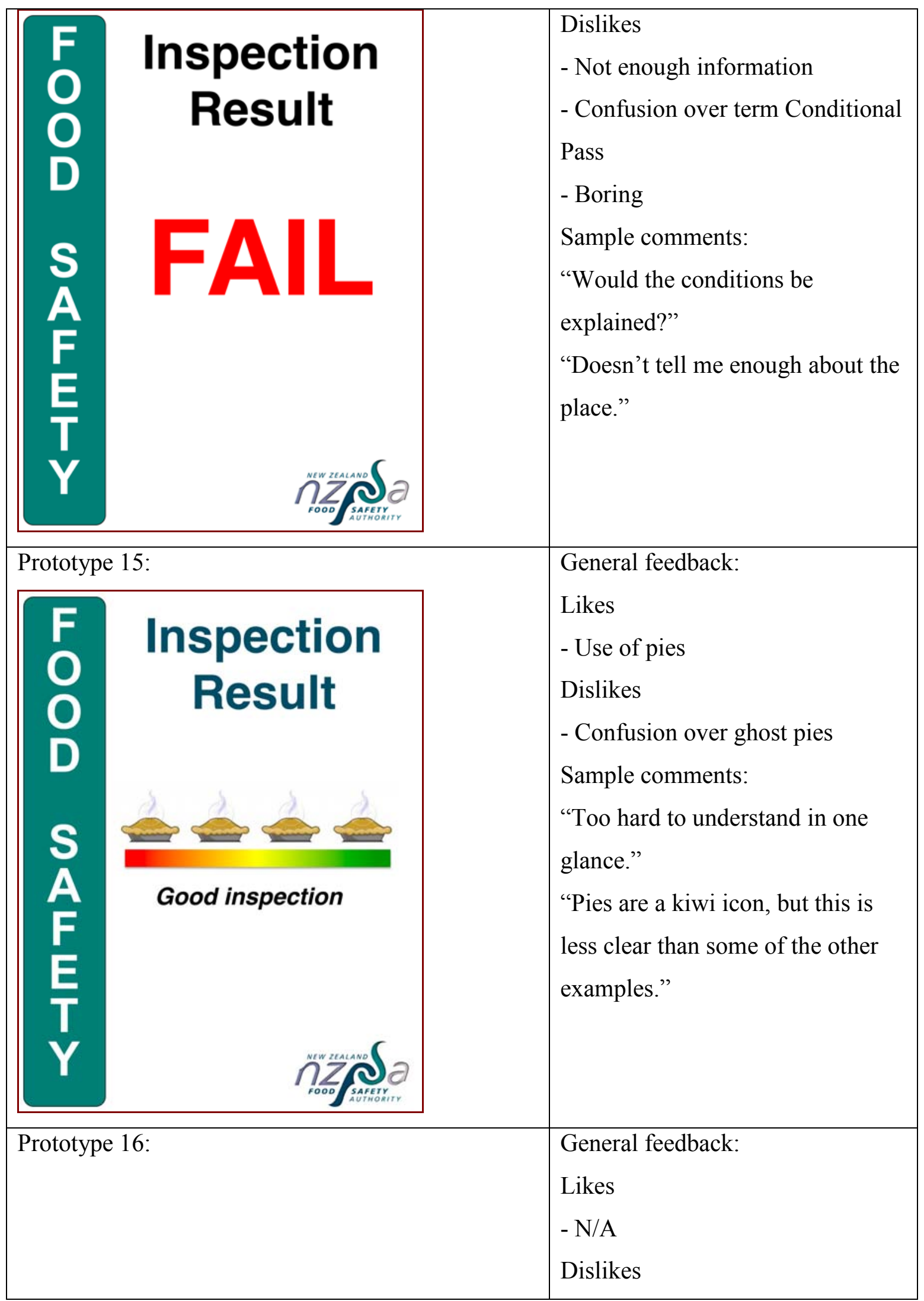




\begin{tabular}{|l|l|l|}
\hline InSpection & & - Images \\
\hline & Result & - Term fail \\
Sample comments: \\
"I wouldn't trust this."
\end{tabular}




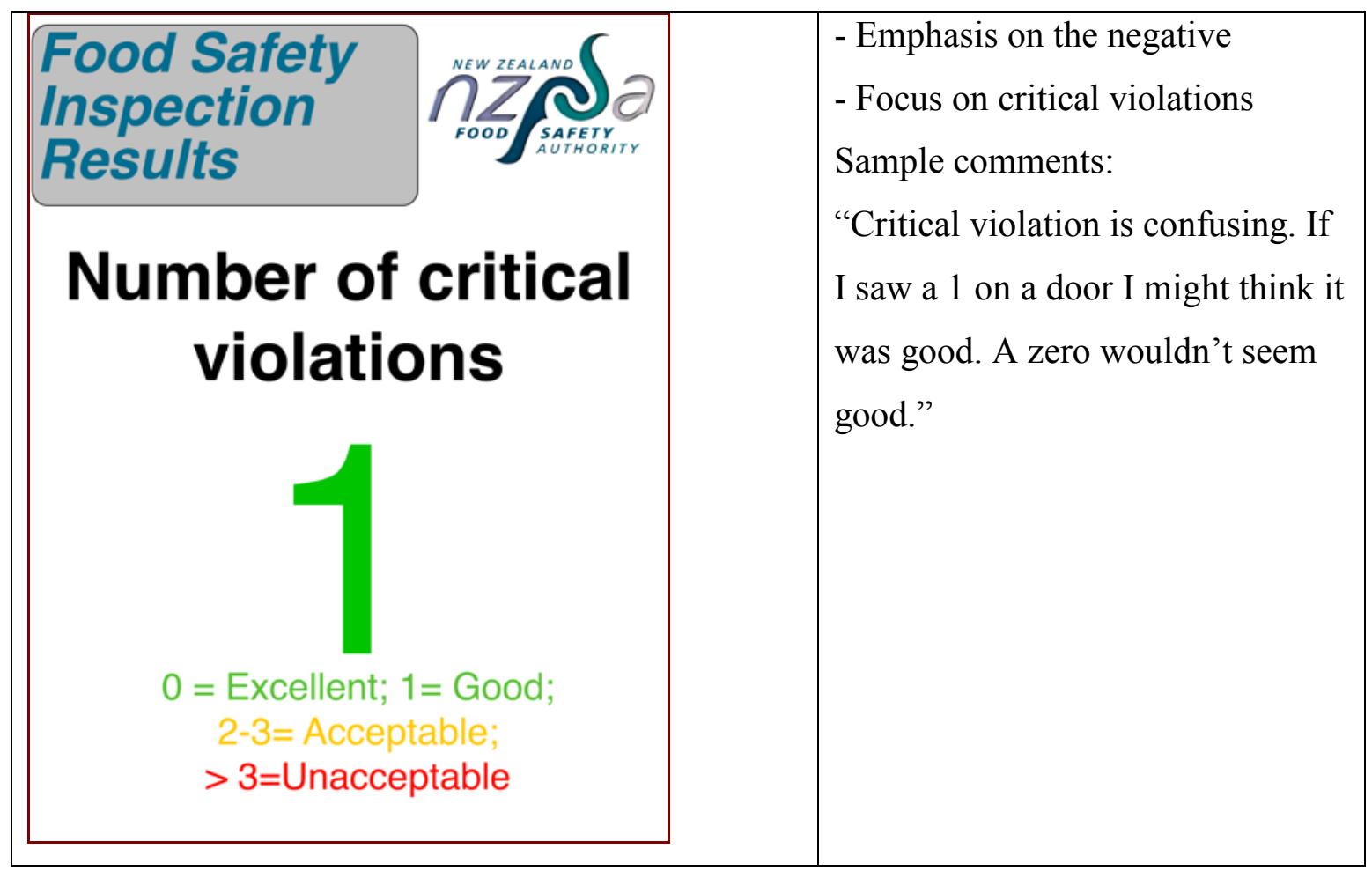

Table A.4 NZFSA and Kansas State University Survey Participant Feedback on the Initial 18 Prototype Grade Cards and Respective Top (Green Highlight) and Bottom (Red Highlight) Selections.

\begin{tabular}{|r|c|c|}
\hline Prototype & $\begin{array}{l}\text { Number of respondents selecting } \\
\text { as a Top 3 }\end{array}$ & $\begin{array}{l}\text { Number of respondents selecting as } \\
\text { a Bottom 3 }\end{array}$ \\
\hline 1 & 16 & 0 \\
\hline 2 & 2 & 0 \\
\hline 3 & 15 & 0 \\
\hline 4 & 19 & 4 \\
\hline 5 & 8 & 3 \\
\hline 6 & 1 & 4 \\
\hline 7 & 8 & 3 \\
\hline 8 & 2 & 3 \\
\hline 9 & 0 & 8 \\
\hline 10 & 4 & \\
\hline
\end{tabular}




\begin{tabular}{|l|l|l|}
\hline 11 & 2 & 7 \\
\hline 12 & 2 & 5 \\
\hline 13 & 0 & 7 \\
\hline 14 & 1 & 3 \\
\hline 15 & 4 & 8 \\
\hline 16 & 1 & 3 \\
\hline 17 & 9 & 8 \\
\hline 18 & 0 & \\
\hline
\end{tabular}

Table A.5 Prototype Redesigns Created by the Researcher Following NZFSA and Kansas State University Feedback.

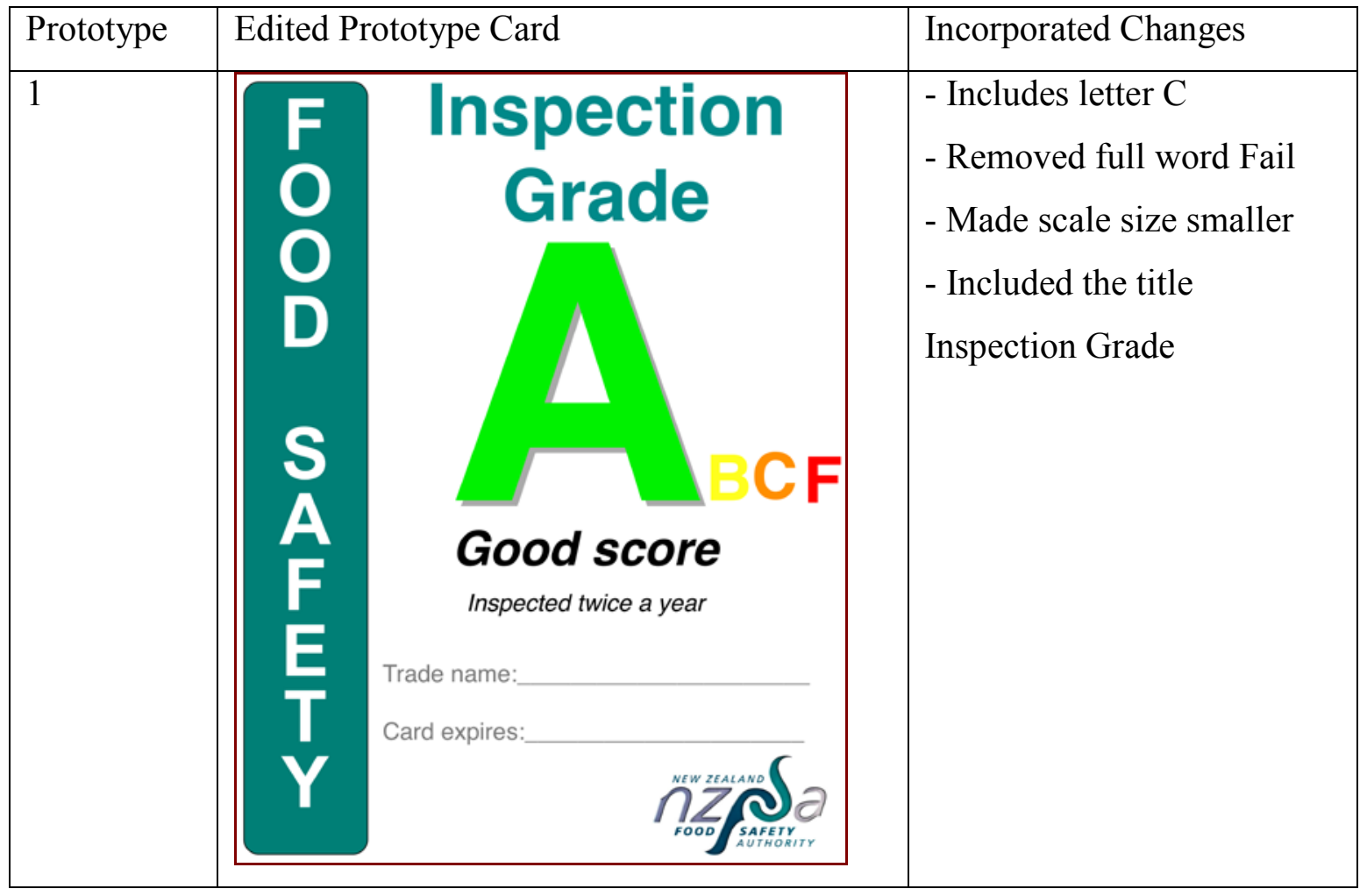




\begin{tabular}{|l|l|l|l|}
\hline 2 & - Included title Food Safety \\
Result
\end{tabular}




\begin{tabular}{|c|c|c|}
\hline 4 & 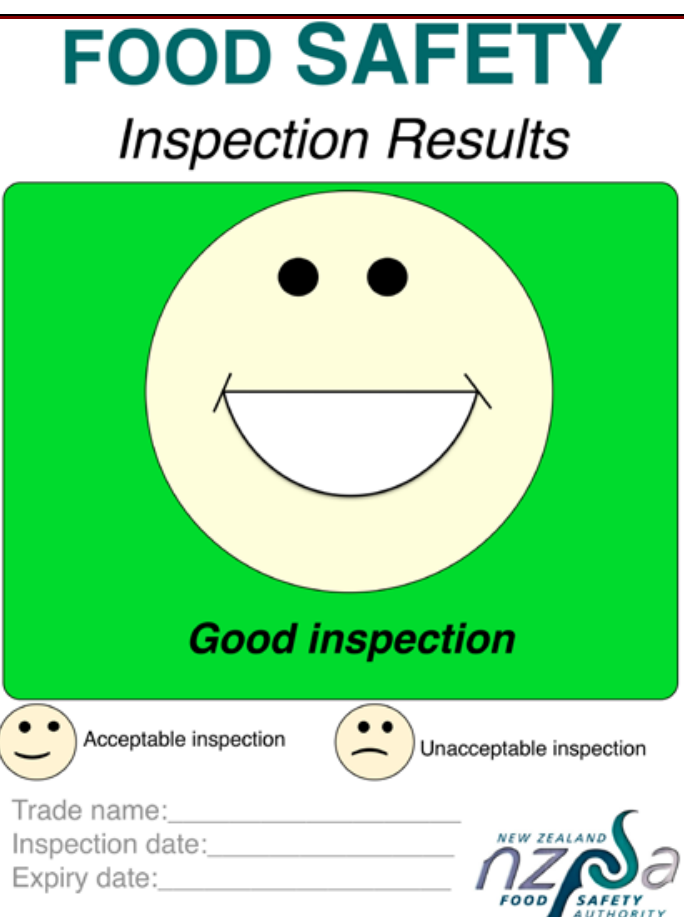 & $\begin{array}{l}\text { - Included a scale with other } \\
\text { possible scores }\end{array}$ \\
\hline 5 & 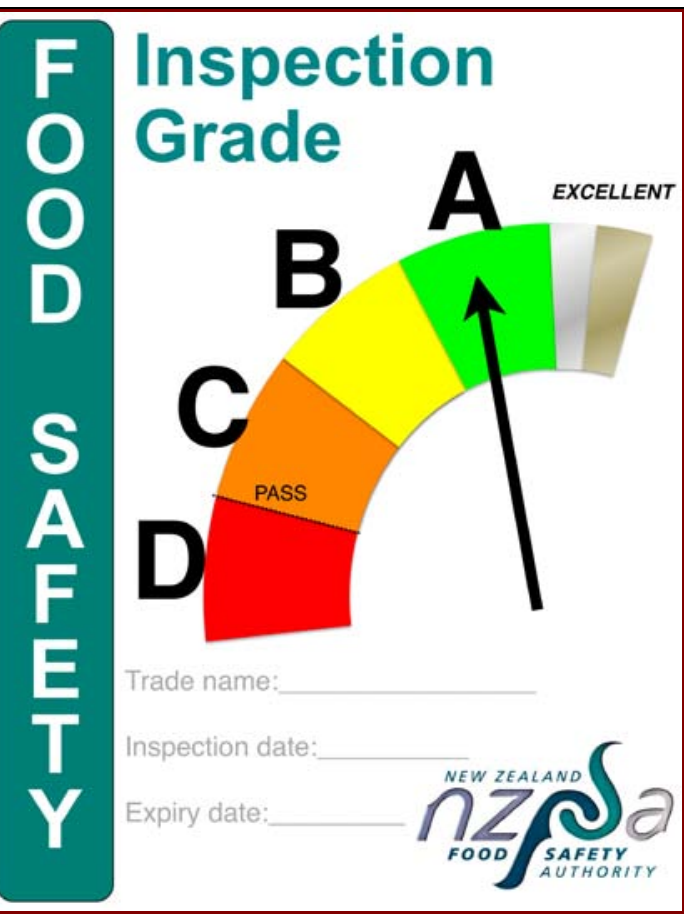 & $\begin{array}{l}\text { - Remove the term Fail } \\
\text { - Clearly define color } \\
\text { blocks for each section }\end{array}$ \\
\hline
\end{tabular}




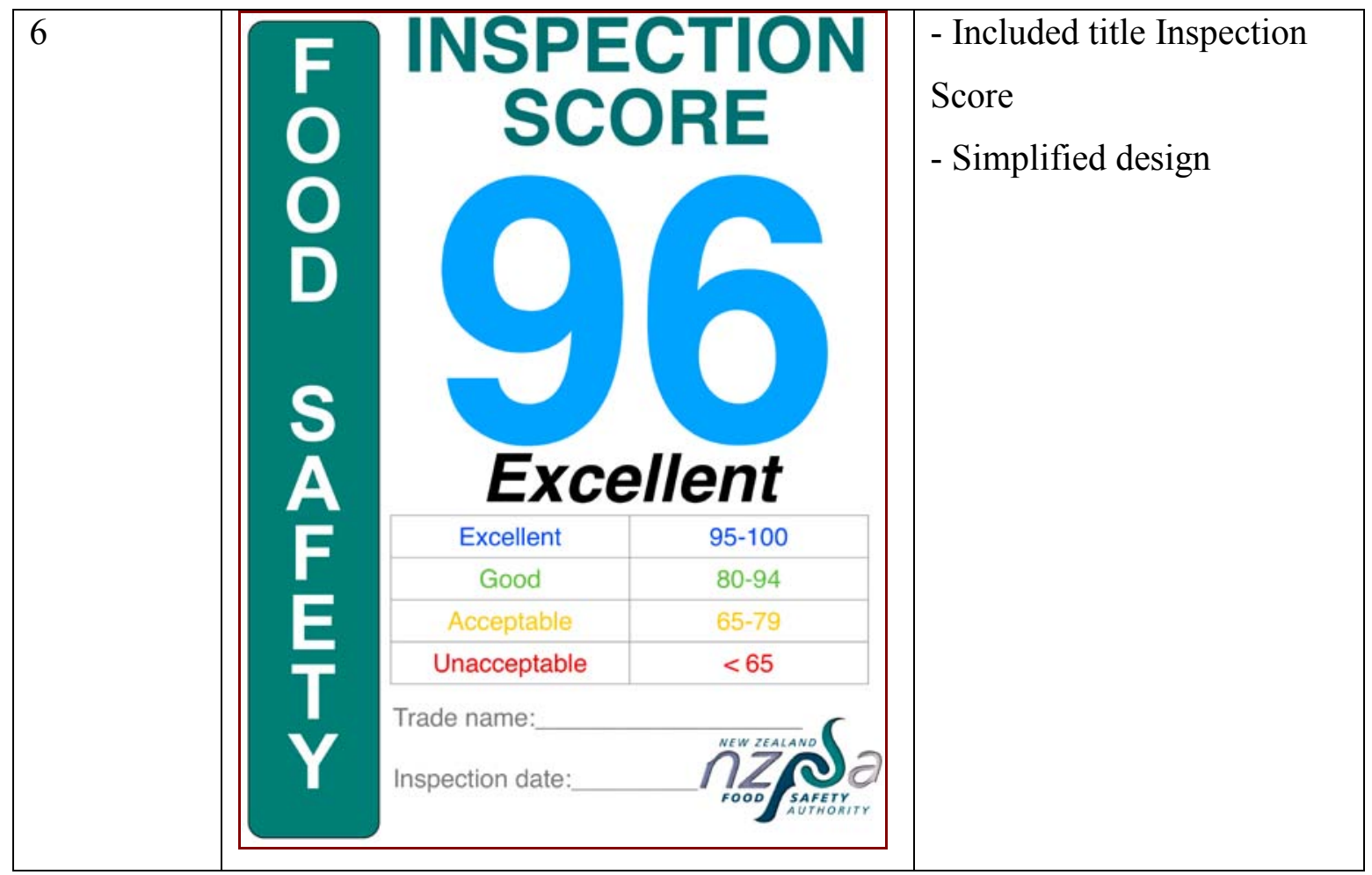

Table A.6 Final Six Prototypes Following Redesign, and Respective Focus Group Comments Towards the Prototypes.

\begin{tabular}{|l|l|l|}
\hline Prototype & Prototype Card & Focus Group Comments \\
\hline
\end{tabular}




\begin{tabular}{|c|c|c|}
\hline 1 & 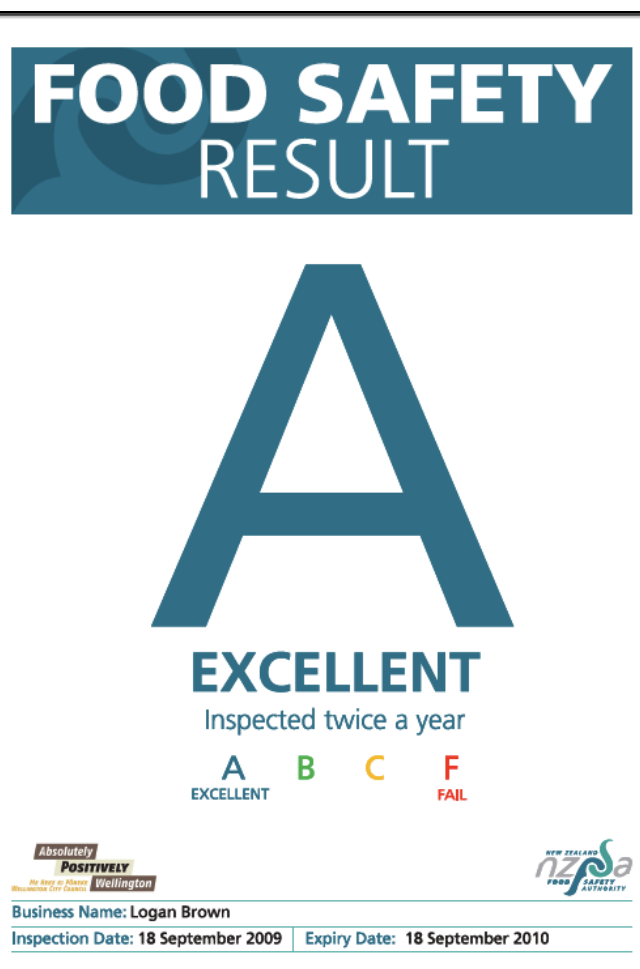 & $\begin{array}{l}\text { Likes } \\
\text {-Simple but relays the } \\
\text { message clearly } \\
\text {-“Inspected twice a year” } \\
\text {-The scale } \\
\text { Dislikes } \\
\text {-Turquoise } \\
\text {-Both council and NZFSA } \\
\text { logos are confusing } \\
\text {-Scale could use words } \\
\text { under each letter } \\
\text {-Plain }\end{array}$ \\
\hline 2 & 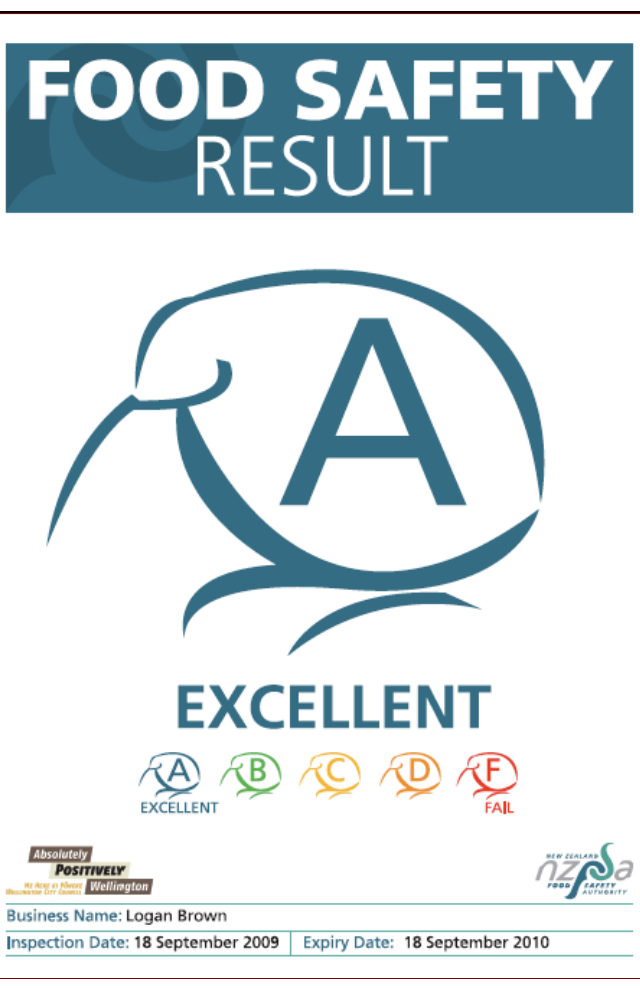 & $\begin{array}{l}\text { Likes } \\
\text {-Kiwi design makes it } \\
\text { interesting } \\
\text {-The scale } \\
\text { Dislikes } \\
\text {-Turquoise } \\
\text {-Both council and NZFSA } \\
\text { logos are confusing } \\
\text {-Scale could use words } \\
\text { under each letter } \\
\text {-A,B,C,F sufficient - D not } \\
\text { needed } \\
\text {-Kiwi design makes it } \\
\text { complicated }\end{array}$ \\
\hline
\end{tabular}




\begin{tabular}{|c|c|c|}
\hline 3 & 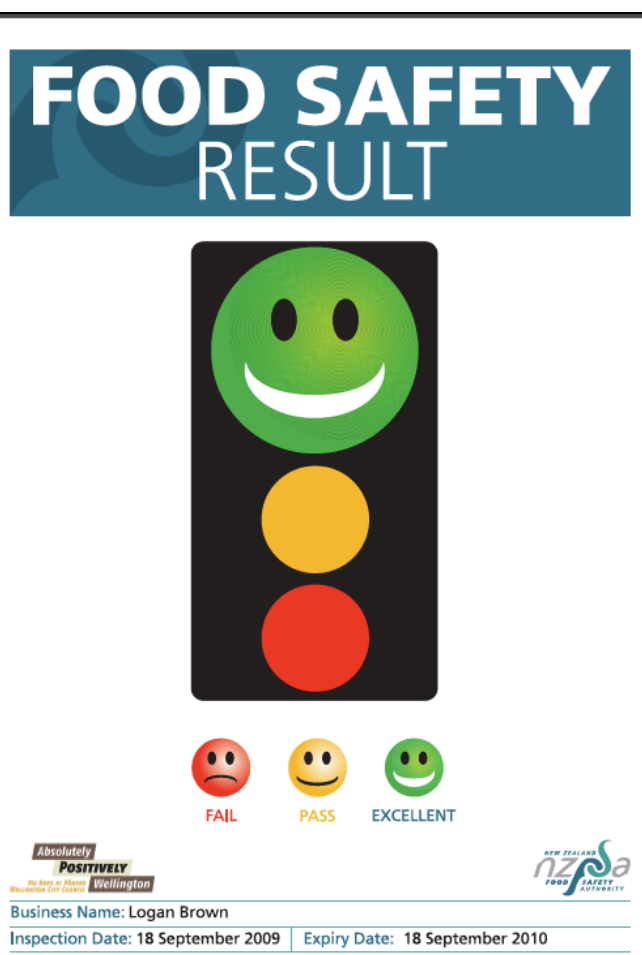 & $\begin{array}{l}\text { Likes } \\
\text { - Simplicity } \\
\text {-Bright colors attract } \\
\text { attention } \\
\text { Dislikes } \\
\text {-Turquoise } \\
\text {-Both council and NZFSA } \\
\text { logos are confusing } \\
\text {-Childish and difficult to } \\
\text { take seriously } \\
\text {-Only three grade } \\
\text { possibilities }\end{array}$ \\
\hline 4 & FAll & $\begin{array}{l}\text { Likes } \\
\text { - Simplicity } \\
\text {-Bright colors attract } \\
\text { attention } \\
\text { Dislikes } \\
\text {-Turquoise } \\
\text {-Both council and NZFSA } \\
\text { logos are confusing } \\
\text {-Childish and difficult to } \\
\text { take seriously } \\
\text {-Only three grade } \\
\text { possibilities }\end{array}$ \\
\hline
\end{tabular}




\begin{tabular}{|c|c|c|}
\hline 5 & 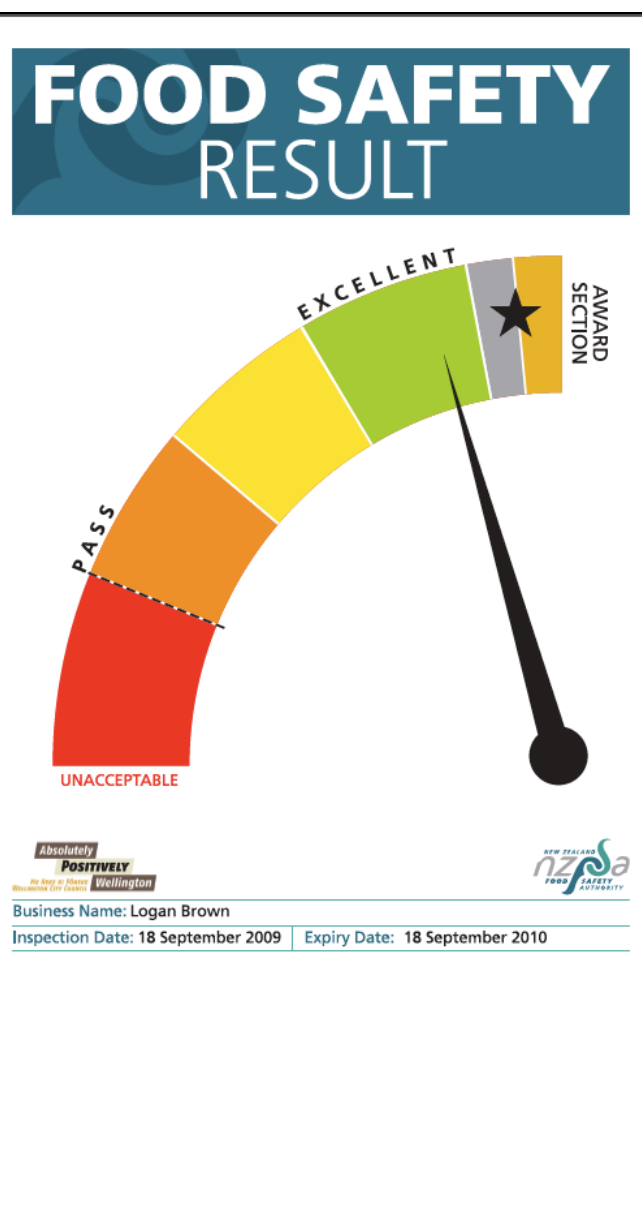 & $\begin{array}{l}\text { Likes } \\
\text { - Easy to see in a glance } \\
\text { where premises lies on scale } \\
\text {-Bright colors attract } \\
\text { attention } \\
\text {-Similarity to Fire Safety } \\
\text { gauge } \\
\text { Dislikes } \\
\text {-Turquoise } \\
\text {-Both council and NZFSA } \\
\text { logos are confusing } \\
\text {-Similarity to Fire Safety } \\
\text { gauge } \\
\text { - Awards section adds } \\
\text { confusion } \\
\text {-Arrow could be larger } \\
\text {-Clearer pass line }\end{array}$ \\
\hline 6 & 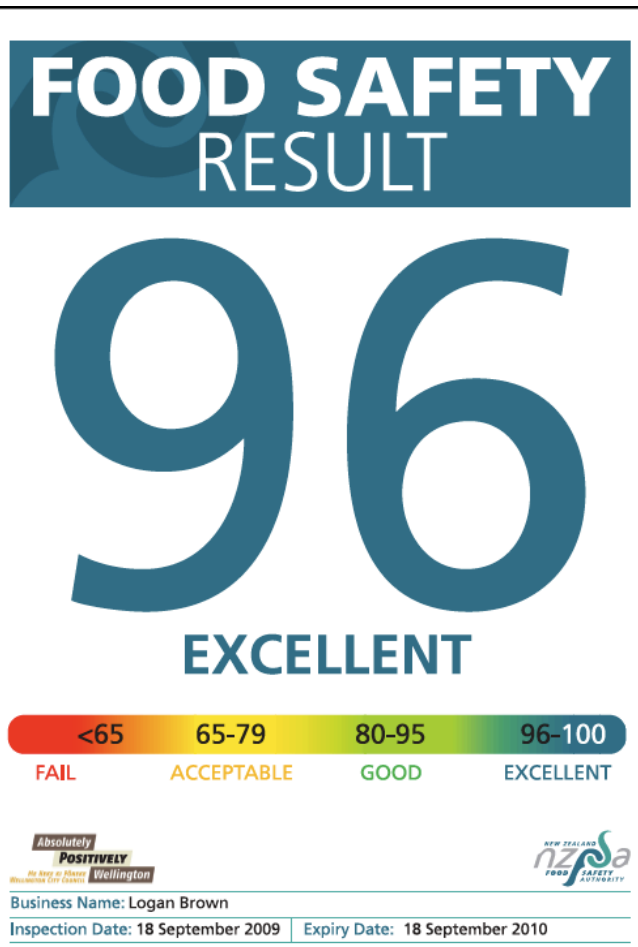 & $\begin{array}{l}\text { Likes } \\
\text { - Provides the most } \\
\text { information of the cards } \\
\text { Dislikes } \\
\text {-Turquoise } \\
\text {-Both council and NZFSA } \\
\text { logos are confusing } \\
\text {-Too much information }\end{array}$ \\
\hline
\end{tabular}




\section{National Grading Trial}

\section{Letter to Foodservice Premises Operators in Trial TAs}

\section{National Grading Project \\ Information for districts involved in the prototype trial phase \\ Project Background}

The fundamentals of restaurant inspection are well-established in developed countries. These inspections are food safety risk management programs in action - to demonstrate to consumers that food providers are cognizant of consumer concerns about food safety and are working to reduce the level of risk. Systems to communicate the results of inspections to consumers are common in developed countries; however, like the inspection process itself, these systems are inconsistent and vary between countries or districts within a country.

The New Zealand Food Safety Authority (NZFSA), as part of the Domestic Food Review, plans to implement a national grading system for food businesses. Currently in New Zealand 25 of the 73 territorial authorities (TAs) have some form of an inspection disclosure (grading) program:

- 24 of the 25 districts have disclosure at the premises in the form of a grading certificate. Certificate posting may be mandatory or voluntary depending on the TA.

○ 20 of the 24 TAs' disclosure at the premises use a letter grade certificate (eg. A, B, D, E), with 4 TAs using a phrase certificate (eg. "Excellent”).

- 9 of the 24 TAs with disclosure at the premises also have an online searchable database.

- One of the 25 districts with disclosure solely has an online database.

In some TAs the issuing of grading certificates is combined with the premise's annual registration; in others it's separate. TAs with mandatory display use a bylaw to enforce this requirement. 
As part of the review of current inspection disclosure systems in New Zealand, eight of the 25 districts with inspection disclosure at the premises were visited to evaluate the positive and negative aspects of these systems. Environmental Health Officers and consumers in these districts were interviewed. Initial findings include the following:

- EHOs indicated that feedback received to the council on current grading systems was generally positive from both consumers and operators; however, noted that during the implementation process resistance was encountered.

- EHOs indicated the importance and difficulty in creating consistent grade assignments between individual EHOs.

- Higher levels of consumer recognition of the certificates in TAs where the letter grade on the certificate itself was larger (taking up the majority of the $8 \times 10$ " card), mandatorily displayed in a prominent location, or media coverage of the disclosure system was present (e.g. newspaper publishing of inspection grades, Target television program).

- Higher levels of consumer understanding (that is, recognition that the grade indicates food safety as opposed to quality) in TAs where the grade certificate included phrases such as "Food Hygiene."

The next phase of the project involves using research from the international and national review of current grading systems to develop a consistent, trusted and compelling national grading system. During the month of November, prototypes of potential grade cards will be designed and evaluated using focus groups representing the New Zealand consumer and tourist population, TA representatives, and food premises operators. By early December two prototypes should have emerged as favored, and these prototypes will be implemented into the suggested six trial districts. Information on this implementation process is below.

\section{Project Trial Phase}

\section{Trial participants and timing:}

There are six TAs proposed to be part of the trial phase of the national grading project. These six TAs include: Tauranga City, Napier City and Upper Hutt City in the 
North Island, and Christchurch City, Marlborough district (Blenheim), and Queenstown Lakes district (Queenstown) in the South Island.

As part of the trial, two prototypes will be selected and implemented into these six districts; the three districts of the North Island taking one prototype and the three districts of the South Island taking the second prototype. The duration of the trial will be three months, with suggested start and end dates as January 1, 2010 to March 31, 2010 respectively.

The central business district (CBD) of the involved towns or cities will be selected as the boundaries of the trial, and any registered food premises in this district will be asked to display the provided grade card prominently and conspicuously at their entrance.

\section{How Grades will be Assigned for the Prototype Trials:}

The grade card assigned to the premises will be based on the most recent inspection conducted by the TA. It is the responsibility of the council to provide the researcher, Katie Filion, with the inspection reports for all registered food premises in the CBD. From these reports Katie will determine the appropriate grade card to assign this premise. Should a decision be difficult to make, Katie may wish to view previous inspection reports for this premise, or consult with an EHO from the TA. Food premises regularly scheduled for their annual inspection during the duration of the trial should proceed as scheduled. Following this inspection the report will be forwarded onto Katie who will adjust the premises current grade accordingly. Premises seeking a re-inspection throughout the duration of the trial would be required to pay for this re-inspection based on the regular re-inspection fees of the TA. Re-inspected premises will be awarded a new grade card in the same manner regularly scheduled premises are awarded one, based on the inspection report Katie will determine the new grade and send out a card. Operators will have the right to appeal assigned grades.

\section{Requiring businesses to display the prototype grading certificate:}

Ideally, grade card display would be mandatory. However, because there will not be any legal control of this (bylaw placement) mandatory display is not possible. Recognizing that some premises, more likely those with a low inspection score, are unlikely to display a card with a poor grade, media influence is proposed to increase 
consumer awareness of the program. It is hypothesized that increased consumer awareness of the grading trial would prompt consumers to question those premises that do not have a card posted. Additionally, it is suggested (and will require council approval) that consumers who recognize a premise not displaying a grade card contact the local council or the researcher (Katie Filion), and this operator will be approached and asked their reasons for not displaying the card.

\section{Resource Expectations for participating TAs:}

The only foreseeable cost to the districts involved in the trials will be some investment in time: providing Katie with inspection reports for CBD premises, and consumer/operator inquiries into the trial. Calls into the council about the grading card trial are likely. The council would be required to answer these queries as far as possible, and any queries beyond this may be forwarded onto Katie. Prior to the trial (likely in mid-December) Katie will arrange a meeting with members of the trial districts to better explain the trial and attempt to answer any questions.

\section{Interview Questions for Foodservice Premises Operators in Trial TAs}

Grade card placement: At entrance, Inside premises, Not displayed Are you happy to display the supplied food safety result card? Why?

Do you feel the design of this card accurately communicates the level of food safety your business has achieved?

Are there any components of the card you particularly like or dislike?

Is there anything you think the card is missing?

Do you think the card will be used by consumers?

Have you had much consumer response to the card?

Why have you chosen to display the card here (only for those not displaying at the entrance)?

\section{Interview Questions for Consumers in Trial TAs}

Are you from this district? If no, are you from New Zealand?

Did you notice a grade/gauge card at the premises before/when entering?

If yes: 
Did you pay much mind to it?

What about it caught your attention? Prompts: color, letter/gauge, logos, text

Did it affect your decision to dine at this restaurant? How so?

Do you know what the card is attempting to communicate? Prompts: what the gauge/letter represents?

Do you think it communicates this information accurately? Interestingly?

Do you know who is responsible for supplying this grade/gauge? Prompt: what authority

Do you trust the information provided on this card?

Is there any other information you would like to see on the card?

Have you noticed this or a similar card at a food location before?

What types of locations would you expect to find these cards at?

Does the assigned grade/gauge meet your expectation for this restaurant?

If no (point out the card):

Why do you think you didn't notice the card?

Is there anything about the card that stands out to you? Prompts: color, letter/gauge, logos, text

Would it have affected your decision to dine at this premises? How so?

Do you know what the card is attempting to communicate? Prompts: what the gauge/letter represents?

Do you think it communicates this information accurately? Interestingly?

Do you know who is responsible for supplying this grade/gauge? Prompt: what authority

Do you trust the information provided on this card?

Is there any other information you would like to see on the card?

Have you noticed this or a similar card at a food location before?

What types of locations would you expect to find these cards at?

Does the assigned grade/gauge meet your expectation for this restaurant?

Table A.7 Queenstown Lakes District Bylaw 


\begin{tabular}{|l|l|}
\hline FOOD HYGIENE TRAINING SCORE & \\
\hline $\begin{array}{l}1 \text { supervisor trained to Unit Standard } 167 \text { and/or } 168 \text { (equivalent or above), in } \\
\text { addition to } 100 \% \text { of remaining employees trained to a level commensurate to their } \\
\text { work activities. }\end{array}$ & 5 \\
\hline $\begin{array}{l}1 \text { supervisor trained to Unit Standard } 167 \text { and/or } 168 \text { (equivalent or above), in } \\
\text { addition to } 75 \% \text { of emplovees trained to a level commensurate to their work } \\
\text { activities. }\end{array}$ & $\begin{array}{l}\text { 1 supervisor trained to Unit Standard 167 and/or 168 (equivalent or above), in } \\
\text { addition to 50\% of remaining employees trained to a level commensurate to their } \\
\text { work activities. }\end{array}$ \\
\hline $\begin{array}{l}\text { 1supervisor trained to Unit Standard } 167 \text { and/or } 168 \text { (equivalent or above). in } \\
\text { addition to } 25 \% \text { of emplovees trained to a level commensurate to their work } \\
\text { activities. }\end{array}$ & \\
\hline $\begin{array}{l}1 \text { supervisor trained to Unit Standard } 167 \text { and/or } 168 \text { (equivalent or above), or } \\
\text { evidence of insufficient training of remaining employees to a level commensurate to } \\
\text { their work activities. }\end{array}$ & \\
\hline $\begin{array}{l}\text { Nobody trained to Unit Standard 167 and/or 168 (equivalent or above), or evidence } \\
\text { of insufficient training of remaining employees to a level commensurate to their work } \\
\text { activities. }\end{array}$ & \\
\hline CLEANING AND SANITISATION SCORE & \\
\hline Excellent overall standard of cleanliness & \\
\hline Very Good overall standard of cleanliness \\
\hline Good standard of cleanliness \\
\hline $\begin{array}{l}\text { General standard of cleanliness reasonable - improvement needed to prevent a fall in } \\
\text { standards }\end{array}$ & \\
\hline Premises In a poor condition/ a overall lack of effective cleaning \\
\hline Premises in an unacceptable condition/ almost total non-compliance with regulations & \\
\hline STRUCTURE SCORE & \\
\hline Excellent overall condition & \\
\hline Very good overall condition & \\
\hline
\end{tabular}




\begin{tabular}{|l|l|}
\hline Good overall condition & \\
\hline Reasonable overall condition - improvements needed to prevent a fall in standards & \\
\hline Poor overall condition - general lack of maintenance & \\
\hline Unacceptable overall condition - almost total non-compliance with regulations & \\
\hline FOOD HYGIENE PRACTICES \& MANAGEMENT CONTROLS SCORE & \\
\hline $\begin{array}{l}\text { Excellent record of compliance and food hygiene practices with a documented food } \\
\text { safetv management system/recording methods }\end{array}$ & \\
\hline $\begin{array}{l}\text { Very good record of compliance and food hygiene practices but no documented food } \\
\text { safetv management system/recording methods }\end{array}$ & \\
\hline $\begin{array}{l}\text { Good record of compliance with an understanding of hazards and control measures in } \\
\text { place }\end{array}$ & \\
\hline $\begin{array}{l}\text { Reasonable record of compliance - some minor non-compliances with statutory } \\
\text { requirements }\end{array}$ & \\
\hline $\begin{array}{l}\text { Poor record of compliance and food safety practices, poor appreciation of hazards } \\
\text { and control measures with improvements needed }\end{array}$ & \\
\hline $\begin{array}{l}\text { Unacceptable record of compliance. Serious regulatory breaches/ significant risk to } \\
\text { health and little or no appreciation of hazards and controls }\end{array}$ & \\
\hline
\end{tabular}

